\title{
MASTER
}

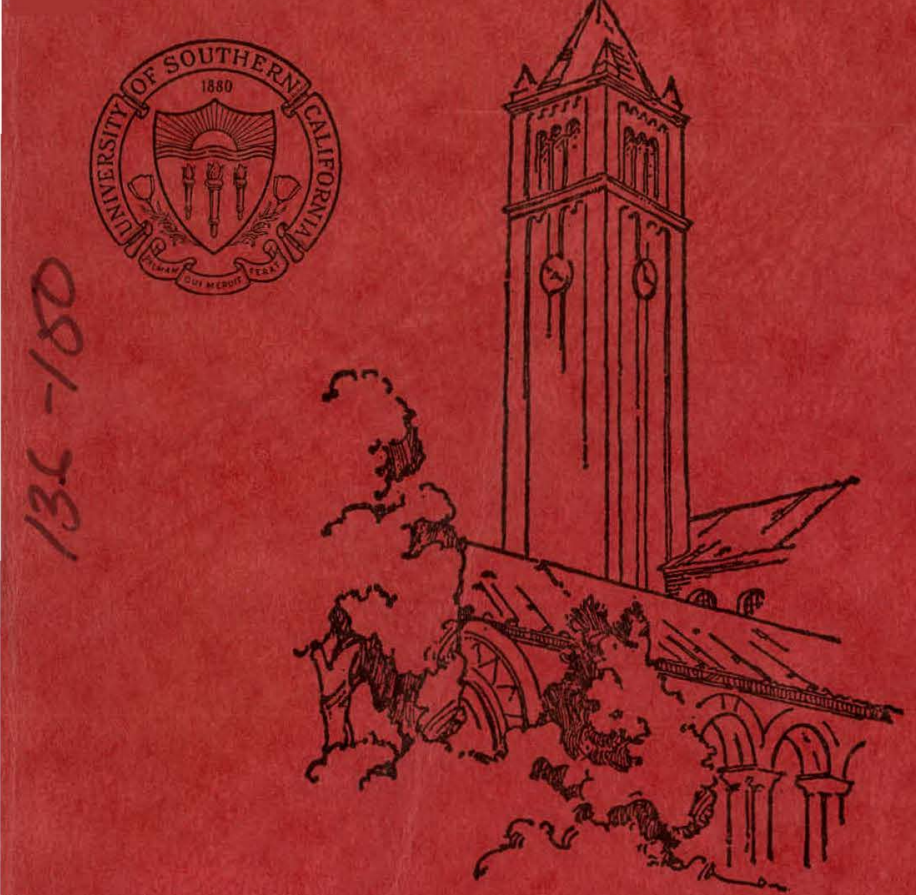

\section{DEPARTMENT OF PHYSICS}

University of Southern California

Los Angeles, California 90007 


\section{DISCLAIMER}

This report was prepared as an account of work sponsored by an agency of the United States Government. Neither the United States Government nor any agency Thereof, nor any of their employees, makes any warranty, express or implied, or assumes any legal liability or responsibility for the accuracy, completeness, or usefulness of any information, apparatus, product, or process disclosed, or represents that its use would not infringe privately owned rights. Reference herein to any specific commercial product, process, or service by trade name, trademark, manufacturer, or otherwise does not necessarily constitute or imply its endorsement, recommendation, or favoring by the United States Government or any agency thereof. The views and opinions of authors expressed herein do not necessarily state or reflect those of the United States Government or any agency thereof. 


\section{DISCLAIMER}

Portions of this document may be illegible in electronic image products. Images are produced from the best available original document. 


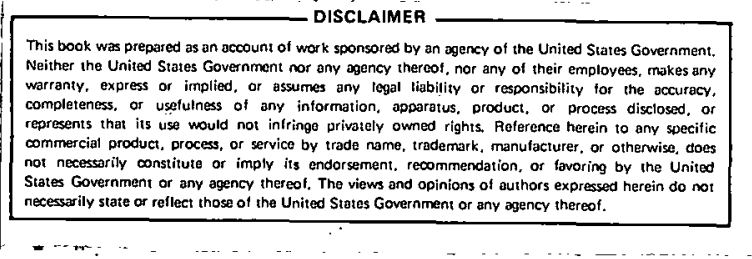

PASSAGE OF CHARGED PARTICLES THROUGH MATTER*

by

Hans Bichse $1^{\dagger}$

Department of. Physics

University of California

Berkeley, Califurinia

Ju1y 1969

* This work was supported by Public Health Service Grant No. CA-08150 from the National Cancer Institute and in part by the U.: S. Atomic Energy Commission Contract No. AT $(04-3)-136$, both with the University of Southern California.

$\uparrow$ On leave of absence from the University of Southern California, Los Angeles, California. 


\section{Table of Contents}

Chapter

1. INTRODUCTORY NOTE. . . . . . . . . . . . . . . 1

2. ATOMIC COLLISION CROSS SECTIONS. . . . . . . . 2

3. STOPPING POWER FOR HEAVY CHARGED PARTICLES . . . . 6

4. RANGE-ENERGY RELATIONS . . . . . . . . . . . . . 11

5. SHELL CORRECTIONS AND I-VALUES . . . . . . . . 14

6. MISCELlANEOUS EFFECTS. . . . . . . . . . . . . 16

A. Charge State Correction . . . . . . . 18

B. Very Low Velocity Particles....... . 19

C. Small Volumes............ . 22

D. Channeling. . . . . . . . . . 23

7. STRAGGLING OF HEAVY PARTICLES. . . . . . . . . 24

A. Thin Absorbers. ........... 24

B. Thick Absorbers . . . . . . . . . 26

8. COULOMB AND MULTIPLE SCATTERING, AND NUCLEAR

INTERACTIONS . . . . . . . . . . . . . . . . 29

A. Coulomb Scattering. . . . . . . . . 29

B. Multiple Scattering in Thin Absorbers . . . 30

C. Multiple Scattering in Thick Absorbers... . 33

D. Nuclear Interactions. . . . . . . . . . 33 
9. ELECTRONS. . . . . . . . . . . . . . . . 34

A. Restricted Stopping Power (LET). . . . . . 36

B. Practical Considerations for Stopping Power. . . . . . . . . . . . 36

C. Electron Ranges and Energy Deposition in Thick Absorbers.... . . . . . . . 37

10. MEAN ENERGY FOR THE FORMATION OF AN ION PAIR . . 39

A. Gases. . . . . . . . . . . . . . . 39

B. Solids . . . . . . . . . . . . . . 39

ACKNOWLEDGMENT... . . . . . . . . . . . . . . . 42

REFERENCES. . . . . . . . . . . . . . . . . . 4 43

TABLES. . . . . . . . . . . . . . . . . 54

FIGURES . . . . . . . . . . . . . . . . . 74 


\section{INTRODUCTORY NOTE}

This article presents some of the commonly used formulas and principal data on the passage of fast charged particles through matter. Because of space limitations, much useful material has been omitted. The bibliography includes mainly the newest available references. Most of the technical reports cited are available from the Clearing House for Federal Scientific and Technical Information, Springfield, Va. 22151. An extensive review of the field is found in Publication 1133 of the National Academy of Sciences - National Research Council (NA67). The "Bibliography of Atomic and Molecular Processes" (ORNL-AMPIC 11, UC-34-Physics for January-June 1968), is published semiannually by the Atomic and Molecular Processes Information Center, Oak Ridge National Laboratory, Oak Ridge, Tennessee. It contains sections concerned with energy losses, ionization, particle range, etc.

A number of papers concerned with particles at the lowest energies considered in this article have appeared in the "Proceedings of an International Conference on Atomic Collisions and Penetration Studies with Energetic Ion Beams", Cha1k River, Ontario, September 18-21, 1967 (DA68), and in the abstracts of the "V International Conference of the Physics of Electronic and Atomic Collisions", (FL67). 


\section{ATOMIC COLLISION CROSS SECTIONS}

The following notation will be used:

The kinetic energy of particles will be denoted. by $\mathrm{T}$, the energy of a secondary electron ( $\delta$-ray) by $E$ or by $W$ if expressed in atomic units [Eq. (2-3)]. Thicknesses $s$ are usually measured in $\mathrm{g} \mathrm{cm}^{-2}$. The stopping power (usually called $d E / d x$ ) will then be denoted as

$$
\mathrm{S}=-\mathrm{dT} / \mathrm{ds} \text {. }
$$

Except for particles with very small or extremely large velocities $v$, the interaction between energetic charged particles (of charge ze) and matter leads mainly to the excitation and ionization of atoms or molecules (FA63). The probability for a collision leading to an atomic state of energy $E_{n}$ is described by the collision cross section $\sigma_{n}$. Relatively little information is available about the details of $\sigma_{n}$ (e.g., FC68, RU68, OL67, ES69). In energy loss experiments, the quantities observed are usually averages over $F_{n}$ and $\sigma_{n}$ (e.g., the stopping power dT/ds is $\sum_{n} E_{n} \sigma_{n}$ ), and even a coarse approximation of $\sigma_{n}$ will give satisfactory answers.

Frequently, the free electron approximation is used for a description of $\sigma_{n}$. The energies $E_{n}$ then are continuously distributed and are equal to the electron energy $E$. The collision cross section is differential with respect to E and is given, nonrelativistically, by (see, e.g., BI68). 


$$
d \sigma^{\circ}=\left(P Z / \beta^{2}\right) E^{-2} d E
$$

where $\mathrm{P}=2 \pi \mathrm{z}^{2} \mathrm{mc}^{2} \mathrm{r}_{\mathrm{o}}{ }^{2} \mathrm{~N}_{\mathrm{o}} / \mathrm{A}=0.15354 \times \mathrm{z}^{2} / \mathrm{A} \mathrm{MeV} / \mathrm{cm}^{2}$

$z=$ charge number of incident particle

$\beta=v / c$, velocity of incident particle relative to velocity of light [see Eq. $(8-3)$ ]

$$
\begin{aligned}
\mathrm{r}_{0}^{2}= & \mathrm{e}^{4} / \mathrm{m}^{2} \mathrm{c}^{4}=7.9408 \times 10^{-26} \mathrm{~cm}^{2} \text { (square of } \\
& \text { "classical electron radius") } \\
\mathrm{m}= & \text { rest mass of electron, } \mathrm{mc}^{2}=0.511004 \mathrm{MeV} \\
\mathrm{N}_{\mathrm{O}}= & \text { Avogadro's number }=6.02217 \times 10^{23} \\
\mathrm{e}= & \text { electron charge } \\
\mathrm{E}= & \text { energy of electron after collision } \\
\mathrm{A}= & \text { atomic weight of stopping material, in grams } \\
\mathrm{Z}= & \text { atomic number of stopping material. }
\end{aligned}
$$

Using the Born approximation, Bethe (BE30) has given the non-relativistic quantum mechanical derivation of do for bound electrons:

$$
\mathrm{d} \sigma=2\left(P / \beta^{2}\right) \sum_{i} \mathrm{~J}_{i}\left(\eta_{i}, W\right) \mathrm{dW}
$$

where $J_{i}$ is called the excitation function (WA56). 
Electron energies $W$ and equivalent particle energies $\eta_{i}$ are measured in atomic units

$$
\begin{aligned}
& W=E /\left[\left(z-d_{i}\right)^{2} R_{y}\right] \\
& n_{i}=m c^{2} \beta^{2} /\left[2 R_{y}\left(z-d_{i}\right)^{2}\right]=18,800 B^{2} /\left(z-d_{i}\right)^{2} \\
& R_{y}=\text { Rydberg }=13.60 \mathrm{eV} \\
& d_{i}=\text { electron defect, depending on the atomic shel1 } i \\
& \quad(i=K, L, M, \cdot \text { shell }) \\
& d_{K}=0.3 \\
& d_{L}=4.15
\end{aligned}
$$

The excitation functions $J_{i}$ have been evaluated, using hydrogenic wavefunctions, for the $K, L$ and M-shells (WA5l, WA52, WA56, BI67, KM66, KH68). While $J_{K}$ probably is reasonably correct for all $\mathrm{Z}$, it appears that $\mathrm{J}_{\mathrm{L}}$ is acceptable without modifications for $Z>30$ only, and $J_{M}$ will have to be recalculated with more realistic wavefunctions. An appreciation of the difference between the two approximations, $d \sigma^{\prime}$ and $d \sigma$, can be obtained from a study of a plot of $\mathrm{J}_{i} \mathrm{w}^{2}$ versus $\mathrm{W}$ (Fig. 1). Further comments will be made later at appropriate places (see also B(69) .

Generally, the Born approximation is valid for $\beta \gg z / 137$ (protons with $\beta=1 / 137$ have a kinetic energy of $25 \mathrm{keV}$ ). Some tests have been made for small particle 
velocities: for protons incident on helium, the Bethe-Born approximation is valid for energies above $450 \mathrm{keV}$ (TH67), while for the vacuum ultraviolet emission of hydrogen gas, produced by fast protons, it appears to be valid above $150 \mathrm{keV}($ DD68).

Almost 100 papers concerning atomic and molecular excitation by electron impact alone are listed in the "Bibliography of Atomic and Molecular Processes" for January to June of 1968. In particular, the following may be of interest: ES69, KY68, OL67, VS68.

Measurements of the excitation of the inner shells with protons have been made: KP67, DK68; see KJ68 and ML58 for further references. At low energies it is necessary to take into account the Coulomb deflection of the incident particle to get reasonable agreements with the Born approximation (BL69). Similar corrections are necessary for incident electrons. 


\section{STOPPING POWER FOR HEAVY CHARGED PARTICLES}

Since the stopping power of heavy charged particles depends largely on the velocity and the charge of the particle, but not its mass (IS67), the discussion of this section applies to all heavy charged particles, with the exceptions specified in Sec. 6. The tables and data presented apply to protons and can be converted for other particles with the procedures described in Sec. 6.

The mean energy loss per unit path length is called the stopping power $S$. It is defined by

$$
\mathrm{S}=-\mathrm{dT} / \mathrm{ds}=\int \mathrm{W} \mathrm{d} \sigma=\left(2 \mathrm{P} / \mathrm{B}^{2}\right) \sum_{i} \mathrm{~B}_{i}
$$

where the stopping number $B_{i}$ is defined by

$$
B_{i}=\int_{I_{i}}^{\infty} J_{i} W d W
$$

$I_{i}=W_{\min }$ is the energy to lift an electron from the $i-t h$ she11 to the lowest unoccupied atomic level, and the integral includes a sum over the discrete atomic energy levels. For large velocitics, Bethe (LB37) has derived the asymptotic expression

$$
B^{\prime}=\Sigma B_{i}^{\prime}=Z \ln \left(2 \mathrm{mv}^{2} / I_{\text {ave }}\right)
$$

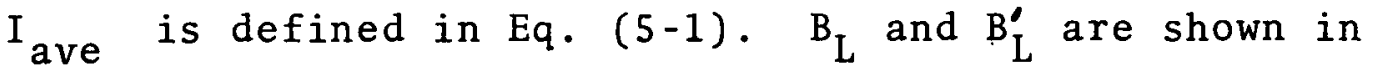
Fig. 2. The "shelil corrections" are defined by

$$
\sum C_{i}\left(n_{i}, z\right)=B^{\prime}-\Sigma B_{i}
$$

and are thus an integral part of the quantum mechanical theory. For higher order Born approximations they will presumably depend on the particle charge $z$. 
If $S$ is calculated using the free electron cross sections $d \sigma^{\prime}$, an unphysical minimum energy $E_{\text {min }}=I_{e}^{2} / 2 \mathrm{mv}^{2}$ has to be used as the lower limit of the integral to get approximately the correct stopping power:

$$
S^{\prime}=\left(P / B^{2}\right) \int_{E_{\min }}^{2 m v^{2}}\left(Z / E^{2}\right) d E=\left(2 P Z / \beta^{2}\right) \ln \left(2 m v^{2} / I_{E}\right)
$$

This choice of $E_{\text {min }}$ is necessary to take into account the increase of. $J$ over $J^{\prime}$ at small energies $W$ (see Fig. 1)

but it will not give exact agreement with the quantum mechanical theory. To achieve this, it is necessary to choose

$$
I_{e}=I_{\text {ave }} \exp \left(\Sigma C_{i} / Z\right)
$$

where $I_{e}$ now of course is energy dependent.

For the practical calculation of stopping power, the following, relativistically correct, formula is used:

$$
S=-\mathrm{dT} / \rho \mathrm{ds}=\left(0.30708 / \beta^{2}\right) \mathrm{z}^{2}(\mathrm{Z} / \mathrm{A})\left[\mathrm{f}(\beta)-\ln \mathrm{I}_{\text {ave }}-\Sigma \mathrm{C}_{\mathrm{i}} / \mathrm{Z}-\delta / 2\right]
$$

Stopping power in units $\mathrm{MeV} \mathrm{cm}^{2} / \mathrm{g}=\mathrm{keV} \mathrm{cm}^{2} / \mathrm{mg}$, and $z$, $\beta, \quad Z$ and $A$ are defined with Eq. $(2-1)$.

$\rho \quad=$ density of stopping material

$\mathrm{C}_{i}=$ shell correction of the $\mathrm{i}-\mathrm{th}$ shell

$\delta \quad=$ density correction at high energies

$I_{\text {ave }}=$ average excitation potential per electron of stopping atom (including low-velocity density effect), a constant by definition. 


$$
f(\beta)=\ln \left[2 m c^{2} \beta^{2} /\left(1-\beta^{2}\right)\right]-\beta^{2}
$$

$\beta^{2}$ and $f(\beta)$ are listed in Table $I$ as functions of the kinetic energy $T$ of several particles. $f(\beta)$ is applicable for any charged particle of velocity $v=\beta c$ and mass $M \gg m$. If an ion of mass $M_{i}$ and kinetic energy $\mathrm{T}_{i}$ is under consideration, its velocity can be found by looking up in Table $I$ the value of $\beta$ corresponding to a proton energy

$$
\mathrm{T}=\mathrm{T}_{\mathrm{i}} / \mathrm{m}_{\mathrm{r}}
$$

where $m_{r}=M_{i} c^{2} / 938.259 \mathrm{MeV}$.

The shell corrections can be obtained from Fig. 4, and I-values from Fig. 5.

For most metals the density effect $\delta$ is negligible for proton energies below $1000 \mathrm{MeV}$. For details see ST67, FA56 and p. 69 of BK58. Experimental confirmation is found, e.g., in NM67.

At low energies (proton energies of less than $0.5 \mathrm{MeV}$, alpha particle energies below $2 \mathrm{MeV}$ ), the charged particle will not have its full charge (see Sec. 6).

A 1 ist of values for $S$ computed. (ref. BJ67) from Eq. (3-6) is given in Table II. For emulsion, see BD63 and BA63. For the other materials, the I-values given in Fig. 5 were used. The shell corrections are discussed in Sec. 5. The density effect is not used. 
For proton energies of 0.05 to $12 \mathrm{MeV}$, the experimental stopping powers for many substances are given in Table III. Most of these numbers are read from the graphs. of refs. WH58, and the tables of AH67 and AS68. This seems the best way to average the experimental results, but see a1so MA68, OR68, WM67, JK68. The stopping cross section in $\mathrm{eVcm}^{2}$ per atom can be obtained by multiplying $S$ with the factor $\left(A / N_{0}\right) \times 10^{6}$ (Avogadro's number $N_{0}$, atomic weight $A$ ).

For protons in other elements, interpolation for $Z$ by the method of Lindhard and Scharff. (LS53) can be. used but direct computation from.Eq. (3-6) is recommended. (A discussion of experimental results is found in BK67).

The stopping power of compounds is within a few per cent an additive function of the stopping power of the elements which make up the compound (Bragg rule, see, e.g., BI68 or BT68). Precise measurements at $300 \mathrm{MeV}$ (TH52) have shown deviations of about 1 per cent from additivity. At energies between 4 and $30 \mathrm{MeV}$ energy dependent deviations of up to $3 \%$ have been observed for $\mathrm{Al}_{2} \mathrm{O}_{3}, \mathrm{SiO}_{2}$ and Lucite (TS67 and BT68). At small energies, energy loss measurements (Sz65) have also shown deviations from the Bragg rulc. For the approximation with an analytic function, the expression

$$
\mathrm{S}=\mathrm{C} \mathrm{T}^{\alpha}
$$

may be used over limited energy ranges; e.g; for protons 
with $5<\mathrm{T}<20 \mathrm{MeV}$ in $\mathrm{Ge}, \mathrm{C}=136.7$ and $\alpha=-0.7313$ will be accurate to better than $0.4 \%$ (see BI68 for other values). If particles of initial energy $T$ are absorbed in a material of thickness $s$, the mean residual energy $\overline{\mathrm{T}}_{1}$ of the particles can be calculated directly:

$$
\bar{T}_{1}=\left(C_{R} T^{\gamma}-s\right)^{1 / \gamma}
$$

where $\quad C_{R}=(C \gamma)^{-1}$ and $\gamma=1-\alpha$.

If the stopping power is used, successive approximations have to be calculated. The computer program of $B J 67$ produces the coefficients $C, C_{R}$ and $\alpha$. 


\section{RANGE - ENERGY RELATIONS}

As long as fewer than about $40 \%$ of the particles are removed from the incident beam by nuclear reactions, the median projected range $R_{m}(T)$ is defined as the thickness of material through which one-half of the incident monoenergetic charged particles of energy $T$ are transmitted (see p. 203 of ref. BI68).

The mean range of monoenergetic particles of kinetic energy $T$ is defined by

$$
R(T)=\int f(R) R d R
$$

where $f(R)$ is the experimentally measured distribution function (the "probability density" of the mathematicians) and can be determined quite readily in cloud or bubble chambers and in photographic emulsions (except for problems connected with the last bubble or grain). It is not a practical quantity for experiments in which the tracks of the particles cannot be followed. In particular, the mean projected range is difficult to determine experimentally hecause of the removal of particles from the beam due to nuclear reactions and multiple scattering.

At energies higher than a few MeV, the number of particles is sensibly reduced owing to nuclear reactions (ref. K064, BI60 and BA61), and appropriate corrections have to be applied (see Sec. 8D) .

The quantity related to $R(T)$ which can be calculated from stopping power theory is the theoretical mean 
range $R_{t}(T)$ in the continuous slowing down approximation (csda) :

$$
R_{t}(T)=\int_{T_{1}}^{T} S^{-1} d T
$$

In principle, $\mathrm{T}_{1}$ is the thermal energy of the particle. For small velocities the description of the stopping power given in Sec. 6B can be used. If $S$ is not known accurately at these energies, a more accurate result for $R_{t}(T)$ may be obtained if $T_{1}$ is chosen to be a higher energy (e.g., $1 \mathrm{MeV}$ for protons) and an experimental value of $\mathrm{R}\left(\mathrm{T}_{1}\right)$ is added to the integral to take care of the low energy contribution to the range. For experimental measurements it will be necessary to consider the detector threshold energy as the energy $T_{1}$ (BM57 and HP60).

A small difference between $R(T)$ and $R_{t}(T)$ is caused by the use of the csda approximation (LE52 and TT68). A simple relation exists between the ranges for different particles. It is discussed in Sec. 6 .

Mean csda ranges for protons in several elements have been computed (ref. BJ67) by numerical integration of the values of Tables II and III. They are listed in Table IV. Values for $R(1 \mathrm{MeV})$ are obtained from refs. BF60, MR67 and RY55. For other elements, the method of ref. SU60 can be used to obtain range-energy relations. For other particles (mesons or heavier ions) see Sec. 6. Extensive tabulations can be found in refs. JA66, BJ69, BB67 and N067. 
For high energies ( $\varepsilon>1,000 \mathrm{MeV}$ for protons) nuclear interactions absorb most of the particles and range becomes a rather meaningless term.

While the straggling in pathlength can be represented approximately by a gaussian (see Sec. 7), the asymmetry of multiple scattering (the zig-zag path taken by a particle can only be longer than the foil thickness, see Sec. 8), and the residual skewness of the electron-loss straggling cause an asymmetry in the range straggling. The median range therefore, is different from the mean range.

The total median range $R_{m}(T)$ (equal to the foil thickness), neglecting the straggling asymmetries, can be obtained from the computed mean pathlength $R_{t}(T)$ by the application of the multiple-scattering correction $\Delta \mathrm{R}$ :

$$
R_{m}(T)=R_{t}(T)-\Delta R \text {. }
$$

The relative correction of $\Delta R / R$ for several elements is plotted in Fig. 3. Further discussion is given in refs. BU60, BF61, BZ67 and TB68. No discussion of the relation of mean and median range seems to be available (see Sec. 7). 


\section{SHELL CORRECTIONS AND I -VALUES}

In principle, the stopping power $S$ can be calculated theoretically using atomic collision cross sections [Eq. (3-1)]. At present, no complete sets of cross sections for all shells are available, and the expression Eq. $(3-6)$ is used for the calculation of $S$. The unknown functions $B_{K}, B_{L}, \ldots$ are then replaced by one unknown constant, $I=I_{\text {ave }}$, and the unknown functions $C_{i}$, which are important only at small energies. If extensive experimental data are available, the shell corrections $C / Z=\sum C_{i} / Z$ can be determined experimentally (AN69), together with the I-value. Usually, experimental uncertainties and limited coverage in energy do not permit this approach. In a modification of an earlier approach (BI61), it is suggested now, that, for $8 \leq Z \leq 25$, Walske's shell corrections (WA52, WA56, BI67, KH68) be used in modified form:

$$
C / Z=\left[C_{K}+V C_{L}\left(H \beta^{2}\right)\right] / Z
$$

with parameters $H, V$ and $I$ determined in a least squares fit to experimental data. Similarly, for $\mathrm{Z} \leqslant 8, \mathrm{C} / \mathrm{Z}=\mathrm{V} \mathrm{C}_{\mathrm{K}}\left(\mathrm{HB} \mathrm{B}^{2}\right)$. For $Z \geq 25$, Bonderup's shell corrections $C_{B}$ (B067) are used, also in a modified form:

$$
\mathrm{C} / \mathrm{Z}=\mathrm{V} \mathrm{C} \mathrm{C}_{\mathrm{B}}\left(\mathrm{H} \mathrm{v}^{2} / \mathrm{v}_{\mathrm{O}}^{2} \mathrm{Z}\right) / \mathrm{Z}
$$

Good fits to experimental data for protons and deuterons are obtained as long as $C_{B} \geq 0$. Values for $H, V$ and $I$ may be found in BJ67. Typically, for $Z \geq 47, \mathrm{H}=0.755, \mathrm{~V}=0.68$ and $I_{A g}=470 \mathrm{eV}, I_{A u}=780 \mathrm{eV}$. For $Z=29, \quad H=0.55$, $\mathrm{V}=0.61$ and $\mathrm{I}_{\mathrm{Cu}}=319.5 \mathrm{eV}$. These fits include effects due 
to the higher Born approximations and are therefore only valid for particles of charge +e.

It was found that the least squares fits do not show singular and distinct minima. For experimental data covering a limited energy range, different local minima will give almost the same $x^{2}$. This is fairly obvious from [Eq. (3-6)]: for a limited velocity range, an increase in $I$ can be almost entirely compensated by a decrease in the shell corrections.

Values of $\mathrm{C} / \mathrm{Z}$ for protons and deuterons adopted in this paper are given in Fig. 4.

While I-values are properly defined by:

$$
\ln I_{\text {ave }} \equiv \sum_{n} f_{n} \ln I_{n}
$$

(DT68), only a few values for light elements have been calculated with this expression (BE66, WH33). They are not as accurate as the experimental values. The quotient $k=I / Z$ is expected to be a constant if $I$ is evaluated using the Thomas-Fermi model (BL33). Fig. 5 shows a plot of the best available values of $k$. Both the rise of $k$ for $20 \leq Z \leq 30$ and the oscillation for even and odd values are unexpected. The interpolation schemes suggested in the past (DT68) cannot be considered reliable, and further measurements appear to be very desirable. 


\section{MISCELLANEOUS EFFECTS}

A difference in the ranges of positive and negative mesons has been observed (BD63, HL69). Similarly, Andersen, Simonsen and Sфrensen (AS69) found a difference between the stopping power of particles of charge one $(p, d)$ and of charge two $\left(\mathrm{He}^{3}, \mathrm{He}^{4}\right)$. This difference presumably is caused by effects due to higher Born approximations. In the further discussions of this section, these effects are implicitly included in the definition of $z^{*}$.

The first Born approximation used in the derivation of the collision cross sections, Eq. (2-2), is valid for $\beta>>\beta_{1}=2 / 137$. For particles with $\beta<\beta_{1}$, atom-atom collisions will contribute increasingly to the stopping process; and an approach based on the use of the Thomas-Fermi model of both the incident ions (with an effective charge $z^{*} e<z e$ ) and the absorber atoms has been fruitful (see Sec. 6B).

The stopping power $S_{M}$ for any particle of mass $M$, nuclear charge ze (values for different particles are given in Table V) and kinetic energy $T$ can bc calculated from the proton stopping power $S_{p}$ with:

$$
S_{M}(T)=z *^{2} S_{p}(\tau)
$$

where $\tau=\mathrm{T} / \mathrm{m}_{\mathrm{r}}$ and $z^{*}$ is discussed in Sec. 6A. Similarly, a simple relation exists between the range $R_{M}$ of the particle and the range $R_{p}$ of a proton:

$$
R_{M}(T)=\left(m_{r} / z^{2}\right) R_{p}(\tau)+m_{r} z^{2 / 3} C_{z}(\beta / z)
$$


where $\mathrm{m}_{\mathrm{r}}=\mathrm{Mc}^{2} / 938.259 \mathrm{MeV}$, and the second term is called the range extension caused by the reduced charge $z^{*} \cdot C_{z}$ is a universal function for any ion in a specific substance. For emulsion, $\mathrm{C}_{z}$ is found in Fig. 5 of ref. HP60 and it is defined for any substance in Eq. (7) of ref. HP60 (see BB67 for data). Another approach can be used: Use Eq. (6-2) to find the range difference $R_{M}(T)-R_{M}\left(T_{1}\right)$ and add $R_{M}\left(T_{1}\right)$ as defined in Sec. $6 B$ to find $R(T)$.

In general, a numerical calculation for a specific case, using Eq. (3-6) with appropriate effective charge $z^{*}$ will be preferable to the use of Eq. (6-2).

\section{Examples}

1. The mean range of $20 \mathrm{MeV}$ muons $\left(\mathrm{m}_{\mathrm{r}}=0.1126\right.$ from $T a b l e ~ V)$ in $A l$ is:

$\mathrm{R}_{\mu}(20 \mathrm{MeV})=0.1126 \times \mathrm{R}_{\mathrm{p}}(177.6 \mathrm{MeV})=0.1126 \times 27.15=3.057 \mathrm{gcm}^{-2}$

2. The mean range of $50 \mathrm{MeV}$ alphas $\left(\mathrm{m}_{r}=3.9726\right)$ in copper is:

$\mathrm{R}_{\alpha}(50 \mathrm{MeV})=(3.9726 / 4) \times \mathrm{R}_{\mathrm{p}}(12.602 \mathrm{MeV})=0.3219 . \mathrm{gcm}^{-2}$

where $R_{p}$ is obtained from Table IV and $C_{z}$ has been neglected. An extensive discussion for heavy ions is given in N067, with many graphs for different incident parti= cles. 
6A. Charge State Correction

For velocities $\beta<\beta_{2}=0.04 \mathrm{z}^{2 / 3}$ it is observed that the nuclear charge $z e$ is not fully effective. A reduced effective charge $z^{*} e$ is used in Eq. (3-6) instead of the nuclear charge $z e(R 060, N 067, H P 60)$. If $z^{*}$ is defined to give the correct observed stopping power, it is not equal to the mean charge per particle of a beam leaving an absorber (PB68, BG65). With an accuracy of about $5 \%$, $z^{*}$ can be obtained from

$$
z * / z=1-\exp \left(-1.316 x+0.1112 x^{2}-0.0650 x^{3}\right)
$$

where $x=100 \mathrm{~B} / \mathrm{z}^{2 / 3}$. This expression is valid for $x>0.27$. In gases, the values are several percent smaller (RS60). It should be noted that the approach described in the next section overlaps the range of validity of Eq. (6-3).

For ions with $21 \leq z \leq 39$, Hvelplund and Fastrup (HV68) have found a periodic dependence of the stopping cross section on $z$ for a carbon absorber. Similar effects were found in WI68 and HA68. Fractional charges for carbon absorbers in CC67 agree with Eq. (6-3) to better than 5\% for most ions. The fluctuations for different absorbers found in their Table III could be due to shell corrections. When available, experimental data should be used. Recent papers include:

$$
\begin{array}{ll}
\mathrm{Br} \text { and } \mathrm{I} \text { ions in } \mathrm{Be}, \mathrm{C}, \mathrm{A} 1, \mathrm{Ag}, \mathrm{Au} & \mathrm{MB} 66 \\
\mathrm{O}^{16} \text { ions in } \mathrm{Ag}, \mathrm{Au} ; \mathrm{S}^{32} \text { ions in } \mathrm{Au} & \mathrm{AH68} \\
\mathrm{S}^{32}, \mathrm{C} 1^{35}, \mathrm{Br}^{79}, \mathrm{I}^{127} \text { ions in Mylar } & \mathrm{PB} 68 \\
0 \text { and } \mathrm{C} 1 \text { ions in } \mathrm{C}, \mathrm{Al}, \mathrm{Ni}, \mathrm{Ag}, \mathrm{Au} & \mathrm{BG65} \\
\mathrm{I}^{127} \text { ions in } \mathrm{C}, \mathrm{A} 1, \mathrm{Ni}, \mathrm{Ag}, \mathrm{Au}, \mathrm{UF}_{4} & \mathrm{BN67}
\end{array}
$$




$$
\begin{array}{ll}
C, N, O, F, \mathrm{Ne} \text { in } \mathrm{Be}, \mathrm{C} & \mathrm{CB} 68 \\
21 \leq z \leq 39 \text { in } \mathrm{C} & \mathrm{HV} 68
\end{array}
$$

Interesting results for charge state populations ( $I^{127}$ in gas and solid) have been found by Moak et al. (ML68). Many references to earlier work are included.

6B. Very Low Velocity Particles

At low velocities, $\beta \leq \beta_{1}=z^{2 / 3} / 137$, ions will carry a reduced charge, and for $\beta<<\beta_{0}=1 / 137=0.0073$, . they will be neutral. The collisions then will be between neutral atoms, and are commonly called "nuclear collisions" (LS63, OH63). Even for this case, energy loss to atomic electrons is still possible (LS63). From a Thomas-Fermi description of the atoms, it is expected that the following dimensionless parameters should result in universal rangeenergy curves:

Energy $\varepsilon=32.53 \times \mathrm{T}(\mathrm{keV}) \mathrm{M}_{2} /\left[\mathrm{zZ}\left(\mathrm{M}_{1}+\mathrm{M}_{2}\right) \sqrt{\zeta}\right]$

Range $\rho=1.660 \times 10^{5} \times R\left(\mathrm{mgcm}^{-2}\right) \mathrm{M}_{1} /\left[\left(\mathrm{M}_{1}+\mathrm{M}_{2}\right)^{2} \zeta\right](6-5)$ where

$$
\begin{aligned}
M_{1}= & \text { Atomic mass of incident particle } \\
M_{2}= & \text { Atomic mass of absorber material } \\
z= & \begin{array}{l}
\text { Atomic number of incident particle (usually } \\
\text { called } Z_{1} \text { ) }
\end{array} \\
Z= & \begin{array}{l}
\text { Atomic number of absorber material (usually } \\
\text { called } Z_{2} \text { ) }
\end{array} \\
\zeta= & z^{2 / 3}+z^{2 / 3}
\end{aligned}
$$


It is found that the stopping power consists of contributions by electronic and nuclear stopping:

$$
s=s_{e}+s_{n} \cdot
$$

From (LS63):

$$
\mathrm{S}_{\mathrm{e}}=\mathrm{k}^{\mathrm{k}} \sqrt{\varepsilon}
$$

where

$$
k=0.0793 \times \xi_{e} \sqrt{2 Z}\left(M_{1}+M_{2}\right)^{3 / 2} /\left[\left(z^{2 / 3}+z^{2 / 3}\right)^{3 / 4} M_{1}^{3 / 2} M_{2}^{1 / 2}\right]
$$

and $\xi_{e}$ is approximately. given by $z^{1 / 6}$. This formula is valid for $\varepsilon<1000$.

The nuclear collision stopping power depends on the ion-atom potential (discussed e.g., in NV66, KE68, LS63, LN68). From Table $I$ of SC66, the following analytic form has been derived (similar to an expression given in BS68)

$$
\left(\frac{d \varepsilon}{d \rho}\right)_{n}=0.5455 \ln (\varepsilon) /\left[\varepsilon\left(1-0.9988 \times \varepsilon^{-1.5391}\right)\right]
$$

and

$$
\begin{aligned}
& S_{n}=1.96 \times 10^{-4} \frac{d \varepsilon}{d \rho} M_{2}\left(M_{1}+M_{2}\right) \sqrt{\zeta} /\left(z Z M_{1}\right) \\
& S_{11} \text { in } \mathrm{keV} / \mathrm{mg} \mathrm{cm}{ }^{-2} .
\end{aligned}
$$

It is seen that $(d \varepsilon / d \rho)_{n}$ is a universal function of $\varepsilon$, while $S_{e}$, through $k$, depends on $z z$. It is therefore only possible to produce a universal range curve $\rho(\varepsilon)=\int_{0}^{\varepsilon} \mathrm{d} \varepsilon^{\prime} /\left(\mathrm{d} \varepsilon^{\prime} / \mathrm{d} \rho\right)_{\mathrm{n}}$ for the nuclear collisions, and if the electronic collisions are of importance, different range curves will be obtained for different values of $k$. 
Different quantities have been defined to describe the path taken by the particle: Linear Range (total pathlength), Vector Range (vector distance from point of incidence to stopping point), and Projected Range (projection of vector range onto direction of incidence). A particle will experience only few collisions, e.g., for $T=12 \mathrm{keV}$ argon atoms in a germanium absorber, the mean collision number is $\sim 6$ (KE68). Both statistical and continuous methods have been used to calculate mean ranges.

For $M_{1} \geq M_{2}$, the ratio of mean projected range $\overline{R_{p}}$ and linear range $R$ is approximately $R / \overline{R_{p}} \sim 1+M_{2} / 3 M_{1}$ (LS63, MS65). A modification of this procedure is suggested in MS65, giving a better agreement with experiment for $\varepsilon<1$.

Using Eqs. (4-2) and (6-10), range-energy curves have been calculated (SC66) for different values of $k$, and are plotted in Fig. 6. In genera1, the agreement between theory and experiment is satisfactory, with accuracies of about 20\%: AG68, BL68, BS68, CA68, JD67, LS67. The use of logarithmic scales in the plots of experimental data tends to hide the differences. Usually, the value of $k$ in Eq. $(6-7)$ is considered an adjustable parameter, and better agreement with the theory can then be achieved (e.g., $\operatorname{CS68,~CB68)~.~}$

Moak and Brown (MB66) and Kahn and Forgue (KF67) have found deviations from the $\sqrt{\varepsilon}$ behavior predicted by 
Eq. (6-7) for $\varepsilon \sim 200$. The deviations in $k$ for light elements are not unexpected: the Thomas-Fermi model may not give a good approximation for $Z<20$.

At higher values of $\varepsilon$ (say $\varepsilon>300)$, the approach presented here overlaps with the Bethe theory using effective charges (Sec. 6A) and experimental data have to be consulted to find the more reliable approach.

6C. Small Volumes

The energy losses discussed in Sec. 3 are as experienced by the charged particles and are not directly related to the energy gained by the absorber material (see the discussion of LET in Sec. 9).

\section{Examples}

a) In a thin silicon detector of the transmission type, in a vacuum, some $\delta$-rays will leave the back surface of the detector, reducing the observed energy loss slightly (for $40 \mathrm{MeV}$ protons in a $200 \mu \mathrm{m}$ detector, the reduction amounts to no more than $0.5 \%$ ).

b) In very small volumes (diameter of $1 \mu \mathrm{m}$ or less of a material of density $\rho=1 \mathrm{~g} / \mathrm{cm}^{2}$, corresponding to the size of living cells), the energy lost by a particle of moderate or large energy is quite uncorrelated to the energy 
absorbed in the volume. Since the behavior of low energy electrons is not well known (energies of less than 1. keV), and since the collision cross sections are not known for low $Z$ materials, calculations are extremely unreliable at present.

6D. Channeling

In single crystals it is observed that energy loss depends on the direction of the particle path with respect to the crystal axes. A detailed discussion of various aspects of the problem is given by Lindhard (LI65). Other calculations are available in several of the experimental papers mentioned below and in BR68.

If particles travel parallel to a major axis of the lattice, some can move "in between" the atoms, reducing the number of collisions with small impact parameters (energy loss and straggling would then both be reduced, see AE67, DM69) while others would move close to nuclear positions, increasing the effects. For a well collimated beam with small multiple scattering, a fraction of the beam may keep away from atoms for long distances.

A number of experiments have recently been published: an especially instructive diagram is given in RS67, a study of 3-11 MeV protons in $\mathrm{Si}$ and $\mathrm{Ge}$ is of interest for the use of solid state detectors: AE67. Other studies are. described in DW68, DM69, ER67, R069, SV68. 


\section{STRAGGLING OF HEAVY PARTICLES}

Particles, in passing through an absorber of thickness $s$, experience a random number of collisions with a wide range of possible energy transfers. The energy losses $\Delta$ of a monoenergetic beam of particles thus will fluctuate ("Straggling") about the mean energy loss $\bar{\Delta}=\mathrm{s}$ S. The straggling distribution function $f(\Delta)$ depends on the velocity $v=\beta c$ of the incident particle, on $S$ and $Z / A$ of the material. For large thicknesses, $f(\Delta)$ approaches a gaussian shape.

7A. Thin Absorbers

Landau (LA44), Symon (SY48), Vavilov (VA57), Shulek, et. al. (SG67) and many others have discussed straggling in thin absorbers. Extensive tabulations are available for the Vavilov distribution (SB67), based on calculations using the free electron collision spectrum [Eq. (2-1)].

A comparison of experimental data (e.g., K068, MR68, AL69) with the theory can be based on the use of the moments of the distribution function. The central moments $C_{n}$ are defined by:

$C_{n}=\int f(\Delta)(\Delta-\bar{\Delta})^{n} d \Delta=c(\Delta-\bar{\Delta})^{n}, \quad . n=0,1,2,3, \ldots$

and $f(\Delta)$ must be normalized, i.e.

$C_{0}-\int f(\Delta) d \Delta=1 . \quad$ Obvious $1 y C_{1}=0$ 
The theoretical quantities $\kappa_{n}$ (the "cumulants" of statistical theory, FA53) related to these moments, calculated with the Vavilov approach, are given by ( $\mathrm{s}$ in $\mathrm{gr} \mathrm{cm}^{-2}$ ) $\kappa_{n}^{\prime}=\frac{0.1535 \mathrm{Zz}^{2}}{\beta^{2} A} \quad \frac{\mathrm{s} \mathrm{E}_{\max }^{\mathrm{n}-1}}{\mathrm{n}-1}\left[1-\beta^{2}(\mathrm{n}-1) / \mathrm{n}\right](\mathrm{MeV})^{\mathrm{n}}$

where $E_{\max } \simeq 2 \mathrm{mc}^{2} \beta^{2} /\left(1-\beta^{2}\right)=1.022 \beta^{2} /\left(1-\beta^{2}\right)$ In particular (e.g., BO48):

$$
\begin{array}{cl}
k_{2}^{\prime \prime}=\frac{0.1569 \mathrm{Zz}^{2}}{A} & \text { s }\left(1-\beta^{2} / 2\right) /\left(1-\beta^{2}\right) \mathrm{MeV}^{2} \\
\text { For } \mathrm{n}=2,3 & \mathrm{C}_{\mathrm{n}}=\kappa_{\mathrm{n}} \\
\mathrm{n}=4 & \mathrm{C}_{4}=\kappa_{4}+3 \mathrm{C}_{2}^{2}, \text { etc. }
\end{array}
$$

The standard deviation $\sigma=\sqrt{k_{2}^{\prime}}$ of a straggling distribution thus is quite insensitive to the incident particle energy. Except for a gaussian, there is no simple relation between the "width at half maximum" and $\sigma$. For practical applications, it will be best to calculate moments by numerical integration from experimental data, and compare thell will $k_{n}$. For thc actual functions, ref. SBG7 should be consulted. For applications in thin silicon detectors, see Fig. 7 .

The Vavilov function will be an approximation due to the use of the free electron collision cross section. No complete quantum mechanical calculations are available. An estimate of the deviations to be expected can be obtained from a comparison of moments $M_{n}=\int W^{n} J$ dW using $J_{K}$ and $\mathrm{J}_{\mathrm{L}}$. Some of these ratios are given for $\mathrm{J}_{\mathrm{L}}$ in Figs. 8 and 9 (BI69). For example, for protons in silicon, the maximum 
deviation in $M_{2}$ is expected to occur at $\eta_{L}=1.6$, corresponding to a kinetic energy $\mathrm{T} i 3.5 \mathrm{MeV}$. The correction by Shulek et al. (SG67) takes into account only $M_{2}$ and therefore cannot be expected to be reliable. It is also much too large for small velocities. Experiments by Nielsen for several elements (NI61, Fig. 7) indicate deviations of the second moment amounting to no more than $20 \%$ from $\dot{K}_{2}^{\prime}=s M_{2}^{\prime}$ while Shulek et al. indicate deviations of up to $100 \%$.

7B. Thick Absorbers

An extensive discussion for large energy losses is given by Symon (SY48) and by Tschalär (TS67, TS68, TT68). For moderate energy losses, Tschalär's results for heavy particles of initial kinetic energy $T$ and residual mean energy. $\mathrm{T}_{1}$ can be approximated by the following expression for the second moment (accurate to about $2 \%$ ).

$$
\mathrm{C}_{2}=\dot{\mathrm{K}}_{2}^{\prime} \mathrm{Q}
$$

$$
\begin{aligned}
& \text { where } Q=\left(T / T_{1}\right)^{1 / 3} \\
& \text { for } \\
& \mathrm{B} / \mathrm{Z} 2.3 \text { and } \mathrm{T}_{1} / \mathrm{T}>0.4 \\
& =0.99\left(\mathrm{~T} / \mathrm{T}_{1}\right)^{1 / 2} \\
& B / 2 \sim 3.5 \\
& \mathrm{~T}_{1} / \mathrm{T}>0.4 \\
& =0.985\left(\mathrm{~T} / \mathrm{T}_{1}\right)^{2 / 3} \\
& \mathrm{~T}_{1} / \mathrm{T}>0.6
\end{aligned}
$$

where $B$ is the stopping number, Eq. (3-3), and

$$
B / Z=f(\beta)-\ln I-\Sigma C_{i} / Z
$$


For larger energy losses, TS68 should be consulted. For the asymmetry of the curves, the third moment should be studied. Tschalär uses the skewness parameter $r_{3}^{\prime}=C_{3} / C_{2}^{3 / 2}$ for this purpose. From his results it is found, that the expression for thin absorbers:

$$
\dot{\gamma}_{3}^{\prime}=\kappa_{3}^{\prime} /\left(\kappa_{2}^{\prime}\right)^{3 / 2} \text { is accurate to a few percent }
$$

for $B / Z \sim 2.3$ and $T_{1} / T>0.5$ and for $B / Z \sim 6$ and $\mathrm{T}_{1} / \mathrm{T}>0.7$. It may be noted that the distribution functions for the cases discussed above are approximately given by the Vavilov functions for the value $k_{v}=0.25 \mathrm{r}_{3}^{-2}$ of the Vavilov parameter $\kappa_{v}=\xi / E_{\max }(\mathrm{SB} 67)$.

For the ranges $R$ of particles with a mean value $\bar{R}$ the second central moment, also called the "mean square fluctuation" $\sigma^{2}$ is defined by

$$
\sigma^{2}=\left\langle R^{2}\right\rangle-\bar{R}^{2}
$$

The distribution $f(R)$ is usually approximated by a gaussian:

$$
f(R) \approx \frac{1}{\sigma \sqrt{2 \pi}} \exp \left[-(R-\bar{R})^{2} / 2 \sigma^{2}\right]
$$

and the probability $p$ of finding a particle with range between $R$ and $R+d R$ is $p d R=f(R) d R$. The deviations from a gaussian are small, but not negligible. They are discussed in LE52 and TT68. Their influence on the Bragg curve has not been studied yet.

The ratio of $\sigma$ to the total mean range $R$ is given in Fig. 10 for protons in several elements. For 
other particles of mass $M$, the value can be calculated from:

$$
\left(\frac{\sigma}{R}\right)_{M}=\sqrt{1 / m_{r}}\left[\frac{\sigma}{R}\left(\mathrm{~T} / \mathrm{m}_{\mathrm{r}}\right)\right] \text { proton }
$$

Estimates for the quantum mechanical corrections have been incorporated in the calculations for Fig. 10. The values of $\frac{\sigma}{R}$ are considerably smaller than the values calculated by Sternheimer (ST60), but they are still slightly larger than experimental values (BU60), which were evaluated neglecting the skewness of the range straggling curves. The observed straggling in range-energy measurements is composed of the energy loss straggling, and an additional asymmetric contribution caused by the multiple scattering process (BU60, BI60). 
8. COULOMB AND MULTIPLE SCATTERING,

AND NUCLEAR INTERACTIONS

8A. Coulomb Scattering

The differential cross section for Coulomb scattering of a charged particle of kinetic energy $\mathrm{T}$ (in MeV), momentum $p$, velocity $v$ and charge ze by a nucleus of charge $Z e$ and mass number $A$ into the solid angle $2 \pi \sin \theta d \theta$ is given by the Rutherford formula:

$$
\begin{aligned}
\mathrm{d} \Phi(\theta) & =\frac{2 \pi \mathrm{e}^{4} \mathrm{z}^{2} z(z+1)}{4 \mathrm{p}^{2} \mathrm{v}^{2} \sin ^{4}(\theta / 2)} \sin \theta \mathrm{d} \theta \\
& \cong \frac{0.814 \mathrm{z}^{2} z(z+1)}{\mathrm{T}^{2}} \cdot \frac{\sin \theta \mathrm{d} \theta}{\sin ^{4}(\theta / 2)} \times 10^{-26} \mathrm{~cm}^{2}
\end{aligned}
$$

where $\theta$ is the angle of scattering from the incident direction. The above formula assumes that the mass of the incident particle is negligible compared with the mass of the nucleus.

Deviations from the Rutherford formula will occur at large angles as the particles begin to feel the influence of nuclear forces. An estimate of the minimum energy $\mathrm{T}_{\mathrm{m}}$ for which a deviation can be expected at $\theta=180^{\circ}$ can be obtained from

$$
\mathrm{T}=\mathrm{z} \mathrm{Z} /(\sqrt[3]{\mathrm{A}+3}) \mathrm{MeV}
$$


A detailed discussion is found in EP61 and JA68. At small angles, the cross section will be smaller than given by Eq. $(8-1)$ because the atomic electrons will shield the nuclear charge. The Rutherford cross section is reduced by $10 \%$ at an angle $\theta_{\mathrm{q}}$ given by (from MO47):

$$
\begin{aligned}
& \theta_{q}=\theta_{0} \sqrt{61.7+421 \alpha^{2}} \text { and by } 50 \% \text { at } \\
& \theta_{r}=\theta_{0} \sqrt{2.75+10.85 \alpha^{2}}
\end{aligned}
$$

where $\theta_{0}=\frac{0.244 \sqrt[3]{Z}}{p c(M e V)} \sim \frac{0.244 \sqrt[3]{Z}}{\sqrt{2 M_{0} c^{2} T}}$

and $\alpha=\frac{Z Z}{137 \beta}$. For large kinetic energies,

$$
\begin{gathered}
\mathrm{pc}=\sqrt{\mathrm{T}^{2}+2 \mathrm{TM} \mathrm{O}_{\mathrm{O}}{ }^{2}} \text {, and with } \zeta=\mathrm{T} / \mathrm{M}_{\mathrm{O}} \mathrm{c}^{2}, \\
\beta^{2}=\zeta(\zeta+2) /(\zeta+1)^{2}
\end{gathered}
$$

Example: $10 \mathrm{MeV}$ alpha particles in $\mathrm{Au}$ : from Table I, $\beta=0.073, \alpha=15.8, \theta_{0}=1.05 / \sqrt{74,600}=3.84 \times 10^{-3}$ degrees. Finally, $\theta_{q}=3.84 \times 10^{-3} \sqrt{61.7}+105,000=1.25^{\circ}$. This reduction is of great importance in the derivation of the multiple scattering formulas.

8B. Multiple Scattering in Thin Absorbers

Multiple Coulomb scattering in thin foils will cause a parallel beam of particles to spread out into a cone. Recent discussions are found in HF68, SC63 and GD68. 
Moliere's theory (MO48, BE53 and M055) is a small-angle approximation to the general problem (BR59, NS61 and TM59) which is in agreement with experimental results, with the possible exception of electrons in heavy elements and also possibly at small energies $\left(\beta^{2}<2 \times 10^{-3}\right)$.

The characteristic quantity occurring in the theory is the angle $\theta_{0}$, defined by $\theta_{0}=\theta_{1} \sqrt{\mathrm{B}}$ where.

$$
\theta_{1}^{2}=0.157 \frac{Z(z+1) z^{2}}{A} \frac{s}{(p v)^{2}}
$$

$\theta_{1}$ is in radians; $s$ is the foil thickness in $\mathrm{g} \mathrm{cm}^{-2}$, $\mathrm{p}$ the momentum, and $v$ the velocity of the particle ( $\mathrm{pv}$ in MeV); $\mathrm{z}, \mathrm{Z}$ and $\mathrm{A}$ have the same meaning as in Sec. 2. B is defined in ref. MO48; for practical purposes it can be obtained from ref. MZ67 or from Table VI for particles with charge 1 with an accuracy of better than 5 per cent. A few values are 1 isted for $z>1$. It is not obvious whether $z^{*}$ or $z$ should be used for a computation of the multiple scattering of heavy ions. The use of $z^{*}$ is suggested. For $z \geq 6$ and $z \geq 50$, all values $B(B, z)$ are larger than $0.98 \times B(\beta=0, z=1)$, and for $z \geq 6$ and $z \geq 20$, all values $B(\beta, z) \geq 0.95 \times B(\beta=0, z=1)$. Moliere's theory modified by Nigam et al. (NS61) gives the distribution function $F(x) d x$ for the relative number of particles entering a cone of angle $x$ and width $\mathrm{dx}$. The reduced angle $\mathrm{x}$ is defined by

$$
x=\theta / \theta_{0}
$$


An extensive discussion of the problem is given in (MZ67). Table VII giving $F(x)$ is obtained from (MZ67).

Also of interest is the relative number $\mathrm{N} / \mathrm{N}_{\mathrm{O}}$ of particles entering a cone of half angle $\alpha$ :

$$
\frac{N}{N_{0}}=\int_{0}^{\alpha / \theta_{0}} f(x) x d x
$$

Values are given in Table VIII. For experimental tests of the theory, see BI58, M058, L067, BN66.

$\underline{\text { Example }}$

2-MeV protons penetrating $3 \mathrm{mg} \mathrm{cm}^{-2}$ of $\mathrm{Ni}$ foil.

The average energy in the foil is $1.87 \mathrm{MeV}$. $\beta^{2} \sim 3.96 \times 10^{-3}$ from Table I, $B \sim 7.7$ from Table VI. $\theta_{1}^{2}=4.72 \times 10^{-4}, \theta_{0}=6.03 \times 10^{-2} \mathrm{rad}$ $=3.46 \mathrm{deg}$. Thus, inside a cone of half angle $7 \mathrm{deg}$, all but about $6.3 \%$ of the protons will be found (see Table VIII).

Caution has to be used for the case of the incident particle of mass approximately equal to or larger than the mass of the scattering nucleus. In this case a considerable fraction of the energy can be lost to the recoil nucleus. This effect is, of course, not included in the fundamental energy-loss formula, Eq. (3-6). 
8C. Multiple Scattering in Thick Absorbers

For thick absorbers, the mean energy correction due to multiple scattering has been calculated in TB68 for energy. losses between $0.5 \mathrm{~T}$ and $0.1 \mathrm{~T}$, for $10<\mathrm{T}<140 \mathrm{MeV}$, for detector angles between $0.005 \mathrm{rad}$ and $0.5 \mathrm{rad}$ for protons in $\mathrm{Al}, \mathrm{Ag}$, and $\mathrm{Au}$.

The multiple scattering correction for median ranges has been discussed in Section 3 .

8D. Nuclear Interactions

Heavy charged particles will be removed from beams by nuclear interactions: the beam intensity will be attenuated exponentially

$$
I=I_{0} e^{-s \Sigma}
$$

where I is the flux density, and $\Sigma$ is the macroscopic cross section $\Sigma=\sigma_{t} n$ ( $\sigma_{t}$ total microscopic cross section, $\mathrm{n}=$ number of nuclei per $\mathrm{cm}^{3}$ ). For estimates, $\Sigma=0.32 / \mathrm{A}^{1 / 3} \mathrm{~cm}^{2} / \mathrm{gm}$ may be used $(\mathrm{A}=$ atomic number of absorber). 


\section{ELECTRONS}

While electrons in passing through matter will experience interactions similar to heavy-particle interactions, two basic differences are manifest:

a) In the collisions with atomic electrons; large energy losses can occur; and

b) Electrons with energies of only a few hundred kiloelectron volts will show relativistic effects.

An extensive review of the theory is found in (BI58), and extensive tabulations are contained in (BS67). The derivation of the stopping power formula is similar to the heavy particle case. It will be assumed that after a collision by a negative electron, the electron with the higher velocity will be considered the primary. The mean collision loss in $\mathrm{MeV} \mathrm{cm} \mathrm{cm}^{2} / \mathrm{g}$ is given by (BS67):

$$
-\left(\frac{\mathrm{dT}}{\rho \mathrm{d} s}\right)_{\mathrm{co} 1}^{ \pm}=\left(\frac{0.1535}{\beta^{2}}\right)\left(\frac{Z}{\mathrm{~A}}\right)\left[\ln \left\{\frac{2(\tau+2)}{\left(I / \mathrm{mc}^{2}\right)^{2}}\right\}+\mathrm{F}^{ \pm}(\tau, \Delta)-\delta\right]
$$

where for electrons $\Delta=1 / 2 \tau$ and

$$
\begin{aligned}
F^{-} & =-1-\beta^{2}+\ln [(\tau-\Delta) \Delta]+[\tau /(\tau-\Delta)] \\
+ & \frac{\frac{1}{2} \Delta^{2}+(2 \tau+1) \ln [1-(\Delta / \tau)]}{(\tau+1)^{2}}
\end{aligned}
$$

and for positrons $\Delta=\tau$ and

$$
\begin{aligned}
F^{+} & =\ln (\tau \Delta)-\frac{\beta}{\tau}\left[\tau+\Delta-\frac{(5 / 4) \Delta^{2}}{(\tau+2)}+\frac{(\tau+1)(\tau+3) \Delta-(1 / 3) \Delta^{3}}{(\tau+2)^{2}}\right. \\
& \left.-\frac{(\tau+1)(\tau+3)(1 / 4) \Delta^{4}-(\tau / 3) \Delta^{3}+(1 / 4) \Delta^{4}}{(\tau+2)^{3}}\right] \quad(9-3)
\end{aligned}
$$


Here $\tau=\left(\mathrm{T} / \mathrm{mc} \mathrm{c}^{2}\right), \quad \delta$ is the density correction, and $\mathrm{mc}^{2}=511004 \mathrm{eV}, \Delta$ is the maximum energy. given to $\delta$ rays, divided by $\mathrm{mc}^{2}$. The other symbols here have the same meaning as in Eq. (3-6). In particular, the same I-values are used as for the heavier particles.

The shell corrections are not included, because their contribution above $0.1 \mathrm{MeV}$ amounts to less than 1 per cent. If desired, the shell corrections discussed above (Fig. 4) can be used to correct stopping power values obtained from Eq. (9-1). The differences between electrons and positrons have been studied by Rohrlich and Carlson (RC54).

The energy loss due to bremsstrahlung is important for electrons at relatively small energies. An estimate of the ratio $r$ of the bremsstrahlung energy loss to $(\mathrm{dT} / \mathrm{ds}) \operatorname{coll}$ is given by

$$
\mathrm{r} \sim \mathrm{T}(\mathrm{Z}+1.2) / 700 \quad(\mathrm{~T} \text { in } \mathrm{MeV})
$$

at $\mathrm{T}_{\mathrm{c}} \sim 700 /(z+1.2) \mathrm{MeV}$ the two energy losses are equal. An important quantity is associated with the traversal of matter by electrons of energies above $\mathrm{T}_{c}$; this is the distance $x_{0}$ in which an electron's energy is reduced to $1 / e=0.3679$ of its original value. $x_{0}$ is called the "radiation length" and is given in Table IX together with 
more accurate values of $\mathrm{T}_{\mathrm{c}}$. Recent experimental results are found in DR68.

9A. Restricted Stopping Power (LET)

Secondary radiation ( $\delta$-rays or bremsstrahlung photons) may travel quite far from the track of a particle. An estimate of the energy deposited inside of a small cylinder around a track can be obtained by setting the quantity $\Delta$ in Eq. (9-1) equal to the energy of $\delta$-rays capable of escaping from the volume of interest. Heavy particles produce relatively few $\delta$-rays of high energy (see Eq. 2-1) and the difference between LET and $\mathrm{dT} / \mathrm{ds}$ is relatively small for energies below $\mathrm{Mc}^{2}$ (see Sec. 6C, though).

9B. Practical Considerations for Stopping Power

Computed values of the electron stopping power are given for some elements in Fig. 11. Extensive tables are found in (BS67). For $\mathrm{T}<5 \mathrm{MeV},(\mathrm{dT} / \rho \mathrm{ds})_{\operatorname{col}} \sim \mathrm{z}^{-1 / 4}$. This factor should be used for interpolation in Fig. 11. Straggling (discussed in detail in KM61) is much larger for electrons than for heavier particles (see, e.g., Fig. 12 in BI68 or Fig. 2 in BR64). The width at half maximum of a straggling distribution may amount to more than $50 \%$ of the mean energy loss. Multiple (VV68) and back scattering contribute to the problem. Comparison of mean 
energy losses calculated from Eq. (9-1) with experimental data (e.g., HU57, HA59, HR68) can be expected to be accurate to better than $10 \%$ only if a detailed study of straggling etc., has been made. A comparison of experiment and theory for 1 and $2 \mathrm{MeV}$ electrons in silicon is found in SI67.

9C. Electron Ranges and Energy Deposition in Thick Absorbers

For electrons traversing thick absorbers, lateral and backscattering will be very important and electron distribution functions will extend over wide ranges in space, angle and energy. A general treatment is found in BE63, KK68, R068, SP55 and SP54. Practical results for many subs.tances are given in SP59, KE66, BS67, LP57 and PE62 and KK68. Detailed investigations have been performed for 5 to $30 \mathrm{keV}$ electrons (CT65), and for 40 to $160 \mathrm{keV}$ electrons (GF59). For hïgher energies, see, e.g., BH58. Electron ranges calculated by the use of Eq. (4-2) do not have a simple relation to any observed quantity: see Table $X$.

The practical range-energy relation for electrons is not strongly dependent on the atomic number of the stopping material. Only that for aluminum is given. Monoenergetic electrons are absorbed as indicated in Fig. 12 which serves to define the "practical range" $R_{p}$ and the "maximum range" $R_{o}$. The practical range, in aluminum is given by

$$
R_{p}=0.537 \mathrm{~T}[1-0.9815 /(1+0.003123 \mathrm{~T})]
$$


$R_{p}$ in $\mathrm{mg} \mathrm{cm}^{-2}$, $T$ in $\mathrm{keV}$, for the energy range $0.3 \mathrm{keV} \leq \mathrm{T} \leq 20 \mathrm{MeV}$, with an accuracy of about $\pm 6 \%$ (KK68). A graph of this relation is given in Fig. 13 .

The formulas given above for monoenergetic electrons can be used for continuous beta-ray spectra where $R_{p}$ and $T_{0}$ refer to the maximum beta-ray range and energy, respect ively. For a discussion of the methods of determining the range from an absorption curve, see KP52.

For practical applications in which information on electron range and energy deposition is required, it appears best to use Spencer's calculations (SP59, see also BI68), but some information is found also in KK68.

Unlike the case for heavy charged particles, determination of electron energies from transmission measurements is not accurate enough for most applications. Energies can be determined much more accurately by measurements with calibrated scintillation or solid state detectors. 
10. MEAN ENERGY FOR THE FORMATION OF AN ION PAIR

10A. Gases

The energy loss $w$ of a charged particle per ion pair formed in the material traversed is nearly. independent of the energy and type of particle for velocities $\beta^{2}>10^{-4} \mathrm{z}$ as can be seen in Table XI. For further values see MY68.

From the measurements of Phipps, Boring and Lowry (PB64), the following approximate velocity dependence of $\mathrm{w}$ has been derived for ions with $A<40$

$$
w=0.119 / \beta \quad(\mathrm{eV}) \quad \text { for } \beta \leq 0.0043
$$

For more accurate values, PB64, BS65 and LH65 should be consulted. For ${ }^{206} \mathrm{~Pb}$ ions with $\mathrm{T}=103 \mathrm{keV}$, measurements have been made by Cano (CA68).

Mixtures of gases do not follow a simple additivity rule for the value of $w$ (MY68, BH54). A large. drop in $w$ of argon for small concentrations of $\mathrm{C}_{2} \mathrm{H}_{4}$ has been observed. For further details, see MY68. Ionization fluctuations and the resolution of ionization chambers is discussed extensively in AK67.

10B. Solids

A recent discussion of the response of $\mathrm{NaI}(\mathrm{T} 1)$ to heavy ions is found in KA68, with references to earlier work. 
The ionization in silicon and germanium has been studied extensively (see almost any issue of "IEEE Transactions on Nuclear Science"). The average energy $\varepsilon$ for the generation of an electron-hole pair is much smaller than for gases. For Si, $\varepsilon \sim 3.6 \mathrm{eV}$, for $\mathrm{Ge}, \varepsilon \sim 2.96 \mathrm{eV}$. For silicon, the following effects have been observed:

a) For low energy electrons (produced with $\gamma$-rays), pulseheights, after correction for charge collection efficiency, are proportional to energy within $0.2 \% \quad$ (ZM69).

b) For a change in temperature from $300 \mathrm{~K}$ to $90 \mathrm{~K}$, an increase of $4 \%$ in $\varepsilon$ has been observed (PG68).

c) $\varepsilon$ is about one percent smaller for alpha particles than for electrons (PG68).

d) For heavy ions, $\varepsilon$ is energy dependent at small energies (BB63, FK67, FS69, KA67, RB69, SA65). For $T_{m} \gg, 6 M$ (keV) ( $M=$ atomic. mass of ion), the energy $\mathrm{T}_{\mathrm{m}}^{\prime}$ calculated from a measured ionization pulse should be increased by an amount $\Delta \mathrm{T} \sim 4 \mathrm{M}(\mathrm{keV})$, the "ionization defect".

The ionization defect (FS69) is for:

protons $\quad 1-2 \mathrm{keV}$ alpha particles $8-12 \mathrm{keV}$ 
Somewhat different results have been given in $\mathrm{RB} 69$. Similar results have been obtained for germanium detectors (DB67, PR69). Several factors determine the resolution of solid state detectors (BL67, AN67, TS67); some of the more important:

a) Electronic noise and drift of amplifier system

b) Ballistic deficit

c) Pulse pile up

d) Recombination and trapping

e) Channeling (see Sec. 7).

f) Absorption in surface layers

g) Statistics of the number $N$ of electron-hole pairs produced.

Fano (FA47) has shown that the standard deviation of the mean number $\bar{N}$ is: $\Delta N^{2}=\left\langle(N-\bar{N})^{2}\right\rangle=F \bar{N}$ where $F \leq 1$. Bilger (BL67) found $F=0.13$ for germanium. Alkazov et al. (AK67) obtained $F \sim 0.1$ for silicon. The problem is also discussed in DF67:

Energy loss tables for $\mathrm{p}, \mathrm{d}, \mathrm{t}, \mathrm{He}^{3}, \mathrm{He}^{4}$ and $\mathrm{Li}^{6}$ with data useful for particle identifier systems are given in BT67 and SK67. Information about the straggling in thin silicon detectors is given in Fig. 7 . 
42.

Acknowledgment

I am grateful for the hospitality of the Lawrence Radiation Laboratory in Berkeley, where most of the calculations of this paper were performed on the CDC -6600 . 


\section{$\underline{\text { References }}$}

NOTE: The symbol in the second column indicates the section in which the reference appears.
AE67 6D
B. R. Appleton, C. Erginsoy and W. M. Gibson, Phys. Rev. 161, 330 (1967).
AG68 6B
M. Ait-Salem, H. Gerhardt, F. Gönnenwein,
H. Hipp, and H. Paap, Nucl. Inst. Meth. $\underline{60}$, 45 (1968).
AH6 73
H. H. Andersen, C. C. Hanke, H. Sørensen and
P. Vajda, Phys. Rev. 153, 338 (19.67).
AH6 8 A
B. H. Armitage and B. W. Hooton, Nucl. Inst.
Meth. 58,29 (1968).
AK67 10
G. D. Alkhazov, A. P. Komar and A. A. Vorob'ev, Nucl. Inst. Meth. 48, 1 (1967).
AL69 7
D. W. Aitken, W. L. Lakin, and H. R. Zulliger, Phys. Rev. 179, 393' (1969).
AN6 $7 \quad 10$
G. Andersson-Lindstroem, Nucl. Inst. Meth. $\underline{56}$, 309 (1967).
AN69 5
H. H. Andersen, H. Sørensen, and P. Vajda, Phys . Rev. 180, 373 (1969).
AS6 83
H. H. Andersen, C. C. Hanke, H. Simonsen,
H. Sфrensen, and P. Vajda, Phys. Rev. 175, 389 (1968).
AS69 6
H. H. Andersen, H. Simonsen and H. Sфrensen, Nuc1. Phys : A125, 171 (1969).

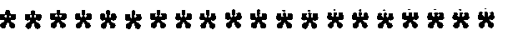
BA61 4
BA63 3
BB63 10
BB6 74,6
BB69 6
BD63 3,6
W. H. Barkas, Phys. Rev. 124, 897 (1961).
W. H. Barkas, "Nuclear Research Emulsions", Academic: Press (1963).
H. Bilger, E. Baldinger and W. Czaja, Helv. Phys. Acta $\underline{36}, 405$ (1963).
W. H. Barkas and M. J. Berger, Paper 7 of NA67.
N. Barash-Schmidt, A. Barbaro-Galtieri, L. R. Price, A. H. Rosenfeld, P. Söding, C. G. Woh1, M. Roos and G. Conforto, Rev. Mod. Phys. 41, 109 (1969).
W. H. Barkas, J. N. Dyer and H. H. Heckman, Phys. Rev. Lett. 11, 26 (1963). 

BE $53 \quad 8$
H. Bethe, Phys. Rev. 89, 1256 (1953).
BE63 9
BE66 5
BF60. 4
BF.61 4
BG65 6,
BH5 410
BH58 9
BH69 5
BI $58 \quad 8$
BI 604,7
BI 615
B I 672,5
B I $682,3,4,9$
BI69 2,7
BJ67 $3,4,5$
BJ69 4
BK $58 \quad 3,9$
BK6 $7^{\circ} 3$
BL3 35
BL67 10
M. J. Berger in "Methods in Computational Physics," ed. Alder, Fernbach and Rotenberg (Academic Press Inc., New York, 1963), Vo1. 1, p. 135.
R. J. Bell and A. Dalgarno, Proc. Phys. Soc. 89 , 55 (1966) and 86,375 (1965).
H. Bichse 1 and B. J. Farmer, Bul1. Am. Phys. Soc. $5,263(1960)$.
W. H. Barkas and S. von Friesen, Nuovo Cim (10) 19, Supp1. 1, p. 41 (1961).
W. Booth and I. S. Grant, Nucl. Phys: 63, 481 (1965).
T. E. Bortner and G. S. Hurst, Phys. Rev. 93, 1236 (1954).
H. Breuer, D. Harder and W. Pohlit, Z. Naturforsch. 13a, 567 (1958).
H. Bichse1, C. C. Hanke and J. Buechner, USC-136- 148 (March, 1969).
H. Bichse1, Phys. Rev. '112, 182 (19.58).
H. Bichse1, Phys. Rev. 120, 1012 (1960).
H. Bichse1, Technical Report, No. 3, University of Southern California.
H. Bichse1, USC-136-120 (Apri1, 1967).
H. Bichse1, "Radiation Dosimetry", Ch. 4, Vol. 1, F. H. Attix and Wm. R. Roesch, eds. Academic Press, New York, January 1968.
H. Bichse1, USC-136-147 (January, 1969).
H. Bichsel, Univ. of California, L.R.L. Technical Report UCRL-17538.
H. Bichsel, Range Energy Tables (to be published).
R. D. Birkhoff, Encyclopedia of Physics, Vol. 34,
34 (Springer, Berlin, 1958).
H. Bichse1, Paper 2 in NA67.
F. B1och, Z. Phys. 81,363 (1933).
H. R. Bilger, Phys. Rev. 163, 238 (1967). 
BL6 8 6B

BL69 2

BM5 74

BN6 68

BN67 6A

B048 7

B067 5

BR59 8

BR6 49

BR6 8 6D

BS65 . 10

BS6 79

BS68 6B

BT67 10

BT68 3

BU60 4,7

BZ67 4

CA68 6B, 10

CB68 6A, B
W. W. Bowman, F. M. Lanzafame, C. K. Kline, Yu-Wen Yu and M. Blann, Phys. Rev. 165, 485 (1968).

W. Brandt and R. Laubert, Phys. Rev. $\underline{178}$, 225 (1969).

H. Bichsel, R. F. Mozley and W. Aron, Phys. Rev. 105, 1788 (1957).

A. A. Bednyakov, V. S. Nikolaev, A. V. Rudchenko and A. F. Tulinov, Soviet Physics JETP 23, 391 (1966).

L. B. Bridwell, L. C. Northcliffe, S. Datz, C. D. Moak and H. O. Lutz, Phys. Rev. 159, 276 $(1967)$.

N. Bohr, Dan. Mat. Fys. Medd. 18, No. 8 (1948) (ed. 2, 1953).

E. Bonderup, Dan. Mat. Fys. Medd. 35, No. 17 (1967).

E. Breitenberger, Proc. Roy. Soc. (London) A250, 514 (1959).

H. Breuer, Z. Phys. 180, 209 (1964).

D. K. Brice, Phys. Rev. 165, 475 (1968).

J. W. Boring, G. E. Strohl and F. R. Woods, Phys. Rev. 140, A1065 (1965).

M. J. Berger and S. M. Seltzer, Paper 10 in NA67.

J. P. Biersack, 2. Phys. 211, 405 (1068) .

H. Bichsel and C. Tschalär, Nuclear Data A3, 343 (1967) and UCRL - 17663.

H. Bichsel and C. Tschalär, Phys. Rev. 175, 476 (1968).

H. Bichsel and E. A. Uehling, Phys. Rev. 119, $1670(1960)$.

M. J. Berger and S. M. Seltzer, Paper 5 in NA67.

$\star * * * * \star * * * * * * * * * * * * * *$

G. L. Cano, Phys. Rev. 169, 277. (1968).

W. K. Chu, P. D. Bourland, K. H. Wang, and

D. Powers, Phys. Rev. 175, 342 (1968). 
$\mathrm{CC67} 6 \mathrm{~A}$

CS68 6B

CT65 9

DA6 8

DB6 710

DD6 $8 \cdot 2$

DF67 10

DK68 2

DM69 6D

DR6 89

DT68 5

DW68 6D

EP61 8

ER67 6D

ES69 2
J. B. Cumming and.V. P. Crespo, Phys. Rev. 161, 287 (1967).

P. D. Croft and K. Street, Jr., Phys. Rev. 165, 1375 (1968).

V. E. Coslett and R. N. Thomas, Brit. J. Appl. Phys , 16, 779 (1965), 15, 1283 (1964), 15, $883(19 \overline{64})$.

J. A. Davies, Conference Secretary, Can. J. Phys. 46, (March 15, 1968).

D. P. Donnel1y, H. W. Baer, J. J. Reidy and M. L. Wiedenbeck, Nucl. Inst. Meth. 57, 219 (1967).

D. A. Dahlberg, D. K. Anderson, and I. E. Dayton, Phys. Rev. 170, 127 (1968).

G. Di Cola and L. Farese, Phys. Rev. 162, 690 (1967).

R. C. Der, T. M. Kavanagh, J. M. Khan, B. P. Curry and R. J. Fortner, Phys. Rev. Lett. 21, 1731 (1968).

S. Datz; C. D. Moak, T. S. Noggle, B. R. Appleton and H. O. Lutz, Phys. Rev. 179, 315 (1969).

W. E. Dance, D. H. Rester, B. J. Farmer, J. H. Johnson and L. L. Baggerly, J. Appl. Phys . 39, 2881 (1968).

P. Dalton and J. E. Turner, Health Physics 15 , 257 (1968).

J.A. Davies, J. Denhartog and J. L. Whitton, Phys. Rev. 165, 345 (1968).

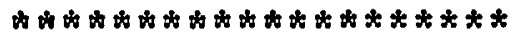

R. M. Eisberg and C. E. Porter, Rev. Mod. Phys. 33,190 (1961).

L. Eriksson, Phys. Rev. 161, 235 (1967).

H. Ehrhardt, M. Schulz, T. Tekaat, and K. Willmann, Phys. Rev. Lett. 22, 89 (1969).

$* * * * * * * * * * * * * * * * * * * *$

FA $4 \% 10$

U. Fano, Phys. Rev. 12,26 (194\%). 

FA53 7
U. Fano, Phys. Rev. 92, 328 (1953).
FA56 3
U. Fano, Phys. Rev. 103, 1202 (1956).
FA63 2
U. Fano, Ann. Rev. Nuc1. Sci. 13, 1 (1963).
Reprinted in NA67.

FB68 6A

B. Fastrup, A. Borup and P. Hvelplund, Canad.

J. Phys. 48,489 (1968).

FC68 2

U. Fano and J. W. Cooper, Rev. Mod. Phys. $\underline{40}, 441$ (1968).

FK67 10

V. Forgue and S. Kahn, Nucl. Inst. Meth. $\underline{48}, 93$ (1967).

FL67 1

I. P. Flaks, V International Conference of the Physics of Electronic and Atomic Collisions, Leningrad, 17-23 July, 1967. Publishing House, "Nauk" Leningrad.

FS69 10

G. Forcinal, P. Siffert and A. Coche, IEEE Trans. Nucl. Science NS15, No. 1, 475 (1968).

\section{$* * * * * * * * * * * * * * * * * * * *$}

GD68 8

Yu. N. Gnedin, A. Z. Dolginov, and A. I. Tsygan, Soviet Physics JETP 27, 267 (1968).

GF59 9

K. Gubernator, and A. Flammersfeld, Z. Phys. 156, 179 (1959).

\section{$* * * * * * * * * * * * * * * * * * * *$}

HA $59 \quad 9$

H. E. Hall, A. O. Hanson and D. Jamnik, Phys. Rev. 115, 633 (1959).

HA68 6 D. E. Harrison, Jr., App1. Phys. Lett. $\underline{13}, 277$ (1968).

HF68 8 P. C. Hemmer and I. E. Farquhar, Phys. Rev. 168, 294 (1968).

HL69 6 H. H. Heckman and P. J. Lindstroem, Phys. Rev. Lett. 22, 871 (1969).

HP60 4,6 H. H. Heckman, B. L. Perkins, W. G. Simon,

F. M. Smith and $\dot{W}$. H. Barkas, Phys. Rev. 117, 544 (1960).

HR6 89

E. Hara, Nucl. Inst. Meth. 65,85 (1968).

HU57 9

A. M. Hudson, Phys. Rev. 105, 1 (1957).

HV6 86
P. Hvelplund and B. Fastrup, Phys. Rev. 165, 408 (1968). 
IS67 3 R. Ishiwari, N. Shiomi, Y. Mori, T. Onata, and Y. Uemura, Bull. Inst. Chem. Res. Kyoto Univ. 45, $379(1967)$.

JA66 4

JA68 8

JD67 6,6B

JK68 3

KA67 10

KA68 10

KE66 9

KE68 6B

KF67 6B

KH6 82,5

KJ68 2

KK68 9

KM61 9

KM66 2

KO64, 4

K068 7

KP52 9

KP67 2

KY68 2
J. F. Janni, AFWL - TR - 65-150.

D. F. Jackson and C. G. Morgan, Phys. Rev. 175, 1402 (1968).

P. Jespersgard and J. A. Davies, Can. J. Phys. 45, 2983 (1967).

C. H. Johns on and R. L. Kernell, Phys. Rev. 169, 974 (1968).

$\star * * * * * * * * * * * * * * * * * * \star$

A. H. Krulisch and R. C. Axtmann, Nucl. Inst. Meth. 55, 238 (1967).

R. Katz and E. J. Kobetich, Phys. Rev. 170,397 (1968).

N. D. Kessaris, Phys. Rev. 145, 164 (1966).

V. S. Kessel'man, Soviet Phys. Semicond. 2, 76, (1968).

S. Kahn and V. Forgue, Phys. Rev. 163, 290 (1967).

G. S. Khandelwa1, Nuc1. Phys. A116, 97 (1968).

G. S. Khandelwal, Phys. Rev. 167, 136 (1968).

E. J. Kobetich and R. Katz, Phys.. Rev. 170, 391 (1968).

G. Knop, A. Minten and B. Nellen, Z. Phys. 165, 533 (1961).

G. S. Khandelwal and E. Merzbacher, Phys. Rev. 144, 349 (1966).

L. Koschmieder, Z. Naturforsch. 19a, 1414 (1964).

J. J. Kolata, T. M. Amos and H. Bichsel, Phys. Rev, 176, 484 (1968).

L. Katz and A. S. Penfold, Rev. Mod. Phys. 24, 28 (1952).

J. M. Khan, D. L. Potter, R. D. Worley and

H. P. Smith, Phys. Rev. 163, 81 (1967).

H. L. Kyle and K. Omidvar, Phys. Rev. $\underline{176}, 164$ (1968). 
LA44 7

LB 373

LE52 4,7

LH65 10

LI65 6D

LN68 6B

L067 8

LP57 9

LS53 3

LS63 6B

LS67 6B

MA6 83

MB6 6 6A, B

ML $58 \quad 2$

ML 68 6

MO4 78

MO $48 \quad 8$

M05 58

M058 8
L. Landau, USSR Jour. Phys . 8, 201 (1944) .

M. S. Livingston and H. Bethe, Rev. Mod. Phys. 9, 263 (1937).

H. W. Lewis, Phys. Rev. 85, 20 (1952).

R. Leimg ruber, P. Huber, and E. Baumgartner, Helv. Phys. Acta 38, 499 (1965).

Jens Lindhard, Mat. Fys. Medd. Dan. Vid. Selsk. 34, No. 14 (1965).

J. Lindhard, V. Nielsen and M. Scharff; Mat.

Fys. Medd. Dan. Vid. Selsk. 36, 10 (1968).

N. O. Lassen and A. Ohrt, Mat. Fys. Medd. Dan. Vid. Selsk $\underline{36}, 9$ (1967).

J. E. Leiss, S. Penner and C. S. Robinson, Phys. Rev. 107, 1544 (1957).

J. Lindhard and M. Scharff, Mat. Fys. Medd. Dan. Vid. Selsk: 2715 (1953).

J. Lindhard, M. Scharff and H. E. Schiфtt, Mat. Fys. Medd. Dan. Vid. Selsk, 3314 (1963).

L. Lehmann, H. Speh1 and N. Wertz, Nucl. Inst. Meth. 55, 201 (1967).

$\star \star * * * * * * * * * * * * * * \star * * *$

A. H. Morton, D. A. Aldcroft and.M. F. Payne, Phys. Rev. 165, 415 (1968).

C. D. Moak and M. D. Brown, Phys. Rev. 149, 244 (1966).

E. Merzbacher and H. W. Lewis, Encyclopedia of Physics 34, (Springer, Berlin, 1958), p. 166 .

C. D. Moak, H. O. Lutz, L. B. Bridwell, L. C. Northcliffe and S. Datz, Phys. Rev. 176, 427 (1968).

G. Moliere, Z. Naturforsch, ZA, 133 (1947).

G. Moliere, Z. Naturforsch 3A, 78 (1947).

G. Moliere, Z. Naturforsch 10A, 177 (1955).

R. F. Mozley, R. C. Sill ith and R. E. Taylor, Phys. Rev. 111, 647 (1958). 
MR6 74

MR6 87

MS65 6B

MT6 56

MY68 10

MZ67 8

NA6 7

NI61 7

NM67 3

N063 6A

N067 6

NS61 8

NV66 6B

OH63 6B

OL67 2

OR6 83
A. Marcinkowski, H. Rzewuski, and $Z$. Werner, Nucl. Inst. and Meth. 57, 338 (1967).

H. D. Maccabee, M. R. Raju and C. A. Tobias, Phys. Rev: 165, 469 (1968).

L. Morbitzer and A. Scharmann, Z. Phys. 185, 488 (1965).

J. H. E. Mattauch, W. Thiele and A. H. Wapstra, Nuclear Physics 67, 1 (1965).

I. T. Myers, Ch. 7 "Ionization", Radiation Dosimetry, 2nd edition (Academic Press, January 1968).

J. B. Marion and B. A. Zimmerman, Nucl. Inst. Meth. 51, 93 (1967).

$* * * * * * * * * * * * * * * * * * * *$

Publication 1133, Nat. Academy Sciences - Nat. Res. Council. U. Fano, ed. 2nd printing (1967).

L. P. Nielsen, Mat. Fys. Medd. Dan. Vid. Selsk. 33, No. 6 (1961).

C. A. Nicoletta, P. J. McNulty and P. L. Jain, Phys. Rev. 164, 1693 (1967).

L. C. Northcliffe, Ann. Rev. Nuc1. Sci. 13, 67 (1963) Reprinted in NA67.

L. C. Northcliffe, Paper 8, NA67.

B. P. Nigam, M. K. Sundaresan and Ta-You Wu, Phys. Rev. 115, 491 (1959).

D. K, -Nichols and V. A. J. Van Lint, Solid State Physics 18, 1 (1966) (Advances in Research Applications, Academic Press).

$\star * * * * * * * * * * * * * * * * * * *$

O. S. Oen, D. K. Holmes, and M. T. Robinson, J. App1. Phys. 34, 302 (1963).

W. J. B. Oldham, Phys. Rev. 161, 1 (1967).

J. H. Ormrod, Can. J. Phys. 46, 497 (1968). 
PB64 1.0

PB 686

PE62 9

PG68 10

PR69 10

RB69 10

$\mathrm{RC} 549$

RO60 6

R068 9

R069 6D

RS60 6

RS67 6D

RU6 8

RY5 4

SA65 10

SB6 77

SC63 8

SC66 6B
J. A. Phipps, J. W. Boring and R. A. Lowry, Phys. Rev. 135, A36 (1964).

T. E. Pierce, W. W. Bowman and M. Blann, Phys. Rev. 172, 287 (1968).

J. F. Perkins, Phys, Rev. 126, 1781 (1962) .

R. H. Pehl, F. S. Goulding, D. A. Landis, and M. Lenzlinger, Nucl. Inst. and Meth. 59, 45 (1968).

J. M. Palms, P. V. Rao, R. E. Wood, IEEE Trans. Nuc1. Science NS 16, No. 1, 36 (1969).

$* * * * * * * * * * * * * * * * * * * *$

J. A. Ray and C. F. Barnett, IEEE Trans. Nucl.

Science NS-16, No. 1, 82 (1969).

F. Rohrlich and B. C. Carlson, Phys. Rev. 93, 38 (1954).

R. G. Roll and F. E. Steiger, Nucl. Phys, 17, 54 (1960).

Wm. C. Roesch, "Radiation Dosimetry" Ch. 5, Vol. 1, F. H. Attix and Wm. C. Roesch, eds. (Academic Press, New York, January, 1968).

M. T. Robinson, Phys. Rev. 179,327 (1969) .

L. C. Northcliffe, Phys. Rev. 120, 1744 (1960).

J. Remillieux, J. J. Samueli, and A. Sarazin, Jour. de Phys. 28, 832 (1967).

M. R. H. Rudge, Rev. Mod. Phys. 40, 564 (1968).

B. V. Rybakov, Soviet Phys. JETP 1,435 (1955).

$\star * * * * * * * * * * * * * * * * * * *$

A. R. Sattler, Phys, Rev: 138, A1815 (1965).

S. M. Seltzer and M. J. Berger, Section 9 in NA67.

W. T. Scott, Rev. Mod. Phys. 35, 231 (1963).

H. Schiфtt, Mat. Fys. Medd. Dan. Vid. Selsk. 35, 9 (1966). 
$\mathrm{SG67} 7$

SI67 9

SK67 10

SP5 49

SP55 9

SP59 9

ST60 4

ST67 3

SU60 4,7

SV6 8 6D

SY 487

SZ65 3

TB68 4,8

TH52 3

TH6 72

TM5 98

TP69. 6

$\operatorname{TS} 67 \quad 3,7,10$

TS68 7

TT68 4,7
P. Shulek, B. M. Golovin, L.A. Kulyukina,

S. V. Medved, and P. Pavlovich, Soviet J.

Nucl. Phys. 4, 400 (1967).

J. J. Singh, NASA TN D-3927 (May 1967).

D. J. Skyrme, Nuc1. Inst. Meth. $\underline{57}, 61$ (1967).

L. V. Spencer and U. Fano, Phys. Rev. 93, 1172 (1954) .

L. V. Spencer, Phys. Rev. 98, 1597 (1955).

L. V. Spencer, Nat. Bur. Std. (U.S.) Monograph 1 .

R. M. Sternheimer, Phys. Rev. 117, 485 (1960).

R. M. Sternheimer, Phys. Rev. 164, 349 (1967).

R. M. Sternheimer, Phys. Rev. 118, 1045 (1960).

A. R. Sattler and F. L. Vook, Phys. Rev. 175, 526 (1968).

K. R. Symon, Thesis, Harvard Univ. (Cambridge, Mass. 1948).

C. A. Sautter and E. J. Zimmerman; Phys. Rev. 140, A490 (1965).

C. Tschalär and H. Bichse1, Nucl. Inst. Meth. 62, 208 (1968).

T. J. Thompson, UCRL-1910.

E. W. Thomás, Physs. Rev. 164, 151 (1967).

M. L. Ter-Mikayelian, Nucl. Phys. 9, 679 (1958-1959).

B. N. Taylor, W. H. Parker, and D. N. Langenberg Rev. Mod. Phys. (to be published).

C. Tschalär, Thesis, University of Southern

California (Los Angeles, January 1967).

C. Tschalär, Nucl. Inst. Meth. 61, 141 (1968).

C. Tscha1är, Nucl. Inst. Meth. 64, 237 (1968). 
VA5 77

VS68 2

VV68 9

WA51 2

WA52 2,5

WA 562,5

WH5 83

WH3 3.5

WI $68 \quad 6 \mathrm{~A}$

WM67 3

ZM69 10
P. V. Vavilov, Sov. Phys. JETP 5, 749 (1957).

L. Vriens, J. A. Simpson and S. R. Mielczarek, Phys. Rev. 165, 7 (1968), 170, 163 (1968).

K. J. VanCamp and V. J. Vanhuyse, Z. Phys. 211, $152 \cdot(1968)$.

M. C. Walske, Thesis, Cornell Univ. (1951).

M. C. Walske, Phys. Rev. 88, 1283 (1952).

M. C. Walske, Phys. Rev. 101, 940 (1950).

Ward Whaling, Encyclopedia of Physics, 34, 202 (1958), Springer, Berlin.

J. A. Wheeler, Phys. Rev. 43, 258 (1933) .

K. B. Winterbo Can. J. Phys. 46, 2429 (1968).

W. White and R. M. Mueller, J. Appl. Phys. $\underline{38}$, 3660 (1967).

H. R. Zulliger, L. M. Middleman and D. W. Aitken, IEEE Trans. Nucl. Science, NS16, 1, 47 (1969). 
Table I. Relativistic velocity $\beta=v / c, \beta^{2}$ and stopping number

function $f(B)$ for heavy ions as a function of the kinetic energy $T$.

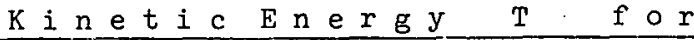

\begin{tabular}{|c|c|c|c|c|c|c|c|}
\hline $\begin{array}{c}\text { Protons } \\
(\mathrm{MeV})\end{array}$ & $\begin{array}{l}\text { Alphas } \\
(\mathrm{MeV})\end{array}$ & $\begin{array}{l}\text { Pions } \\
(\mathrm{MeV})\end{array}$ & $\begin{array}{l}\text { Muons } \\
(\mathrm{MeV})\end{array}$ & $\begin{array}{c}\text { Electrons } \\
(\mathrm{keV})\end{array}$ & $R$ & $B^{2}$ & $f(\rho)$ \\
\hline $\begin{array}{l}.50 \\
.55 \\
.60 \\
.65 \\
.70 \\
.75 \\
.80 \\
.85 \\
.90 \\
.95\end{array}$ & $\begin{array}{l}1.9863 \\
2.1849 \\
2 \cdot 3836 \\
2 \cdot 5822 \\
2.7808 \\
2.9795 \\
3 \cdot 1781 \\
3.3767 \\
3.5753 \\
3.7740\end{array}$ & $\begin{array}{l}.0744 \\
.0818 \\
.0893 \\
.0967 \\
.1041 \\
.1116 \\
.1190 \\
.1265 \\
.1339 \\
.1413\end{array}$ & $\begin{array}{l}.0563 \\
.0619 \\
.0676 \\
.0732 \\
.0788 \\
.0845 \\
.0901 \\
.0957 \\
.1014 \\
.1070\end{array}$ & $\begin{array}{r}.2723 \\
.2995 \\
.3268 \\
.3540 \\
.3812 \\
.4085 \\
.4357 \\
.4629 \\
.4902 \\
.5174\end{array}$ & $\begin{array}{l}.032634 \\
.034225 \\
.035745 \\
.037204 \\
.038606 \\
.039960 \\
.041269 \\
.042537 \\
.043769 \\
.044966\end{array}$ & $\begin{array}{l}.001065 \\
.001171 \\
.001278 \\
.001384 \\
.001490 \\
.001597 \\
.001703 \\
.001809 \\
.001916 \\
.002022\end{array}$ & $\begin{array}{l}6.9925 \\
7.0877 \\
7.1746 \\
7.2546 \\
7.3286 \\
7.3975 \\
7.4620 \\
7.5225 \\
7.5796 \\
7.6336\end{array}$ \\
\hline $\begin{array}{l}1.00 \\
1.10 \\
1.20 \\
1.30 \\
1.40 \\
1.50 \\
1.60 \\
1.70 \\
1.80 \\
1.90\end{array}$ & $\begin{array}{l}3.9726 \\
4.3699 \\
4.7671 \\
5.1644 \\
5.5616 \\
5.9589 \\
6.3562 \\
6.7534 \\
7.1507 \\
7.5479\end{array}$ & $\begin{array}{l}.1488 \\
.1636 \\
.1785 \\
.1934 \\
.2083 \\
.2231 \\
.2380 \\
.2529 \\
.2678 \\
.2827\end{array}$ & $\begin{array}{l}.1126 \\
.1239 \\
.1351 \\
.1464 \\
.1577 \\
.1689 \\
.1802 \\
.1914 \\
.2027 \\
.2140\end{array}$ & $\begin{array}{r}.5446 \\
.5991 \\
.6536 \\
.7080 \\
.7625 \\
.8169 \\
.8714 \\
.9259 \\
.9803 \\
1.0348\end{array}$ & $\begin{array}{l}.046132 \\
.048380 \\
.050528 \\
.052587 \\
.054567 \\
.056478 \\
.058326 \\
.060116 \\
.061854 \\
.063544\end{array}$ & $\begin{array}{l}.002128 \\
.002341 \\
.002553 \\
.002765 \\
.002978 \\
.003190 \\
.003402 \\
.003614 \\
.003826 \\
.004038\end{array}$ & $\begin{array}{l}7.6848 \\
7.7800 \\
7.8668 \\
7.9467 \\
8.0206 \\
8.0895 \\
8.1539 \\
8.2143 \\
8.271 .3 \\
8.3252\end{array}$ \\
\hline $\begin{array}{l}2 \cdot 00 \\
2 \cdot 10 \\
2 \cdot 20 \\
2 \cdot 30 \\
2.40 \\
2.50 \\
2 \cdot 60 \\
2 \cdot 70 \\
2.80 \\
2.90\end{array}$ & $\begin{array}{r}7.9452 \\
8.3425 \\
8.7397 \\
9.1370 \\
9.5342 \\
9.9315 \\
10.3288 \\
10.7260 \\
11.1233 \\
11.5205\end{array}$ & $\begin{array}{l}.2975 \\
.3124 \\
.3273 \\
.3422 \\
.3570 \\
.3719 \\
.3868 \\
.4017 \\
.4165 \\
.4314\end{array}$ & $\begin{array}{l}.2252 \\
.2365 \\
.2477 \\
.2590 \\
.2703 \\
.2815 \\
.2928 \\
.3041 \\
.3153 \\
.3266\end{array}$ & $\begin{array}{l}1.0893 \\
1.1437 \\
1.1982 \\
1.2526 \\
1.3071 \\
1.3616 \\
1.4160 \\
1.4705 \\
1.5250 \\
1.5794\end{array}$ & $\begin{array}{l}.065189 \\
.066794 \\
.068360 \\
.069891 \\
.071388 \\
.072855 \\
.074292 \\
.075701 \\
.077084 \\
.078442\end{array}$ & $\begin{array}{l}.004250 \\
.004461 \\
.004673 \\
.004885 \\
.005096 \\
.005308 \\
.005519 \\
.005731 \\
.005942 \\
.006153\end{array}$ & $\begin{array}{l}8.3764 \\
8.4250 \\
8.4714 \\
8.5157 \\
8.5581 \\
8.5987 \\
8.6378 \\
8.6754 \\
8.7116 \\
8.7465\end{array}$ \\
\hline $\begin{array}{l}3.00 \\
3.10 \\
3.20 \\
3.30 \\
3.40 \\
3.50 \\
3.60 \\
3.70 \\
3.80 \\
3.90\end{array}$ & $\begin{array}{l}11.9178 \\
12.3151 \\
12.7123 \\
13.1096 \\
13.5068 \\
13.9041 \\
14.3014 \\
14.6986 \\
15.0959 \\
15.4931\end{array}$ & $\begin{array}{l}.4463 \\
.4612 \\
.4760 \\
.4909 \\
.5058 \\
.5207 \\
.5356 \\
.5504 \\
.5653 \\
.5802\end{array}$ & $\begin{array}{l}.3378 \\
.3491 \\
.3604 \\
.3716 \\
.3829 \\
.3941 \\
.4054 \\
.4167 \\
.4279 \\
.4392\end{array}$ & $\begin{array}{l}1.6339 \\
1.6884 \\
1.7428 \\
1.7973 \\
1.8517 \\
1.9062 \\
1.9607 \\
1.0151 \\
2.0696 \\
2.1241\end{array}$ & $\begin{array}{l}.079776 \\
.081089 \\
.082380 \\
.083650 \\
.084901 \\
.086134 \\
.087349 \\
.088547 \\
.089728 \\
.090894\end{array}$ & $\begin{array}{l}.006364 \\
.006575 \\
.006786 \\
.006997 \\
.007208 \\
.007419 \\
.007630 \\
.007861 \\
.008051 \\
.008262\end{array}$ & $\begin{array}{l}8.7803 \\
8.8129 \\
8.8445 \\
8.8751 \\
8.9048 \\
8.9336 \\
8.9616 \\
8.9899 \\
9.0154 \\
9.0412\end{array}$ \\
\hline $\begin{array}{l}4.00 \\
4.10 \\
4.20 \\
4.30 \\
4.40 \\
4.50 \\
4.60 \\
4.70 \\
4.80 \\
4.90\end{array}$ & $\begin{array}{l}15.8904 \\
16.2877 \\
16.6849 \\
17.0822 \\
17.4794 \\
17.8767 \\
18.2740 \\
18.6712 \\
19.0685 \\
19.4657\end{array}$ & $\begin{array}{l}.5951 \\
.6099 \\
.6248 \\
.6397 \\
.6546 \\
.6694 \\
.6843 \\
.6992 \\
.7141 \\
.7289\end{array}$ & $\begin{array}{l}.4505 \\
.4617 \\
.4730 \\
.4842 \\
.4955 \\
.5068 \\
.5180 \\
.5293 \\
.5405 \\
.5518\end{array}$ & $\begin{array}{l}2.1785 \\
2.2330 \\
2.2874 \\
2.3419 \\
2.3964 \\
2.4508 \\
2.5053 \\
2.5598 \\
2.6142 \\
2.6687\end{array}$ & $\begin{array}{l}.092045 \\
.093181 \\
.094303 \\
.095411 \\
.096507 \\
.097589 \\
.098660 \\
.099718 \\
.100766 \\
.101802\end{array}$ & $\begin{array}{l}.008472 \\
.008683 \\
.008893 \\
.009103 \\
.009314 \\
.009524 \\
.009734 \\
.009944 \\
.0101154 \\
.010364\end{array}$ & $\begin{array}{l}9.0664 \\
9.0909 \\
9.1148 \\
9.1382 \\
9.1610 \\
9.1834 \\
9.2052 \\
9.2265 \\
9.2474 \\
9.2679\end{array}$ \\
\hline $\begin{array}{l}5.00 \\
5.50 \\
6.00 \\
6.50 \\
7.00 \\
7.50 \\
8.00 \\
8.50 \\
9.00 \\
9.50\end{array}$ & $\begin{array}{l}19.8630 \\
21.8493 \\
23.8356 \\
25.8219 \\
27.8082 \\
29.7945 \\
31.780 .8 \\
33.7671 \\
35.7534 \\
37.7397\end{array}$ & $\begin{array}{r}.7438 \\
.8182 \\
.8926 \\
.9670 \\
1.0414 \\
1.1157 \\
1.1901 \\
1.2645 \\
1.3389 \\
1.4133\end{array}$ & $\begin{array}{r}.5631 \\
.6194 \\
.6757 \\
.7320 \\
.7883 \\
.8446 \\
.9009 \\
.9572 \\
1.0135 \\
1.0698\end{array}$ & $\begin{array}{l}2.7232 \\
2.9955 \\
3.2678 \\
3.5401 \\
3.8124 \\
4.0847 \\
4.3570 \\
4.6294 \\
4.9017 \\
5.1740\end{array}$ & $\begin{array}{l}.102827 \\
.107803 \\
.112552 \\
.117102 \\
.121474 \\
.125688 \\
.129758 \\
.133699 \\
.137521 \\
.141233\end{array}$ & $\begin{array}{l}.010573 \\
.011622 \\
.012668 \\
.013713 \\
.014756 \\
.015797 \\
.016837 \\
.017875 \\
.018912 \\
.019947\end{array}$ & $\begin{array}{l}9.2379 \\
9.382 .5 \\
9.4687 \\
9.5480 \\
9.6213 \\
9.6895 \\
9.7533 \\
9.8131 \\
9.8695 \\
9.9278\end{array}$ \\
\hline
\end{tabular}


Table I (continued)

\begin{tabular}{|c|c|c|c|c|c|c|c|}
\hline $\begin{array}{c}\text { Protons } \\
(\mathrm{MeV})\end{array}$ & $\begin{array}{l}\text { Alphas } \\
(\mathrm{MeV})\end{array}$ & $\begin{array}{l}\text { Pions } \\
(\mathrm{MeV})\end{array}$ & $\begin{array}{l}\text { Muons } \\
(\mathrm{MeV})\end{array}$ & $\begin{array}{l}\text { Electrons } \\
(\mathrm{keV})\end{array}$ & $B$ & $\beta^{2}$ & $f(\beta)$ \\
\hline $\begin{array}{l}10.00 \\
10.50 \\
11.00 \\
11.50 \\
12.00 \\
12.50 \\
13.00 \\
13.50 \\
14.00 \\
14.50\end{array}$ & $\begin{array}{l}39.7260 \\
41.7123 \\
43.6986 \\
45.6849 \\
47.6712 \\
49.6575 \\
51.6438 \\
53.6301 \\
55.6164 \\
57.6027\end{array}$ & $\begin{array}{l}1.4876 \\
1.5620 \\
1.6364 \\
1.7108 \\
1.7852 \\
1.8596 \\
1.9339 \\
2.0083 \\
2.0827 \\
2.1571\end{array}$ & $\begin{array}{l}1.1261 \\
1.1824 \\
1.2387 \\
1.2950 \\
1.3514 \\
1.4077 \\
1.4640 \\
1.5203 \\
1.5766 \\
1.6329\end{array}$ & $\begin{array}{l}5.4463 \\
5.7186 \\
5.9909 \\
6.2632 \\
6.5356 \\
6.8079 \\
7.0802 \\
7.3525 \\
7.6248 \\
7.8971\end{array}$ & $\begin{array}{l}.144845 \\
.148363 \\
.151795 \\
.155145 \\
.158420 \\
.161623 \\
.164759 \\
.167831 \\
.170844 \\
.173800\end{array}$ & $\begin{array}{l}.020980 \\
.022012 \\
.023042 \\
.024070 \\
.025097 \\
.026122 \\
.027145 \\
.028167 \\
.029188 \\
.030206\end{array}$ & $\begin{array}{l}9.973 .3 \\
10.0213 \\
10.0671 \\
10.1108 \\
10.1526 \\
10.1927 \\
10.2311 \\
10.2681 \\
10.3037 \\
10.3380\end{array}$ \\
\hline $\begin{array}{l}15.00 \\
15.50 \\
16.00 \\
16.50 \\
17.00 \\
17.50 \\
18.00 \\
18.50 \\
19.00 \\
19.50\end{array}$ & $\begin{array}{l}59.5890 \\
61.5753 \\
63.5616 \\
65.5479 \\
67.5342 \\
69.5205 \\
71.5068 \\
73.4931 \\
75.4794 \\
77.4657\end{array}$ & $\begin{array}{l}2.2315 \\
2.3059 \\
2.3802 \\
2.4546 \\
2.5290 \\
2.6034 \\
2.6778 \\
2.7522 \\
2.8265 \\
2.9009\end{array}$ & $\begin{array}{l}1.6892 \\
1.7455 \\
1.8018 \\
1.8581 \\
1.9144 \\
1.9707 \\
2.0270 \\
2.0833 \\
2.1396 \\
2.1960\end{array}$ & $\begin{array}{r}8.1695 \\
8.4418 \\
8.7141 \\
8.9864 \\
9.2587 \\
9.5310 \\
9.8033 \\
10.0757 \\
10.3480 \\
10.6203\end{array}$ & $\begin{array}{l}.176701 \\
.179552 \\
.182353 \\
.185108 \\
.187818 \\
.190486 \\
.193112 \\
.195700 \\
.198249 \\
.200762\end{array}$ & $\begin{array}{l}.031223 \\
.032239 \\
.033253 \\
.034265 \\
.035276 \\
.036285 \\
.037292 \\
.038298 \\
.039303 \\
.040306\end{array}$ & $\begin{array}{l}10.3712 \\
10.403 .2 \\
10.4342 \\
10.4643 \\
10.4934 \\
10.52 .6 \\
10.5400 \\
10.5757 \\
10.60 .6 \\
10.6269\end{array}$ \\
\hline $\begin{array}{l}20.00 \\
21.00 \\
22.00 \\
23.00 \\
24.00 \\
25.00 \\
26.00 \\
27.00 \\
28.00 \\
29.00\end{array}$ & $\begin{array}{r}79.4520 \\
83.4246 \\
87.3972 \\
91.3698 \\
95.3424 \\
99.3150 \\
103.2876 \\
107.2602 \\
111.2328 \\
115.2054\end{array}$ & $\begin{array}{l}2.9753 \\
3.1241 \\
3.2728 \\
3.4216 \\
3.5704 \\
3.7191 \\
3.8679 \\
4.0167 \\
4.1654 \\
4.3142\end{array}$ & $\begin{array}{l}2.2523 \\
2.3649 \\
2.4775 \\
2.5901 \\
2.7027 \\
2.8153 \\
2.9279 \\
3.0405 \\
3.1532 \\
3.2658\end{array}$ & $\begin{array}{l}10.8926 \\
11.4372 \\
11.9819 \\
12.5265 \\
13.0711 \\
13.6158 \\
14.1604 \\
14.7050 \\
15.2496 \\
15.7943\end{array}$ & $\begin{array}{l}.203241 \\
.208097 \\
.212829 \\
.217443 \\
.221947 \\
.226348 \\
.230652 \\
.234864 \\
.238989 \\
.243032\end{array}$ & $\begin{array}{l}.041307 \\
.043305 \\
.045296 \\
.047281 \\
.049261 \\
.051234 \\
.053200 \\
.055161 \\
.057116 \\
.059064\end{array}$ & $\begin{array}{l}10.651 .4 \\
10.6988 \\
10.7438 \\
10.7868 \\
10.8279 \\
10.8673 \\
10.9051 \\
10.9414 \\
10.9763 \\
11.0100\end{array}$ \\
\hline $\begin{array}{l}30.00 \\
31.00 \\
32.00 \\
33.00 \\
34.00 \\
35.00 \\
36.00 \\
37.00 \\
38.00 \\
39.00\end{array}$ & $\begin{array}{l}119.1780 \\
123.1506 \\
127.1232 \\
131.0958 \\
139.0684 \\
139.0410 \\
143.0136 \\
146.9862 \\
150.9588 \\
154.9314\end{array}$ & $\begin{array}{l}4.4629 \\
4.6117 \\
4.7605 \\
4.9092 \\
5.0580 \\
5.2068 \\
5.3555 \\
5.5043 \\
5.6531 \\
5.8018\end{array}$ & $\begin{array}{l}3.3784 \\
3.4910 \\
3.6036 \\
3.7162 \\
3.8288 \\
3.9414 \\
4.0541 \\
4.1667 \\
4.2793 \\
4.3919\end{array}$ & $\begin{array}{r}16.3389 \\
16.8835 \\
17.4282 \\
17.9728 \\
18.5174 \\
19.0621 \\
19.6067 \\
20.1513 \\
20.6959 \\
21.2406\end{array}$ & $\begin{array}{l}.246996 \\
.250885 \\
.254704 \\
.258454 \\
.262140 \\
.265763 \\
.269327 \\
.272833 \\
.276284 \\
.279683\end{array}$ & $\begin{array}{l}.061007 \\
.062943 \\
.064874 \\
.066799 \\
.068717 \\
.070630 \\
.072537 \\
.074438 \\
.076333 \\
.078222\end{array}$ & $\begin{array}{l}11.0425 \\
11.0738 \\
11.1042 \\
11.1325 \\
11.1620 \\
11.1896 \\
11.2164 \\
11.2424 \\
11.2677 \\
11.2923\end{array}$ \\
\hline $\begin{array}{l}40.00 \\
41.00 \\
42.00 \\
43.00 \\
44.00 \\
45.00 \\
46.00 \\
47.00 \\
48.00 \\
49.00\end{array}$ & $\begin{array}{l}158.9040 \\
162.8766 \\
166.8492 \\
170.8218 \\
174.7944 \\
178.7670 \\
182.7396 \\
186.7122 \\
190.6848 \\
194.6574\end{array}$ & $\begin{array}{l}5.9506 \\
6.0994 \\
6.2481 \\
6.3969 \\
6.5457 \\
6.6944 \\
6.8432 \\
6.9919 \\
7.1407 \\
7.2895\end{array}$ & $\begin{array}{l}4.5045 \\
4.6171 \\
4.7297 \\
4.8424 \\
4.9550 \\
5.0676 \\
5.1802 \\
5.2928 \\
5.4054 \\
5.5180\end{array}$ & $\begin{array}{l}21.7852 \\
22.3298 \\
22.8745 \\
23.4191 \\
23.9637 \\
24.5084 \\
25.0530 \\
25.5976 \\
26.1422 \\
26.6869\end{array}$ & $\begin{array}{l}.283030 \\
.286328 \\
.289579 \\
.292784 \\
.295944 \\
.299062 \\
.302138 \\
.305173 \\
.308170 \\
.311129\end{array}$ & $\begin{array}{l}.080106 \\
.081984 \\
.083856 \\
.085722 \\
.087583 \\
.089438 \\
.091287 \\
.093131 \\
.094969 \\
.096801\end{array}$ & $\begin{array}{l}11.3163 \\
11.3396 \\
11.3624 \\
11.3845 \\
11.4062 \\
11.4273 \\
11.4480 \\
11.4682 \\
11.4879 \\
11.3072\end{array}$ \\
\hline $\begin{array}{l}50.00 \\
52.50 \\
55.00 \\
57.50 \\
60.00 \\
62.50 \\
65.00 \\
67.50 \\
70.00 \\
72.50\end{array}$ & $\begin{array}{l}198.6300 \\
208.5615 \\
218.4930 \\
228.4245 \\
238.3560 \\
248.2875 \\
258.2190 \\
268.1505 \\
278.0820 \\
288.0135\end{array}$ & $\begin{array}{r}7.4382 \\
7.8102 \\
8.1821 \\
8.5540 \\
8.9259 \\
9.2978 \\
9.6697 \\
10.0416 \\
10.4135 \\
10.7855\end{array}$ & $\begin{array}{l}5.6306 \\
5.9122 \\
6.1937 \\
6.4752 \\
6.7568 \\
7.0383 \\
7.3198 \\
7.6014 \\
7.8829 \\
8.1644\end{array}$ & $\begin{array}{l}27.2315 \\
28.5931 \\
29.9547 \\
31.3162 \\
32.6778 \\
34.0394 \\
35.4010 \\
36.7625 \\
38.1241 \\
39.4857\end{array}$ & $\begin{array}{l}.314051 \\
.321203 \\
.328147 \\
.334896 \\
.341463 \\
.347858 \\
.354091 \\
.360170 \\
.366105 \\
.371903\end{array}$ & $\begin{array}{r}.098628 \\
.103171 \\
.107680 \\
.1112155 \\
.116597 \\
.121005 \\
.125380 \\
.129723 \\
.134033 \\
.138312\end{array}$ & $\begin{array}{l}11.5261 \\
11.571 .6 \\
11.61 .49 \\
11.6562 \\
11.6956 \\
11.7333 \\
11.7695 \\
11.8041 \\
11.8375 \\
11.8696\end{array}$ \\
\hline
\end{tabular}


Table I (continued)

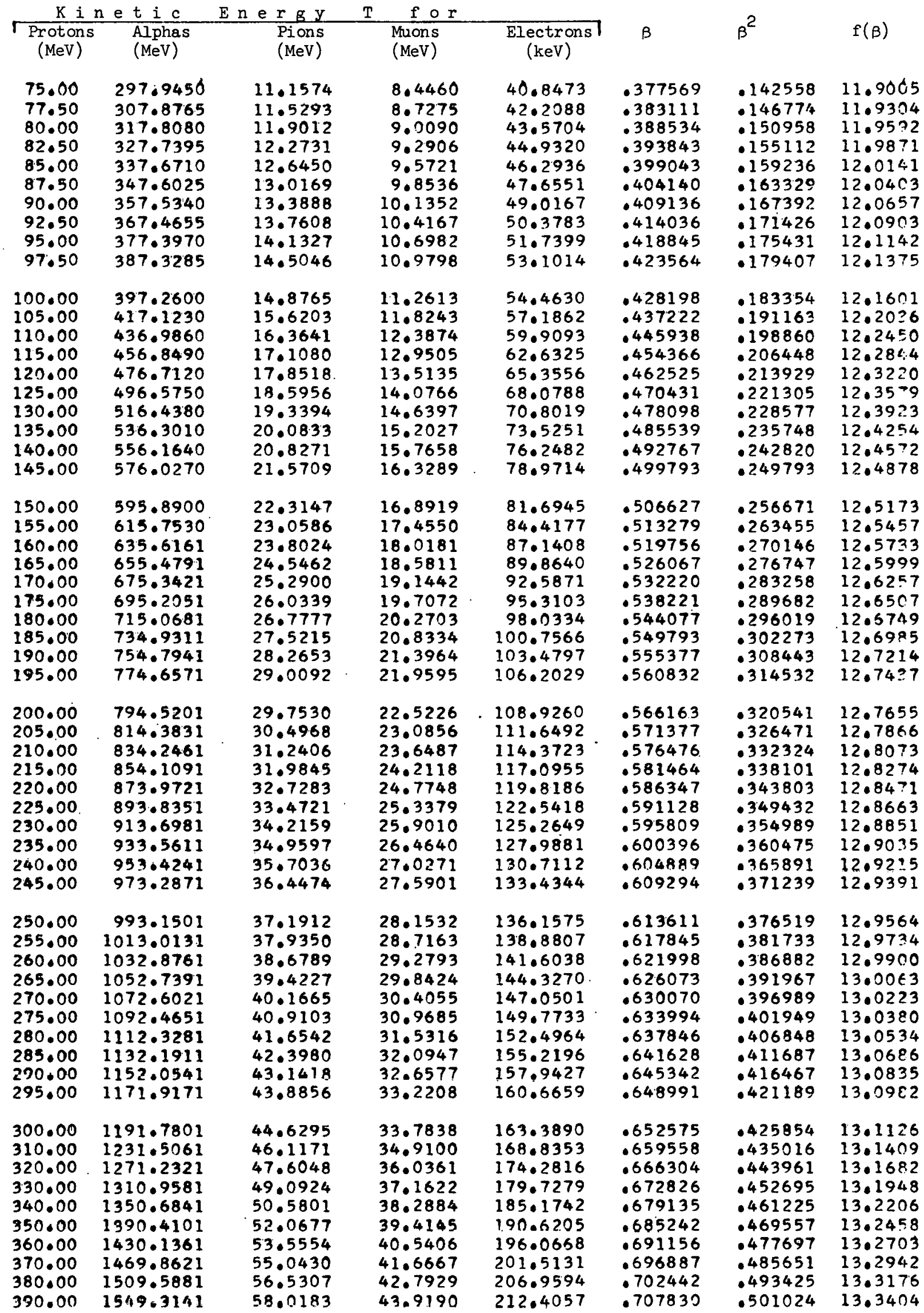


Table I (continued)

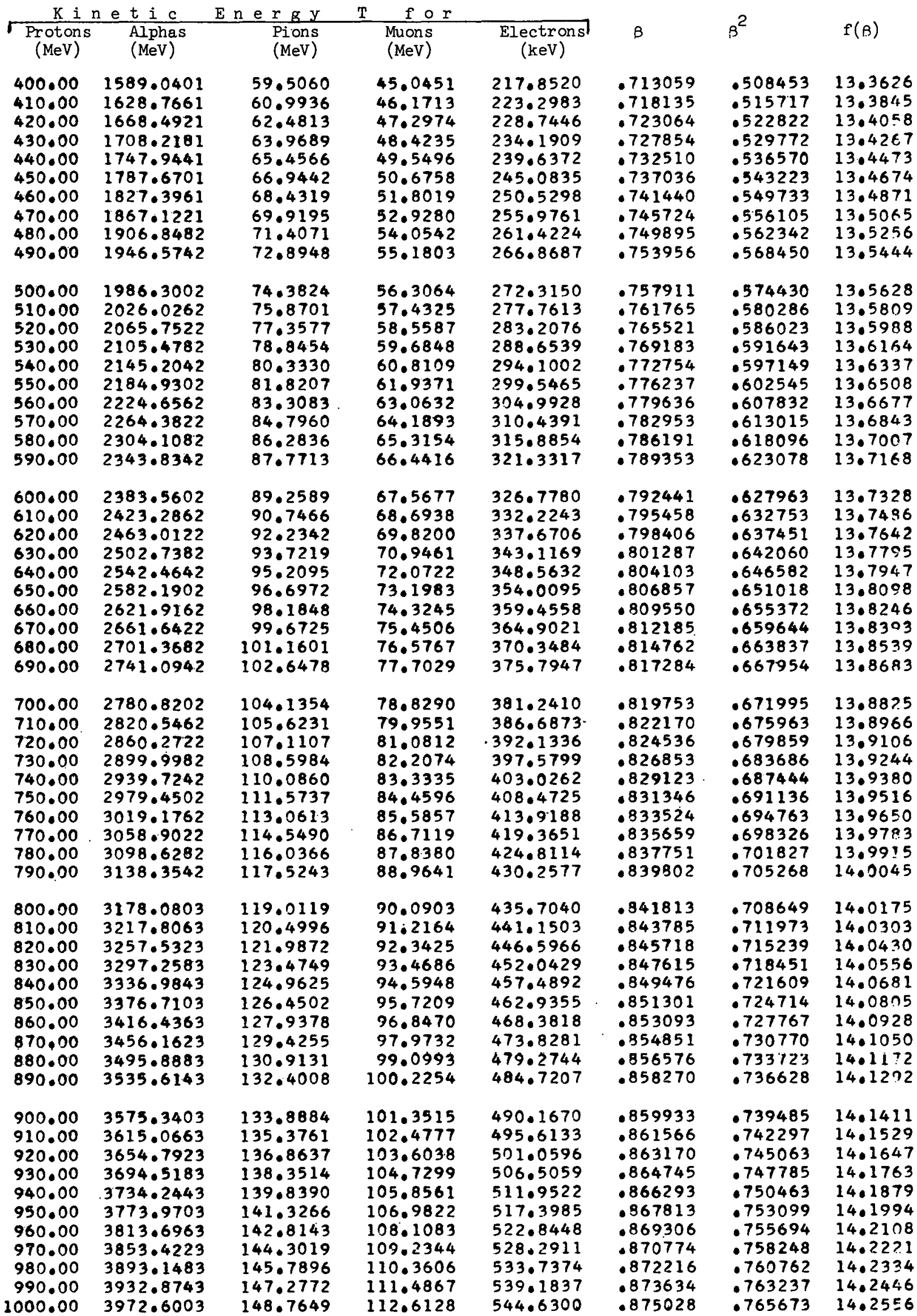


Table II. Calculated mass stopping power $\mathrm{S} / \rho\left(\mathrm{MeV} / \mathrm{g} / \mathrm{cm}^{2}\right)$ for protons.

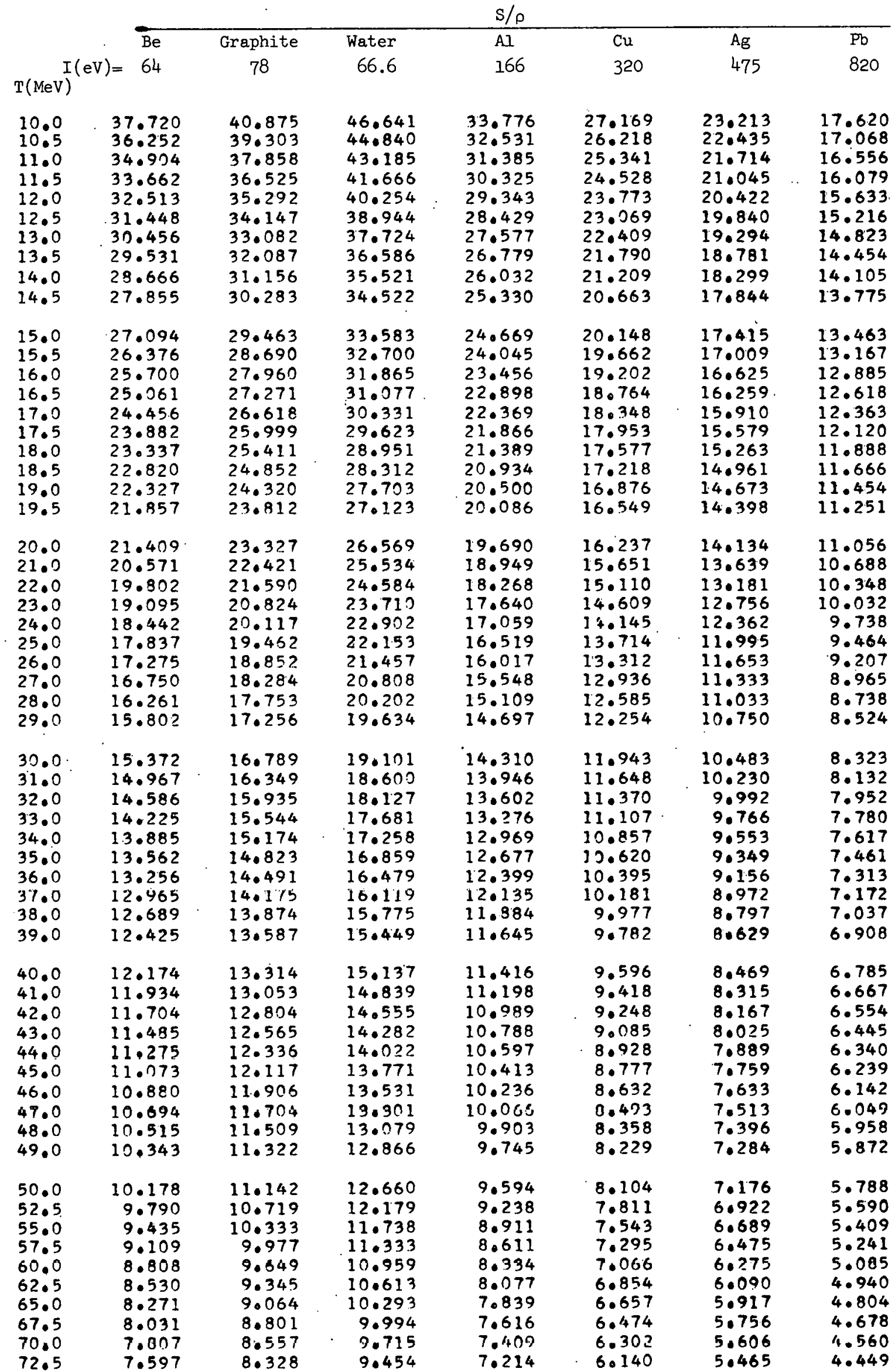


59.

Table II. Continued.

\begin{tabular}{|c|c|c|c|c|c|c|c|}
\hline & & & & $\mathrm{s} / \mathrm{\rho}$ & & & \\
\hline & $\mathrm{Be}$ & Graphite & Water & $\mathrm{Al}$ & $\mathrm{Cu}$ & $\mathrm{Ag}$ & $\mathrm{Pb}$ \\
\hline 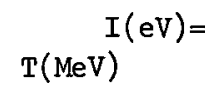 & $=64$ & 78 & 66.6 & 166 & 320 & 475 & 820 \\
\hline $\begin{array}{l}75.0 \\
77.5 \\
80.0 \\
82.5 \\
85.0 \\
87.5 \\
90.0 \\
92.5 \\
95.0 \\
97.5\end{array}$ & $\begin{array}{l}7.400 \\
7.215 \\
7.041 \\
6.877 \\
6.722 \\
6.576 \\
6.437 \\
6.305 \\
6.180 \\
6.060\end{array}$ & $\begin{array}{l}8.113 \\
7.911 \\
7.721 \\
7.542 \\
7.373 \\
7.213 \\
7.061 \\
6.917 \\
6.780 \\
6.650\end{array}$ & $\begin{array}{l}9.210 \\
8.9 .80 \\
8.764 \\
8.560 \\
8.368 \\
8.185 \\
8.013 \\
7.849 \\
7.693 \\
7.545\end{array}$ & $\begin{array}{l}7.032 \\
6.860 \\
6.699 \\
6.546 \\
6.402 \\
6.266 \\
6.136 \\
6.013 \\
5.897 \\
5.785\end{array}$ & $\begin{array}{l}5.988 \\
5.846 \\
5.711 \\
5.584 \\
5.463 \\
3.350 \\
5.241 \\
5.139 \\
5.041 \\
4.948\end{array}$ & $\begin{array}{l}5.332 \\
5.207 \\
5.090 \\
4.978 \\
4.873 \\
4.773 \\
4.679 \\
4.589 \\
4.503 \\
4.422\end{array}$ & $\begin{array}{l}4.344 \\
4.246 \\
4.153 \\
4.065 \\
3.982 \\
3.902 \\
3.827 \\
3.755 \\
3.687 \\
3.622\end{array}$ \\
\hline $\begin{array}{l}100.0 \\
105.0 \\
110.0 \\
115.0 \\
120.0 \\
125.0 \\
130.0 \\
135.0 \\
140.0 \\
145.0\end{array}$ & $\begin{array}{l}5.947 \\
5.735 \\
5.541 \\
5.364 \\
5.200 \\
5.049 \\
4.909 \\
4.779 \\
4.657 \\
4.544\end{array}$ & $\begin{array}{l}6.526 \\
6.294 \\
6.083 \\
5.888 \\
5.709 \\
5.544 \\
5.391 \\
5.248 \\
5.116 \\
4.992\end{array}$ & $\begin{array}{l}7.403 \\
7.140 \\
6.899 \\
6.678 \\
6.475 \\
6.287 \\
6.1113 \\
5.951 \\
5.800 \\
5.659\end{array}$ & $\begin{array}{l}5.679 \\
5.481 \\
5.300 \\
5.134 \\
4.980 \\
4.839 \\
4.707 \\
4.585 \\
4.471 \\
4.364\end{array}$ & $\begin{array}{l}4.859 \\
4.693 \\
4.542 \\
4.402 \\
4.274 \\
4.155 \\
4.044 \\
3.942 \\
3.845 \\
3.755\end{array}$ & $\begin{array}{l}4.343 \\
4.197 \\
4.063 \\
3.940 \\
3.826 \\
3.721 \\
3.623 \\
3.532 \\
3.447 \\
3.368\end{array}$ & $\begin{array}{l}3.559 \\
3.443 \\
3.337 \\
3.238 \\
3.148 \\
3.064 \\
2.986 \\
2.912 \\
2.844 \\
2.780\end{array}$ \\
\hline $\begin{array}{l}150.0 \\
155.0 \\
160.0 \\
165.0 \\
170.0 \\
175.0 \\
180.0 \\
185.0 \\
190.0 \\
195.0\end{array}$ & $\begin{array}{l}4.438 \\
4.338 \\
4.245 \\
4.157 \\
4.073 \\
3.995 \\
3.921 \\
3.850 \\
3.783 \\
3.720\end{array}$ & $\begin{array}{l}4.876 \\
4.767 \\
4.664 \\
4.568 \\
4.477 \\
4.391 \\
4.309 \\
4.232 \\
4.159 \\
4.089\end{array}$ & $\begin{array}{l}5.527 \\
5.403 \\
5.287 \\
5.177 \\
5.074 \\
4.976 \\
4.883 \\
4.796 \\
4.712 \\
4.633\end{array}$ & $\begin{array}{l}4.264 \\
4.171 \\
4.083 \\
4.000 \\
3.921 \\
3.847 \\
3.777 \\
3.710 \\
3.647 \\
3.587\end{array}$ & $\begin{array}{l}3.671 \\
3.592 \\
3.517 \\
3.447 \\
3.381 \\
3.318 \\
3.259 \\
3.202 \\
3.149 \\
3.098\end{array}$ & $\begin{array}{l}3.293 \\
3.224 \\
3.158 \\
3.096 \\
3.037 \\
2.982 \\
2.929 \\
2.879 \\
2.832 \\
2.787\end{array}$ & $\begin{array}{l}2.720 \\
2.664 \\
2.611 \\
2.560 \\
2.513 \\
2.468 \\
2.426 \\
2.386 \\
2.347 \\
2.311\end{array}$ \\
\hline $\begin{array}{l}200.0 \\
205.0 \\
210.0 \\
215.0 \\
220.0 \\
225.0 \\
230.0 \\
235.0 \\
240.0 \\
245.0\end{array}$ & $\begin{array}{l}3.659 \\
3.601 \\
3.547 \\
3.494 \\
3.444 \\
3.396 \\
3.350 \\
3.306 \\
3.264 \\
3.223\end{array}$ & $\begin{array}{l}4.023 \\
3.960 \\
3.900 \\
3.842 \\
3.787 \\
3.735 \\
3.684 \\
3.636 \\
3.590 \\
3.546\end{array}$ & $\begin{array}{l}4.558 \\
4.486 \\
4.418 \\
4.353 \\
4.290 \\
4.230 \\
4.173 \\
4.118 \\
4.066 \\
4.015\end{array}$ & $\begin{array}{l}3.530 \\
3.475 \\
3.424 \\
3.374 \\
3.326 \\
3.281 \\
3.238 \\
3.196 \\
3.156 \\
3.117\end{array}$ & $\begin{array}{l}3.049 \\
3.003 \\
2.959 \\
2.917 \\
2.877 \\
2.838 \\
2.801 \\
2.766 \\
2.732 \\
2.699\end{array}$ & $\begin{array}{l}2.744 \\
2.703 \\
2.664 \\
2.626 \\
2.590 \\
2.556 \\
2.523 \\
2.492 \\
2.461 \\
2.432\end{array}$ & $\begin{array}{l}2.276 \\
2.243 \\
2.211 \\
2.181 \\
2.152 \\
2.125 \\
2.098 \\
2.072 \\
2.048 \\
2.024\end{array}$ \\
\hline $\begin{array}{l}250.0 \\
255.0 \\
260.0 \\
265.0 \\
270.0 \\
275.0 \\
280.0 \\
285.0 \\
290.0 \\
295.0\end{array}$ & $\begin{array}{l}3.184 \\
3.147 \\
3.111 \\
3.076 \\
3.043 \\
3.010 \\
2.979 \\
2.949 \\
2.920 \\
2.892\end{array}$ & $\begin{array}{l}3.503 \\
3.462 \\
3.422 \\
3.384 \\
3.348 \\
3.312 \\
3.278 \\
3.245 \\
3.214 \\
3.183\end{array}$ & $\begin{array}{l}3.967 \\
3.920 \\
3.876 \\
3.832 \\
3.791 \\
3.751 \\
3.712 \\
3.675 \\
3.634 \\
3.604\end{array}$ & $\begin{array}{l}3.081 \\
3.045 \\
3.011 \\
2.978 \\
2.946 \\
2.916 \\
2.886 \\
2.858 \\
2.830 \\
2.804\end{array}$ & $\begin{array}{l}2.668 \\
2.638 \\
2.609 \\
2.581 \\
2.554 \\
2.528 \\
2.503 \\
2.479 \\
2.456 \\
2.433\end{array}$ & $\begin{array}{l}2.404 \\
2.378 \\
2.352 \\
2.327 \\
2.303 \\
2.280 \\
2.258 \\
2.236 \\
2.215 \\
2.195\end{array}$ & $\begin{array}{l}2.001 \\
1.980 \\
1.959 \\
1.938 \\
1.919 \\
1.900 \\
1.882 \\
1.864 \\
1.847 \\
1.831\end{array}$ \\
\hline $\begin{array}{l}300.0 \\
310.0 \\
320.0 \\
330.0 \\
340.0 \\
350.0 \\
360.0 \\
370.0 \\
380.0 \\
390.0\end{array}$ & $\begin{array}{l}2.865 \\
2.814 \\
2.766 \\
2.720 \\
2.678 \\
2.637 \\
2.599 \\
2.564 \\
2.530 \\
2.497\end{array}$ & $\begin{array}{l}3.153 \\
3.097 \\
3.044 \\
2.994 \\
2.947 \\
2.903 \\
2.862 \\
2.822 \\
2.785 \\
2.750\end{array}$ & $\begin{array}{l}3.570 \\
3.506 \\
3.446 \\
3.389 \\
3.336 \\
3.286 \\
3.239 \\
3.194 \\
3.152 \\
3.112\end{array}$ & $\begin{array}{l}2.778 \\
2.729 \\
2.683 \\
2.640 \\
2.600 \\
2.562 \\
2.526 \\
2.492 \\
2.459 \\
2.429\end{array}$ & $\begin{array}{l}2.411 \\
2.370 \\
2.331 \\
2.294 \\
2.260 \\
2.227 \\
2.196 \\
2.168 \\
2.140 \\
2.114\end{array}$ & $\begin{array}{l}2.176 \\
2.139 \\
2.104 \\
2.071 \\
2.041 \\
2.012 \\
1.984 \\
1.958 \\
1.934 \\
1.911\end{array}$ & $\begin{array}{l}1.815 \\
1.785 \\
1.757 \\
1.730 \\
1.705 \\
1.601 \\
1.659 \\
1.638 \\
1.618 \\
1.599\end{array}$ \\
\hline
\end{tabular}


Table II. Continued.

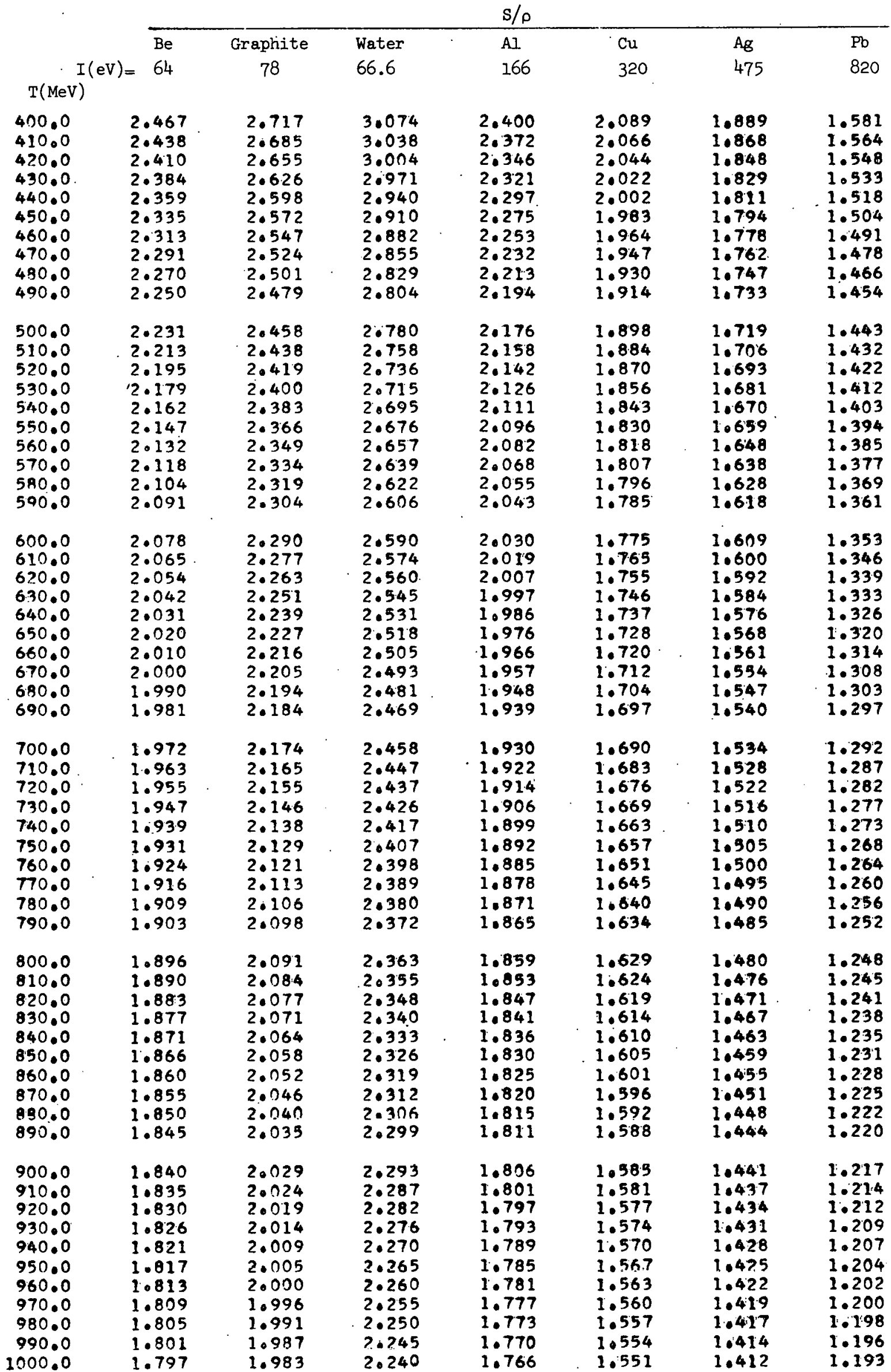


Table IIIA. Low energy proton stopping power $\mathrm{S}\left(\mathrm{MeV}=\mathrm{m}^{2} / \mathrm{B}\right)$ for several substances. Accuracy: 2-20\% .

\begin{tabular}{|c|c|c|c|c|c|c|c|c|c|c|c|c|c|c|c|c|c|c|c|c|}
\hline $\mathrm{T}(\mathrm{MeV})$ & $\mathrm{H}_{2}$ & He & L1 & $\mathrm{Be}$ & c & $\mathrm{N}_{2}$ & $o_{2}$ & $\mathrm{Ne}$ & Al & A & $\mathrm{Ni}$ & $\mathrm{Cu}$ & $\mathbf{K r}$ & $\mathrm{AB}$ & $\mathrm{Sn}$ & $\mathrm{Xe}$ & $\mathrm{Au}$ & ?b & Air & $\mathrm{H}_{2} \mathrm{O}$ \\
\hline .01 & & & . & & 440 & & &. & 260 & & 100 & 70 & & & & & 22 & & & \\
\hline .02 & & & & & 560 & & & & 360 & & 145 & 160 & & & & & 44 & & & \\
\hline .03 & & & & & 640 & & & & 410 & & 177 & 190 & & & & & 60 & & & \\
\hline .04 & & & & & 700 & & & & 440 & & 200 & 200 & & & & & 75 & & & \\
\hline .05 & 3800 & 1050 & & 690 & T2O & 750 & 600 & 350 & 460 & 480 & 220 & 210 & 270 & & & 240 & 85 & & 730 & 890 \\
\hline .10 & 3500 & 1090 & 750 & 700 & 710 & $780^{\circ}$ & 610 & 440 & 440 & 480 & 260 & 220 & 290 & & & 230 & 105 & 122 & 730 & 910 \\
\hline .15 & 2800 & 960 & 680 & 640 & 650 & 690 & 600 & 440 & 390 & 430 & 270 & 220 & 250 & & & 210 & 112 & 127 & 650 & 830 \\
\hline .20 & 2300 & 830 & 610 & 570 & 580 & 610 & 540 & 420 & 340 & 380 & 260 & 220 & 220 & $\ddots$ & & $192^{\circ}$ & 119 & 127 & 580 & 740 \\
\hline .25 & 1990 & 740 & 550 & 510 & 540 & 530 & 500 & 390 & 320 & 330 & 250 & 210 & 198 & . & & 176 & 116 & 120 & 520 & 660 \\
\hline .30 & 1740 & 660 & 500 & 460 & 490 & 480 & 450 & 360 & 310 & 300 & 230 & 200 & 182 & & & 163 & $110^{\circ}$ & 113 & 480 & 600 \\
\hline .35 & 1560 & 600 & 450 & 430 & 460 & 440 & 410 & 340 & 290 & 270 & 220 & 192 & 169 & & & 152 & 104 & 106 & 430 & 540 \\
\hline .40 & 1410 . & 550 & 420 & 390 & 430 & 400 & 380 & 320 & 280 & 250 & 210 & 183 & 159 & 15.1 & 142 & 143 & 98 & 100 & 410 & 500 \\
\hline .45 & $1280^{\circ}$ & 510 & 390 & 370 & 390 & 370 & 360 & 300 & 270 & 230. & 193 & 175 & 150 & 142 & 134 & 134 & 93 & 95 & 380 & 460 \\
\hline .50 & 1180 & 480 & 360 & 350 & 370 & 350 & 340 & 290 & 250 & 220 & 182 & 168 & 143 & 134 & 127 & $\mathrm{i} 27$ & 88 & 90 & 350 & 430 \\
\hline .55 & 1090 & 450 & 340 & 330. & 350 & 321 & 320 & 270 & 240 & 210 & $173^{\circ}$ & 161 & 137 & 128 & 121 & 121 & 84 & 86 & 330 & 400 \\
\hline .60 & 1020 & 420 & 320 & 310 & 330 & 310 & 300 & 260 & 230 & 200 & 165 & $i 55$ & 132 & 122 & 115 & 115 & 81 & 83 & 310 & 380 \\
\hline .70 & 910 & 380 & 290 & 280 & 290 & 28. & 270 & 230 & 210 & 184 & 151 & 144 & 123 & 113 & 107 & 106 & 75 & 77 & 280 & 340 \\
\hline .80 & 810 & 340 & 260 & 260 & 270 & 250 & 250 & 210 & 197 & 171 & 141 & 135 & 116 & 105 & 100 & 98 & 70 & 71 & 260 & 310 \\
\hline .90 & 740 & 310 & 240 & 240 & 250 & 243 & 230 & 198 & 185 & 160 & 133 & 128 & 109 & 99 & 94 & 92 & 66 & 67 & 240 & 290 \\
\hline 1.00 & 680 & 290 & 230 & 220 & 230 & 220 & 220 & 185 & 173 & 150 & 126 & 121 & 104 & 94 & 89 & 87 & 63 & 63 & 220 & 260 \\
\hline 1.1 & 630 & 270 & 220 & 210 & 220 & 210 & 200 & 174 & 163 & 142 & 120 & 114 & 99 & 89 & 85 & $82^{\circ}$ & 60 & 60 & 210 & 260 \\
\hline 1.2 & 590 & 250 & 210 & 198 & 200 & 194 & 192 & 164 & 155 & 134 & 115 & 109 & 94 & 85 & 81 & 78 & 57 & 58 & 198 & 230 \\
\hline 1.3 & 550 & 240 & 200 & 187 & 192 & 185 & 182 & 156 & 147 & 127 & 110 & 104 & 90 & $8 \dot{2}$ & 78 & 75 & 54 & 55 & 186 & 220 \\
\hline 1.4 & 520 & 220 & 195 & 179 & 183 & 176 & $173^{\circ}$ & 149 & 140 & 121 & 106 & 99 & 87 & 79 & 75 & 72 & 53 & 53 & 177 & 210 \\
\hline 1.5 & 500 & 210 & 188 & 170 & 175 & $1 \in 8$ & 165 & 144 & 134 & 116 & 101 & 95 & 84 & 75 & 71 & 69 & 51 & 52 & 168 & 197 \\
\hline 1.6 & 470 & 200 & 184 & 161 & 167 & $1 \in 0$ & 157 & 137 & 129 & 112 & 97 & 92 & 81 & 72 & 68 & 66 & 49 & 50 & 160 & 188 \\
\hline 1.8 & 430 & 183 & 173 & 148 & 154 & 148 & 144 & 127 & 119 & 103 & 91 & 85 & 76 & 68 & 65. & 62 & 47 & 47 & 147 & 172 \\
\hline 2.0 & 390 & 168 & 164 & 137 & 143 & $1 \vdots 7$ & 134 & 119 & 111 & 95 & 85 & 80 & 72 & 64 & 61 & 59 & 44 & 45 & 136 & 159 \\
\hline
\end{tabular}


TABLE IIIB

EXPERIMENTAL PROTON STOPPING POWER S (MEV/GM/SQCM). FROM AH6T, AS6B.

\begin{tabular}{|c|c|c|c|c|c|c|c|c|c|c|c|c|c|c|c|c|}
\hline (MEV) & $B E$ & $A L$ & $\mathrm{CA}$ & SC & $T 1$ & v & $C R$ & MN & FE & $\mathrm{CO}$ & NI & $\mathrm{Cu}$ & ZN & AG & PT & AU \\
\hline $\begin{array}{l}2.00 \\
2.25 \\
2.50 \\
2.75 \\
3.00 \\
3.25 \\
3.50 \\
3.75 \\
4.00\end{array}$ & $\begin{array}{r}134.25 \\
122.70 \\
113.21 \\
105.19 \\
98.36 \\
92.42 \\
87.24 \\
82.65 \\
78.57\end{array}$ & $\begin{array}{r}110.67 \\
101.92 \\
94.68 \\
88.52 \\
83.19 \\
78.50 \\
74.51 \\
70.94 \\
67.76\end{array}$ & $\begin{array}{r}107.21 \\
98.91 \\
92.03 \\
86.15 \\
81.09 \\
76.65 \\
72.76 \\
69.30 \\
66.18\end{array}$ & $\begin{array}{l}96.58 \\
89.24 \\
83.15 \\
77.94 \\
73.40 . \\
69.45 \\
65.97 \\
62.87 \\
60.08\end{array}$ & $\begin{array}{l}93.19 \\
86.11 \\
80.23 \\
75.20 \\
70.87 \\
67.11 \\
63.78 \\
60.81 \\
58.15\end{array}$ & $\begin{array}{l}90.61 \\
83.73 \\
78.02 \\
73.14 \\
68.91 \\
65.22 \\
61.93 \\
59.04 \\
56.44\end{array}$ & $\begin{array}{l}89.57 \\
82.93 \\
77.41 \\
72.69 \\
68.60 \\
65.01 \\
61.82 \\
58.98 \\
56.42\end{array}$ & $\begin{array}{l}86.51 \\
80.07 \\
74.72 \\
70.13 \\
66.16 \\
62.60 \\
59.59 \\
56.86 \\
54.40\end{array}$ & $\begin{array}{l}87.30 \\
80.83 \\
75.45 \\
70.85 \\
66.84 \\
63.32 \\
60.21 \\
57.45 \\
55.00\end{array}$ & $\begin{array}{l}.74 \\
.64 \\
.56 \\
.18 \\
.37 \\
.04 \\
.09 \\
.46 \\
.10\end{array}$ & $\begin{array}{l}45 \\
14 \\
89 \\
35 \\
41 \\
96 \\
97 \\
28 \\
88\end{array}$ & $\begin{array}{l}81.09 \\
75.19 \\
70.28 \\
66.07 \\
62.44 \\
59.25 \\
56.43 \\
53.91 \\
51.65\end{array}$ & $\begin{array}{l}80.89 \\
75.02 \\
70.13 \\
65.92 \\
62.32 \\
59.16 \\
56.36 \\
53.85 \\
51.60\end{array}$ & $\begin{array}{l}63.74 \\
59.63 \\
56.18 \\
53.16 \\
50.46 \\
48.07 \\
45.94 \\
44.02 \\
42.28\end{array}$ & $\begin{array}{l}45.43 \\
42.85 \\
40.67 \\
38.71 \\
36.97 \\
35.39 \\
33.96 \\
32.66\end{array}$ & $\begin{array}{l}5.78 \\
3.12\end{array}$ \\
\hline $\begin{array}{l}4.25 \\
4.50 \\
4.75 \\
5.00 \\
5.25 \\
5.50 \\
5.75 \\
6.00 \\
6.50 \\
7.00\end{array}$ & $\begin{array}{l}74.90 \\
71.60 \\
68.58 \\
65.87 \\
63.36 \\
61.06 \\
58.93 \\
56.96 \\
53.42 \\
50.34\end{array}$ & $\begin{array}{l}64.85 \\
62.21 \\
59.80 \\
57.59 \\
55.56 \\
53.68 \\
51.93 \\
50.31 \\
47.38 \\
44.81\end{array}$ & $\begin{array}{l}63.38 \\
60.83 \\
58.51 \\
56.37 \\
54.41 \\
52.59 \\
50.91 \\
49.35 \\
46.53 \\
44.04\end{array}$ & $\begin{array}{l}57.57 \\
55.29 \\
53.21 \\
51.30 \\
49.53 \\
47.90 \\
46.38 \\
44.97 \\
42.41 \\
40.17\end{array}$ & $\begin{array}{l}55.74 \\
53.54 \\
51.53 \\
49.68 \\
47.98 \\
46.40 \\
44.93 \\
43.56 \\
41.10 \\
38.92\end{array}$ & $\begin{array}{l}54.09 \\
51.95 \\
50.00 \\
48.21 \\
46.56 \\
45.03 \\
43.61 \\
42.29 \\
39.90 \\
37.80\end{array}$ & $\begin{array}{l}54.09 \\
51.97 \\
50.04 \\
48.25 \\
46.61 \\
45.09 \\
43.68 \\
42.37 \\
39.98 \\
37.89\end{array}$ & $\begin{array}{l}52.19 \\
50.16 \\
48.31 \\
46.62 \\
45.05 \\
43.60 \\
42.25 \\
40.99 \\
36.72 \\
36.71\end{array}$ & $\begin{array}{l}52.79 \\
50.78 \\
48.94 \\
47.24 \\
45.67 \\
44.22 \\
42.87 \\
41.60 \\
39.31 \\
37.28\end{array}$ & $\begin{array}{l}50 \\
49 \\
47 \\
45 \\
44 \\
42 \\
41 \\
40 \\
38 \\
36\end{array}$ & $\begin{array}{l}52 \\
50 \\
48 \\
47 \\
45 \\
44 \\
42 \\
41 \\
39 \\
37\end{array}$ & $\begin{array}{l}60 \\
72 \\
99 \\
42 \\
95 \\
59 \\
33 \\
15 \\
01 \\
12\end{array}$ & $\begin{array}{l}55 \\
69 \\
99 \\
42 \\
97 \\
61 \\
36 \\
19 \\
07\end{array}$ & $\begin{array}{l}40.70 \\
39.26 \\
37.93 \\
36.71 \\
35.58 \\
34.53 \\
33.55 \\
32.63 \\
30.97\end{array}$ & $\begin{array}{l}39 \\
40 \\
49 \\
65 \\
85 \\
12 \\
43 \\
79 \\
60 \\
54\end{array}$ & $\begin{array}{l}55 \\
56 \\
65 \\
79 \\
60 \\
25 \\
56\end{array}$ \\
\hline 7.50 & 47.62 & 42.52 & 41.83 & 50.18 & 36.99 & 35.93 & & $?$ & 35.47 & & & & $33: 52$ & 28.14 & & \\
\hline $\begin{array}{r}3.00 \\
8.50 \\
9.00 \\
9.50 \\
10.00 \\
10.50 \\
11.00 \\
11.50\end{array}$ & $\begin{array}{l}45.21 \\
43.05 \\
41.10 \\
39.34 \\
37.74 \\
36.27 \\
34.93 \\
33.69 \\
32.54\end{array}$ & $\begin{array}{l}40.47 \\
38.64 \\
36.97 \\
35.40 \\
34.08 \\
32.82 \\
31.60 \\
30.58 \\
29.58\end{array}$ & $\begin{array}{l}39.85 \\
38.08 \\
36.47 \\
35.00 \\
33.66 \\
32.43 \\
31.30 \\
30.25 \\
29.28\end{array}$ & $\begin{array}{l}36.38 \\
34.77 \\
33.31 \\
31.98 \\
30.76 \\
29.65 \\
28.61 \\
27.66 \\
26.77\end{array}$ & $\begin{array}{l}35.27 \\
33.71 \\
32.30 \\
31.02 \\
29.84 \\
28.77 \\
27.77 \\
26.85 \\
26.00\end{array}$ & $\begin{array}{l}34.26 \\
32.75 \\
31.39 \\
30.15 \\
29.01 \\
27.97 \\
27.01 \\
26.12 \\
25.30\end{array}$ & $\begin{array}{l}34.35 \\
32.85 \\
31.49 \\
30.25 \\
29.11 \\
28.06 \\
27.10 \\
26.21\end{array}$ & $\begin{array}{l}33.32 \\
31.86 \\
30.57 \\
29.36 \\
28.28 \\
27.28 \\
26.35 \\
25.49 \\
24.69\end{array}$ & $\begin{array}{l}33.85 \\
32.39 \\
31.06 \\
29.85 \\
28.74 \\
27.72 \\
26.78 \\
25.90 \\
25.09\end{array}$ & $\begin{array}{l}32.78 \\
31.37 \\
30.09 \\
28.92 \\
27.85 \\
26.87 \\
25.96 \\
25.12 \\
24.33\end{array}$ & $\begin{array}{l}33.90 \\
32.45 \\
31.14 \\
29.95 \\
28.84 \\
27.83 \\
26.89 \\
26.02\end{array}$ & $\begin{array}{l}31.93 \\
30.57 \\
29.33 \\
28.21 \\
27.17 \\
26.22 \\
25.35 \\
24.54\end{array}$ & $\begin{array}{l}32.01 \\
30.65 \\
29.41 \\
28.29 \\
27.26 \\
26.30 \\
25.42 \\
24.61\end{array}$ & $\begin{array}{l}26.94 \\
25.85 \\
24.86 \\
23.95 \\
23.11 \\
22.34 \\
21.62 \\
20.96 \\
20.34\end{array}$ & $\begin{array}{l}20.72 \\
19.94 \\
19.22 \\
18.56 \\
17.95 \\
17.39 \\
16.88 \\
16.39 \\
15.93\end{array}$ & \\
\hline
\end{tabular}


Table IV. Calculated csda ranges $R\left(\mathrm{~g} / \mathrm{cm}^{2}\right)$. for protons of kinetic energy $T$.

\begin{tabular}{|c|c|c|c|c|c|c|c|}
\hline & & & & $\mathrm{R}$ & & & \\
\hline $\mathrm{T}(\mathrm{MeV})$ & $\mathrm{Be}$ & $\begin{array}{l}\text { Graphite } \\
\quad:\end{array}$ & Water & Al & $\mathrm{Cu}$ & $\mathrm{Ag}$ & $\mathrm{Pb}$ \\
\hline $\begin{array}{l}1.0 \\
1.1 \\
1.2 \\
1.3 \\
1.4 \\
1.5 \\
1.6 \\
1.7 \\
1.8 \\
1.9\end{array}$ & $\begin{array}{l}.0029 \\
.0034 \\
.0039 \\
.0044 \\
.0050 \\
.0055 \\
.0062 \\
.0068 \\
.0075 \\
.0032\end{array}$ & $\begin{array}{l}.0039 \\
.0043 \\
.0048 \\
.0053 \\
.0059 \\
.0064 \\
.0070 \\
.0076 \\
.0083 \\
.0089\end{array}$ & $\begin{array}{l}.0039 \\
.0043 \\
.0047 \\
.0051 \\
.0056 \\
.0061 \\
.0066 \\
.0071 \\
.0077 \\
.0083\end{array}$ & $\begin{array}{l}.0042 \\
.0048 \\
.0054 \\
.0061 \\
.0068 \\
.0075 \\
.0083 \\
.0091 \\
.0099 \\
.0108\end{array}$ & $\begin{array}{l}.0061 \\
.0070 \\
.0078 \\
.0088 \\
.0098 \\
.0108 \\
.0118 \\
.0129 \\
.0141 \\
.0153\end{array}$ & $\begin{array}{l}.0080 \\
.0091 \\
.0103 \\
.0115 \\
.0128 \\
.0141 \\
.0154 \\
.0168 \\
.0183 \\
.0198\end{array}$ & $\begin{array}{r}.0116 \\
.0133 \\
.0151 \\
.0169 \\
.0188 \\
.0208 \\
.0228 \\
.0248 \\
.0270 \\
.0291\end{array}$ \\
\hline $\begin{array}{l}2.0 \\
2.1 \\
2.2 \\
2.3 \\
2.4 \\
2.5 \\
2.6 \\
2.7 \\
2.8 \\
2.9\end{array}$ & $\begin{array}{l}.0089 \\
.0097 \\
.0105 \\
.0113 \\
.0121 \\
.0130 \\
.0139 \\
.0148 \\
.0158 \\
.0167\end{array}$ & $\begin{array}{l}.0096 \\
.0104 \\
.0111 \\
.0119 \\
.0127 \\
.0135 \\
.0143 \\
.0152 \\
.0161 \\
.01170\end{array}$ & $\begin{array}{l}.0089 \\
.0095 \\
.0101 \\
.0108 \\
.0115 \\
.0122 \\
.0130 \\
.0137 \\
.0145 \\
.0153\end{array}$ & $\begin{array}{l}.0117 \\
.0126 \\
.0136 \\
.0146 \\
.0156 \\
.0166 \\
.0177 \\
.0188 \\
.0200 \\
.0211\end{array}$ & $\begin{array}{l}.0165 \\
.0178 \\
.0190 \\
.0204 \\
.0218 \\
.0232 \\
.0246 \\
.0261 \\
.0276 \\
.0291\end{array}$ & $\begin{array}{r}.0213 \\
.0229 \\
.0245 \\
.0262 \\
.0279 \\
.0296 \\
.0314 \\
.0332 \\
.0351 \\
.0370\end{array}$ & $\begin{array}{l}.0314 \\
.0336 \\
.0360 \\
.0384 \\
.0408 \\
.0433 \\
.0458 \\
.0484 \\
.0511 \\
.0538\end{array}$ \\
\hline $\begin{array}{l}3.0 \\
3.1 \\
3.2 \\
3.3 \\
3.4 \\
3.5 \\
3.6 \\
3.7 \\
3.8 \\
3.9\end{array}$ & $\begin{array}{l}.0177 \\
.0188 \\
.0198 \\
.0209 \\
.0220 \\
.0232 \\
.0243 \\
.0255 \\
.0267 \\
.0279\end{array}$ & $\begin{array}{l}.0180 \\
.0189 \\
.0199 \\
.0209 \\
.0220 \\
.0230 \\
.0241 \\
.0252 \\
.0263 \\
.0275\end{array}$ & $\begin{array}{l}.0161 \\
.0170 \\
.0178 \\
.0187 \\
.0196 \\
.0205 \\
.0215 \\
.0225 \\
.0234 \\
.0245\end{array}$ & $\begin{array}{l}.0223 \\
.0236 \\
.0248 \\
.0261 \\
.0274 \\
.0287 \\
.0301 \\
.0315 \\
.0329 \\
.0344\end{array}$ & $\begin{array}{l}.0307 \\
.0323 \\
.0340 \\
.0357 \\
.0374 \\
.0392 \\
.0409 \\
.0428 \\
.0446 \\
.0465\end{array}$ & $\begin{array}{l}.0390 \\
.0409 \\
.0430 \\
.0450 \\
.0471 \\
.0493 \\
.0515 \\
.0537 \\
.0559 \\
.0582\end{array}$ & $\begin{array}{l}.0565 \\
.0593 \\
.0621 \\
.0650 \\
.0680 \\
.0709 \\
.0740 \\
.0771 \\
.0802 \\
.0834\end{array}$ \\
\hline $\begin{array}{l}4.0 \\
4.1 \\
4.2 \\
4.3 \\
4.4 \\
4.5 \\
4.6 \\
4.7 \\
4.8 \\
4.9\end{array}$ & $\begin{array}{l}.0292 \\
.0305 \\
.0318 \\
.0331 \\
.0345 \\
.0359 \\
.0373 \\
.0397 \\
.0402 \\
.0416\end{array}$ & $\begin{array}{l}.0287 \\
.0299 \\
.0311 \\
.0323 \\
.0336 \\
.0349 \\
.0362 \\
.0375 \\
.0389 \\
.0403\end{array}$ & $\begin{array}{l}.0255 \\
.0265 \\
.0276 \\
.0287 \\
.0298 \\
.0309 \\
.0321 \\
.0332 \\
.0344 \\
.0356\end{array}$ & $\begin{array}{r}.0358 \\
.0373 \\
.0389 \\
.0404 \\
.0420 \\
.0436 \\
.0453 \\
.0469 \\
.0486 \\
.0503\end{array}$ & $\begin{array}{l}.0484 \\
.0504 \\
.0524 \\
.0544 \\
.0564 \\
.0585 \\
.0606 \\
.0628 \\
.0649 \\
.0672\end{array}$ & $\begin{array}{l}.0605 \\
.0629 \\
.0653 \\
.0677 \\
.0702 \\
.0727 \\
.0753 \\
.0778 \\
.0805 \\
.0831\end{array}$ & $\begin{array}{r}.0866 \\
.0899 \\
.0932 \\
.0965 \\
.0999 \\
.1034 \\
.1069 \\
.1104 \\
.1140 \\
.11176\end{array}$ \\
\hline $\begin{array}{l}5.0 \\
5.5 \\
6.0 \\
6.5 \\
7.0 \\
7.5 \\
8.0 \\
8.5 \\
9.0 \\
9.5\end{array}$ & $\begin{array}{r}.0432 \\
.0510 \\
.0595 \\
.0656 \\
.0782 \\
.0884 \\
.0992 \\
.1106 \\
.1225 \\
.1349\end{array}$ & $\begin{array}{l}.0417 \\
.0490 \\
.0569 \\
.0653 \\
.0742 \\
.0837 \\
.0937 \\
.1042 \\
.1152 \\
.1266\end{array}$ & $\begin{array}{l}.0369 \\
.0433 \\
.0502 \\
.0575 \\
.0653 \\
.0736 \\
.0824 \\
.0915 \\
.1012 \\
.1112\end{array}$ & $\begin{array}{l}.0521 \\
.0612 \\
.0709 \\
.0812 \\
.0922 \\
.1038 \\
.1160 \\
.1288 \\
.1421 \\
.1561\end{array}$ & $\begin{array}{l}.0694 . \\
.0810 \\
.0934 \\
.1066 \\
.1205 \\
.1351 \\
.1504 \\
.1664 \\
.1831 \\
.2005\end{array}$ & $\begin{array}{r}.0858 \\
.0997 \\
.1145 \\
.1302 \\
.1466 \\
.1639 \\
.1820 \\
.2008 \\
.2205 \\
.2409\end{array}$ & $\begin{array}{l}.1213 \\
.1403 \\
.1603 \\
.1814 \\
.2035 \\
.2267 \\
.2508 \\
.2759 \\
.3019 \\
.3289\end{array}$ \\
\hline
\end{tabular}


Table IV. Continued.

\begin{tabular}{|c|c|c|c|c|c|c|c|}
\hline & & & & & & & \\
\hline $\mathrm{T}(\mathrm{MeV})$ & $\mathrm{Be}$ & Graphite & Water & $\mathrm{Al}$ & $\mathrm{Cu}$ &. $\mathrm{Ag}$ & $\mathrm{Pb}$ \\
\hline $\begin{array}{l}10.0 \\
10.5 \\
11.0 \\
11.5 \\
12.0 \\
12.5 \\
13.0 \\
13.5 \\
14.0 \\
14.5\end{array}$ & $\begin{array}{r}1479 \\
.1614 \\
.1755 \\
.1901 \\
.2052 \\
.2208 \\
.2370 \\
.2536 \\
.2708 \\
.2885\end{array}$ & $\begin{array}{r}.1386 \\
.1511 \\
.1641 \\
.1775 \\
.1915 \\
.2059 \\
.2207 \\
.2361 \\
.2519 \\
.2682\end{array}$ & $\begin{array}{l}.1217 \\
.1327 \\
.1440 \\
.1558 \\
.1680 \\
.1807 \\
.1937 \\
.2072 \\
.2211 \\
.2353\end{array}$ & $\begin{array}{r}.1706 \\
.1857 \\
.2013 \\
.2175 \\
.2343 \\
.2516 \\
.2695 \\
.2879 \\
.3068 \\
.3263\end{array}$ & $\begin{array}{r}.2186 \\
.2373 \\
.2567 \\
.2768 \\
.2975 \\
.3188 \\
.3408 \\
.3635 \\
.3867 \\
.4106\end{array}$ & $\begin{array}{l}.2620 \\
.2840 \\
.3066 \\
.3300 \\
.3541 \\
.3790 \\
.4045 \\
.4308 \\
.4578 \\
.4855\end{array}$ & $\begin{array}{r}.3568 \\
.3856 \\
.4154 \\
.4460 \\
.4776 \\
.5100 \\
.5433 \\
.5775 \\
.6125 \\
.6484\end{array}$ \\
\hline $\begin{array}{l}15.0 \\
15.5 \\
16.0 \\
16.5 \\
17.0 \\
17.5 \\
18.0 \\
18.5 \\
19.0 \\
19.5\end{array}$ & $\begin{array}{r}.3067 \\
.3254 \\
.3446 \\
.3643 \\
.3845 \\
.4052 \\
.4264 \\
.4481 \\
.4702 \\
.4929\end{array}$ & $\begin{array}{r}.2849 \\
.3021 \\
.3198 \\
.3379 \\
.3564 \\
.3755 \\
.3949 \\
.4148 \\
.4351 \\
.4559\end{array}$ & $\begin{array}{l}.2500 \\
.2651 \\
.2806 \\
.2965 \\
.3128 \\
.3295 \\
.3465 \\
.3640 \\
.3819 \\
.4001\end{array}$ & $\begin{array}{r}.3463 \\
.3668 \\
.3879 \\
.4095 \\
.4316 \\
.4542 \\
.4773 \\
.5009 \\
.5251 \\
.5497\end{array}$ & $\begin{array}{l}.4351 \\
.4602 \\
.4860 \\
.5123 \\
.5393 \\
.5668 \\
.5950 \\
.6237 \\
.6530 \\
.6830\end{array}$ & $\begin{array}{r}.5138 \\
.5429 \\
.5726 \\
.6030 \\
.6341 \\
.6659 \\
.6983 \\
.7314 \\
.7651 \\
.7995\end{array}$ & $\begin{array}{r}.6851 \\
.7226 \\
.7610 \\
.8002 \\
.8403 \\
.8811 \\
.9228 \\
.9652 \\
1.0085 \\
1.0525\end{array}$ \\
\hline $\begin{array}{l}20.0 \\
21.0 \\
22.0 \\
23.0 \\
24.0 \\
25.0 \\
26.0 \\
27.0 \\
28.0 \\
29.0\end{array}$ & $\begin{array}{r}.5160 \\
.5637 \\
.6132 \\
.6646 \\
.7179 \\
.7731 \\
.8301 \\
.8889 \\
.9495 \\
1.0119\end{array}$ & $\begin{array}{l}.4771 \\
.5209 \\
.5663 \\
.6135 \\
.6624 \\
.7129 \\
.7651 \\
.8190 \\
.8745 \\
.9317\end{array}$ & $\begin{array}{r}.4187 \\
.4571 \\
.4970 \\
.5385 \\
.5814 \\
.6258 \\
.6717 \\
.7190 \\
.7678 \\
.8180\end{array}$ & $\begin{array}{r}.5748 \\
.6266 \\
.6804 \\
.7361 \\
.7937 \\
.8533 \\
.9148 \\
.9782 \\
1.0434 \\
1.1106\end{array}$ & $\begin{array}{r}.7135 \\
.7762 \\
.8412 \\
.9086 \\
.9781 \\
1.0499 \\
1.1240 \\
1.2002 \\
1.2786 \\
1.3591\end{array}$ & $\begin{array}{r}.8346 \\
.9066 \\
.9812 \\
1.0584 \\
1.1380 \\
1.2201 \\
1.3047 \\
1.3918 \\
1.4812 \\
1.5730\end{array}$ & $\begin{array}{l}1.0974 \\
1.1894 \\
1.2845 \\
1.3826 \\
1.4838 \\
1.5880 \\
1.6952 \\
1.8052 \\
1.9182 \\
2.0341\end{array}$ \\
\hline $\begin{array}{l}30.0 \\
31.0 \\
32.0 \\
33.0 \\
34.0 \\
35.0 \\
36.0 \\
37.0 \\
38.0 \\
39.0\end{array}$ & $\begin{array}{l}1.0760 \\
1.1420 \\
1.2096 \\
1.2791 \\
1.3502 \\
1.4231 \\
1.4977 \\
1.5740 \\
1.6520 \\
1.7316\end{array}$ & $\begin{array}{r}.9904 \\
1.0508 \\
1.1127 \\
1.1763 \\
1.2414 \\
1.3081 \\
1.3763 \\
1.4461 \\
1.5174 \\
1.5903\end{array}$ & $\begin{array}{r}.8696 \\
.9227 \\
.9772 \\
1.0330 \\
1.0903 \\
1.1489 \\
1.2089 \\
1.2703 \\
1.3330 \\
1.3971\end{array}$ & $\begin{array}{l}1.1795 \\
1.2503 \\
1.3229 \\
1.3974 \\
1.4736 \\
1.5516 \\
1.6313 \\
1.7129 \\
1.7961 \\
1.8811\end{array}$ & $\begin{array}{l}1.4418 \\
1.5266 \\
1.6135 \\
1.7025 \\
1.7935 \\
1.8867 \\
1.9818 \\
2.0791 \\
2.1783 \\
2.2795\end{array}$ & $\begin{array}{l}1.6672 \\
1.7638 \\
1.8627 \\
1.9640 \\
2.0675 \\
2.1733 \\
2.2814 \\
2.3918 \\
2.5043 \\
2.6191\end{array}$ & $\begin{array}{l}2.1529 \\
2.2744 \\
2.3988 \\
2.5259 \\
2.6558 \\
2.7885 \\
2.9239 \\
3.0620 \\
3.2027 \\
3.3462\end{array}$ \\
\hline $\begin{array}{l}40.0 \\
41.0\end{array}$ & $\begin{array}{l}1.8129 \\
1.8959\end{array}$ & $\begin{array}{l}1.6646 \\
1.7405\end{array}$ & $\begin{array}{l}1.4625 \\
1.5292\end{array}$ & $\begin{array}{l}1.9679 \\
2.0563\end{array}$ & $\begin{array}{l}2.3827 \\
2.4879\end{array}$ & $\begin{array}{l}2.7361 \\
2.8553\end{array}$ & $\begin{array}{l}3.4922 \\
3.6409\end{array}$ \\
\hline $\begin{array}{l}42.0 \\
43.0 \\
44.0 \\
45.0 \\
46.0 \\
47.0 \\
48.0 \\
49.0\end{array}$ & $\begin{array}{l}1.9805 \\
2.0668 \\
2.1546 \\
2.2441 \\
2.3353 \\
2.4280 \\
2.5223 \\
2.6182\end{array}$ & $\begin{array}{l}1.8178 \\
1.8967 \\
1.9770 \\
2.0588 \\
2.1421 \\
2.2268 \\
2.3129 \\
2.4006\end{array}$ & $\begin{array}{l}1.5972 \\
1.6666 \\
1.7373 \\
1.8092 \\
1.8825 \\
1.9570 \\
2.0329 \\
2.1099\end{array}$ & $\begin{array}{l}2.1465 \\
2.2383 \\
2.3319 \\
2.4271 \\
2.5239 \\
2.6224 \\
2.7226 \\
2.8244\end{array}$ & $\begin{array}{l}2.5951 \\
2.7042 \\
2.8152 \\
2.9282 \\
3.0431 \\
3.1599 \\
3.2786 \\
3.3992\end{array}$ & $\begin{array}{l}2.9766 \\
3.1002 \\
3.2258 \\
3.3537 \\
3.4836 \\
3.6157 \\
3.7498 \\
3.8861\end{array}$ & $\begin{array}{l}3.7922 \\
3.9461 \\
4.1025 \\
4.2615 \\
4.4231 \\
4.5871 \\
4.7537 \\
4.9228\end{array}$ \\
\hline $\begin{array}{l}50.0 \\
52.5 \\
55.0 \\
57.5 \\
60.0 \\
62.5 \\
65.0 \\
67.5 \\
70.0 \\
72.5\end{array}$ & $\begin{array}{l}2.7156 \\
2.9661 \\
3.2263 \\
3.4960 \\
3.7752 \\
4.0637 \\
4.3614 \\
4.6681 \\
4.9839 \\
5.3086\end{array}$ & $\begin{array}{l}2.4896 \\
2.7184 \\
2.9560 \\
3.2023 \\
3.4571 \\
3.7204 \\
3.9921 \\
4.2720 \\
4.5602 \\
4.8563\end{array}$ & $\begin{array}{l}2.1883 \\
2.3897 \\
2.5988 \\
2.8156 \\
3.0400 \\
3.2718 \\
3.5111 \\
3.7576 \\
4.0113 \\
4.2722\end{array}$ & $\begin{array}{l}2.9278 \\
3.1934 \\
3.4690 \\
3.7545 \\
4.0496 \\
4.3544 \\
4.6686 \\
4.9922 \\
5.3251 \\
5.6671\end{array}$ & $\begin{array}{l}3.5216 \\
3.8359 \\
4.1617 \\
4.4988 \\
4.8470 \\
5.2063 \\
5.5764 \\
5.9573 \\
6.3487 \\
6.7507\end{array}$ & $\begin{array}{l}4.0244 \\
4.3792 \\
4.7466 \\
5.1266 \\
5.5188 \\
5.9233 \\
6.3398 \\
6.7682 \\
7.2083 \\
7.6601\end{array}$ & $\begin{array}{l}5.0943 \\
5.5339 \\
5.9886 \\
6.4583 \\
6.9426 \\
7.4415 \\
7.9547 \\
8.4821 \\
9.0235 \\
9.5786\end{array}$ \\
\hline
\end{tabular}


Table IV. Continued.

\begin{tabular}{|c|c|c|c|c|c|c|c|}
\hline $\mathrm{T}(\mathrm{MeV})$ & $\mathrm{Be}$ & Graphite & Water & Al & $\mathrm{Cu}$ & $\mathrm{Ag}$ & $\mathrm{Pb}$ \\
\hline $\begin{array}{l}75.0 \\
77.5 \\
80.0 \\
82.5 \\
85.0 \\
87.5 \\
90.0 \\
92.5 \\
95.0 \\
97.5\end{array}$ & $\begin{array}{l}5.642 \\
5.984 \\
6.335 \\
6.694 \\
7.062 \\
7.438 \\
7.822 \\
8.215 \\
8.615 \\
9.024\end{array}$ & $\begin{array}{l}5.161 \\
5.473 \\
5.792 \\
6.120 \\
6.455 \\
6.798 \\
7.149 \\
7.506 \\
7.871 \\
8.244\end{array}$ & $\begin{array}{l}4.540 \\
4.815 \\
5.097 \\
5.386 \\
5.681 \\
5.983 \\
6.292 \\
6.607 \\
6.929 \\
7.257\end{array}$ & $\begin{array}{l}6.018 \\
6.378 \\
6.747 \\
7.124 \\
7.511 \\
7.905 \\
8.309 \\
8.720 \\
9.140 \\
9.568\end{array}$ & $\begin{array}{r}7.163 \\
7.586 \\
9.018 \\
8.461 \\
8.914 \\
9.376 \\
9.848 \\
10.330 \\
10.821 \\
11.322\end{array}$ & $\begin{array}{r}8.123 \\
8.598 \\
9.083 \\
9.580 \\
10.088 \\
10.606 \\
11.135 \\
11.675 \\
12.225 \\
12.785\end{array}$ & $\begin{array}{l}10.147 \\
10.729 \\
11.325 \\
11.933 \\
12.555 \\
13.189 \\
13.836 \\
14.495 \\
15.167 \\
15.852\end{array}$ \\
\hline $\begin{array}{l}100.0 \\
105.0 \\
110.0 \\
115.0 \\
120.0 \\
125.0 \\
130.0 \\
135.0 \\
140.0 \\
145.0\end{array}$ & $\begin{array}{r}9.440 \\
10.297 \\
11.184 \\
12.101 \\
13.048 \\
14.024 \\
15.029 \\
16.061 \\
17.121 \\
18.208\end{array}$ & $\begin{array}{r}8.623 \\
9.404 \\
10.212 \\
11.047 \\
11.910 \\
12.799 \\
13.713 \\
14.654 \\
15.619 \\
16.608\end{array}$ & $\begin{array}{r}7.592 \\
8.279 \\
8.992 \\
9.729 \\
10.489 \\
11.273 \\
12.080 \\
12.909 \\
13.760 \\
14.633\end{array}$ & $\begin{array}{l}10.004 \\
10.901 \\
11.828 \\
12.787 \\
13.776 \\
14.795 \\
15.843 \\
16.919 \\
18.024 \\
19.156\end{array}$ & $\begin{array}{l}11.892 \\
12.879 \\
13.962 \\
15.081 \\
16.233 \\
17.420 \\
18.640 \\
19.893 \\
21.177 \\
2 ? .493\end{array}$ & $\begin{array}{l}13.355 \\
14.527 \\
15.738 \\
16.988 \\
18.276 \\
19.601 \\
20.963 \\
22.361 \\
23.794 \\
25.262\end{array}$ & $\begin{array}{l}16.548 \\
17.976 \\
19.452 \\
20.973 \\
22.539 \\
24.150 \\
25.803 \\
27.499 \\
29.236 \\
31.015\end{array}$ \\
\hline $\begin{array}{l}150.0 \\
155.0 \\
160.0 \\
165.0 \\
170.0 \\
175.0 \\
180.0 \\
185.0 \\
190.0 \\
195.0\end{array}$ & $\begin{array}{l}19.322 \\
20.462 \\
21.627 \\
22.817 \\
24.032 \\
25.272 \\
26.536 \\
27.923 \\
29.133 \\
30.466\end{array}$ & $\begin{array}{l}17.622 \\
18.659 \\
19.720 \\
20.803 \\
21.909 \\
23.037 \\
24.186 \\
25.357 \\
26.549 \\
27.761\end{array}$ & $\begin{array}{l}15.527 \\
16.442 \\
17.378 \\
18.334 \\
19.309 \\
20.304 \\
21.319 \\
22.352 \\
23.404 \\
24.474\end{array}$ & $\begin{array}{l}20.315 \\
21.500 \\
22.712 \\
23.950 \\
25.212 \\
26.500 \\
27.812 \\
29.147 \\
30.507 \\
31.889\end{array}$ & $\begin{array}{l}23.840 \\
25.217 \\
26.623 \\
28.059 \\
29.524 \\
31.017 \\
32.538 \\
34.086 \\
35.661 \\
37.262\end{array}$ & $\begin{array}{l}26.763 \\
28.298 \\
29.865 \\
31.464 \\
33.095 \\
34.757 \\
36.449 \\
38.171 \\
39.922 \\
41.702\end{array}$ & $\begin{array}{l}32.833 \\
34.691 \\
36.587 \\
38.521 \\
40.492 \\
42.500 \\
44.544 \\
46.622 \\
48.735 \\
50.882\end{array}$ \\
\hline $\begin{array}{l}200.0 \\
205.0 \\
210.0 \\
215.0 \\
220.0 \\
225.0 \\
230.0 \\
235.0 \\
240.0 \\
245.0\end{array}$ & $\begin{array}{l}31.821 \\
33.199 \\
34.598 \\
36.018 \\
37.460 \\
38.922 \\
40.404 \\
41.907 \\
43.429 \\
44.971\end{array}$ & $\begin{array}{l}28.994 \\
30.247 \\
31.519 \\
32.811 \\
34.122 \\
35.451 \\
36.799 \\
38.165 \\
39.549 \\
40.951\end{array}$ & $\begin{array}{l}25.562 \\
26.668 \\
27.791 \\
28.932 \\
30.089 \\
31.262 \\
32.452 \\
33.659 \\
34.880 \\
36.118\end{array}$ & $\begin{array}{l}33.294 \\
34.722 \\
36.171 \\
37.643 \\
39.135 \\
40.649 \\
42.183 \\
43.737 \\
45.312 \\
46.906\end{array}$ & $\begin{array}{l}38.888 \\
40.541 \\
42.218 \\
43.920 \\
45.646 \\
47.396 \\
49.169 \\
50.965 \\
52.784 \\
54.625\end{array}$ & $\begin{array}{l}43.510 \\
45.346 \\
47.210 \\
49.100 \\
51.018 \\
52.961 \\
54.930 \\
56.924 \\
58.943 \\
60.987\end{array}$ & $\begin{array}{l}53.063 \\
55.276 \\
57.521 \\
59.798 \\
62.106 \\
64.444 \\
66.813 \\
69.211 \\
71.638 \\
74.094\end{array}$ \\
\hline $\begin{array}{l}250.0 \\
255.0 \\
260.0 \\
265.0 \\
270.0 \\
275.0 \\
280.0 \\
285.0 \\
290.0 \\
295.0\end{array}$ & $\begin{array}{l}46.531 \\
48.111 \\
49.709 \\
51.325 \\
52.960 \\
54.612 \\
56.282 \\
57.968 \\
59.672 \\
61.392\end{array}$ & $\begin{array}{l}42.370 \\
43.806 \\
45.258 \\
46.727 \\
48.213 \\
49.714 \\
51.232 \\
52.765 \\
54.313 \\
55.876\end{array}$ & $\begin{array}{l}37.371 \\
38.639 \\
39.921 \\
41.219 \\
42.531 \\
43.857 \\
45.197 \\
46.551 \\
47.918 \\
49.299\end{array}$ & $\begin{array}{l}48.520 \\
50.152 \\
51.804 \\
53.473 \\
55.161 \\
56.867 \\
58.591 \\
60.332 \\
62.090 \\
63.865\end{array}$ & $\begin{array}{l}56.489 \\
58.373 \\
60.279 \\
62.206 \\
64.154 \\
66.121 \\
68.109 \\
70.116 \\
72.143 \\
74.188\end{array}$ & $\begin{array}{l}63.054 \\
65.145 \\
67.260 \\
69.397 \\
71.557 \\
73.739 \\
75.943 \\
78.169 \\
80.416 \\
82.683\end{array}$ & $\begin{array}{r}76.578 \\
79.090 \\
81.630 \\
84.196 \\
86.789 \\
89.408 \\
92.052 \\
94.722 \\
97.416 \\
100.135\end{array}$ \\
\hline $\begin{array}{l}300.0 \\
310.0 \\
320.0 \\
330.0 \\
340.0 \\
350.0 \\
360.0 \\
370.0\end{array}$ & $\begin{array}{l}63.129 \\
66.651 \\
70.236 \\
73.883 \\
77.588 \\
81.352 \\
85.171 \\
89.045\end{array}$ & $\begin{array}{l}57.455 \\
60.655 \\
63.912 \\
67.225 \\
70.591 \\
74.010 \\
77.479 \\
80.998\end{array}$ & $\begin{array}{l}50.693 \\
53.520 \\
56.397 \\
59.323 \\
62.297 \\
65.318 \\
68.383 \\
71.492\end{array}$ & $\begin{array}{l}65.657 \\
69.289 \\
72.984 \\
76.741 \\
80.558 \\
84.434 \\
89.365 \\
92.352\end{array}$ & $\begin{array}{r}76.253 \\
80.437 \\
84.692 \\
89.017 \\
93.410 \\
97.868 \\
102.389 \\
106.973\end{array}$ & $\begin{array}{r}84.971 \\
89.608 \\
94.322 \\
99.113 \\
103.978 \\
108.914 \\
113.920 \\
118.993\end{array}$ & $\begin{array}{l}102.877 \\
108.434 \\
114.081 \\
119.818 \\
125.641 \\
131.548 \\
137.535 \\
143.601\end{array}$ \\
\hline $\begin{array}{l}380.0 \\
390.0\end{array}$ & $\begin{array}{l}92.972 \\
96.951\end{array}$ & $\begin{array}{l}84.565 \\
88.178\end{array}$ & $\begin{array}{l}74.644 \\
77.836\end{array}$ & $\begin{array}{r}96.392 \\
100.484\end{array}$ & $\begin{array}{l}111.616 \\
116.317\end{array}$ & $\begin{array}{l}124.131 \\
129.333\end{array}$ & $\begin{array}{l}149.744 \\
155.960\end{array}$ \\
\hline
\end{tabular}


Table IV. Continued.

\begin{tabular}{|c|c|c|c|c|c|c|c|}
\hline & & & & $\mathrm{R}$ & & & \\
\hline $\mathrm{T}(\mathrm{MeV})$ & $\mathrm{Be}$ & Graphite & Water & $\mathrm{Al}$ & $\mathrm{Cu}$ & $\mathrm{Ag}$ & $\mathrm{Pb}$ \\
\hline $\begin{array}{l}400.0 \\
410.0 \\
420.0 \\
430.0 \\
440.0 \\
450.0 \\
460.0 \\
470.0 \\
480.0 \\
490.0\end{array}$ & $\begin{array}{l}100.980 \\
105.058 \\
109.183 \\
113.355 \\
117.572 \\
121.832 \\
126.136 \\
130.481 \\
134.866 \\
139.291\end{array}$ & $\begin{array}{r}91.837 \\
95.540 \\
99.286 \\
103.074 \\
106.902 \\
110.770 \\
114.677 \\
118.621 \\
122.602 \\
126.619\end{array}$ & $\begin{array}{r}81.070 \\
84.342 \\
87.653 \\
91.000 \\
94.384 \\
97.803 \\
101.256 \\
104.742 \\
108.261 \\
111.812\end{array}$ & $\begin{array}{l}104.626 \\
108.818 \\
113.057 \\
117.342 \\
121.673 \\
126.048 \\
130.465 \\
134.924 \\
139.423 \\
143.962\end{array}$ & $\begin{array}{l}121.075 \\
125.889 \\
130.756 \\
135.675 \\
140.644 \\
145.663 \\
150.731 \\
155.844 \\
161.003 \\
166.207\end{array}$ & $\begin{array}{l}134.597 \\
139.921 \\
145.304 \\
150.743 \\
156.237 \\
161.785 \\
167.384 \\
173.035 \\
178.734 \\
184.482\end{array}$ & $\begin{array}{l}162.249 \\
168.607 \\
175.033 \\
181.525 \\
188.081 \\
194.699 \\
201.378 \\
208.115 \\
214.909 \\
221.758\end{array}$ \\
\hline $\begin{array}{l}500.0 \\
510.0 \\
520.0 \\
530.0 \\
540.0 \\
550.0 \\
560.0 \\
570.0 \\
580.0 \\
590.0\end{array}$ & $\begin{array}{l}143.754 \\
148.255 \\
152.792 \\
157.365 \\
161.972 \\
166.614 \\
171.288 \\
175.994 \\
180.732 \\
185.501\end{array}$ & $\begin{array}{l}130.670 \\
134.755 \\
138.873 \\
143.023 \\
147.205 \\
151.417 \\
155.658 \\
159.929 \\
164.228 \\
168.555\end{array}$ & $\begin{array}{l}115.393 \\
119.005 \\
122.645 \\
126.314 \\
130.011 \\
133.735 \\
137.486 \\
141.262 \\
145.063 \\
148.889\end{array}$ & $\begin{array}{l}148.539 \\
153.154 \\
157.805 \\
162.492 \\
167.213 \\
171.967 \\
176.755 \\
181.574 \\
186.425 \\
191.306\end{array}$ & $\begin{array}{l}171.453 \\
176.741 \\
182.070 \\
187.439 \\
192.846 \\
198.291 \\
203.773 \\
209.290 \\
214.842 \\
220.428\end{array}$ & $\begin{array}{l}190.276 \\
196.115 \\
201.999 \\
207.925 \\
213.893 \\
219.902 \\
225.951 \\
232.038 \\
238.162 \\
244.323\end{array}$ & $\begin{array}{l}228.662 \\
235.618 \\
242.624 \\
249.681 \\
256.785 \\
263.937 \\
271.134 \\
278.375 \\
285.660 \\
292.987\end{array}$ \\
\hline $\begin{array}{l}600.0 \\
610.0 \\
620.0 \\
630.0 \\
640.0 \\
650.0 \\
660.0 \\
670.0 \\
680.0 \\
690.0\end{array}$ & $\begin{array}{l}190.299 \\
195.126 \\
199.982 \\
204.865 \\
209.775 \\
214.712 \\
219.675 \\
224.062 \\
229.675 \\
234.711\end{array}$ & $\begin{array}{l}172.908 \\
177.288 \\
181.693 \\
186.124 \\
190.579 \\
195.057 \\
199.559 \\
204.083 \\
208.630 \\
213.198\end{array}$ & $\begin{array}{l}152.739 \\
156.612 \\
160.508 \\
164.426 \\
168.365 \\
172.326 \\
176.308 \\
180.309 \\
184.330 \\
188.371\end{array}$ & $\begin{array}{l}196.216 \\
201.156 \\
206.124 \\
211.119 \\
216.140 \\
221.188 \\
226.262 \\
231.360 \\
236.482 \\
241.628\end{array}$ & $\begin{array}{l}226.047 \\
2 \Xi 1.097 \\
237.380 \\
243.093 \\
248.035 \\
254.007 \\
260.406 \\
266.234 \\
272.088 \\
277.968\end{array}$ & $\begin{array}{l}250.520 \\
256.751 \\
263.017 \\
269.315 \\
275.645 \\
282.006 \\
288.397 \\
294.819 \\
301.269 \\
307.747\end{array}$ & $\begin{array}{l}300.355 \\
307.763 \\
315.211 \\
322.696 \\
330.218 \\
337.776 \\
345.369 \\
352.996 \\
360.657 \\
368.349\end{array}$ \\
\hline $\begin{array}{l}700.0 \\
710.0 \\
720.0 \\
730.0 \\
740.0 \\
750.0 \\
760.0 \\
770.0 \\
780.0 \\
790.0\end{array}$ & $\begin{array}{l}239.770 \\
244.853 \\
249.957 \\
255.084 \\
260.231 \\
265.400 \\
270.589 \\
275.797 \\
281.025 \\
286.272\end{array}$ & $\begin{array}{l}217.787 \\
222.396 \\
227.026 \\
231.676 \\
236.344 \\
241.031 \\
245.737 \\
250.460 \\
255.201 \\
259.959\end{array}$ & $\begin{array}{l}192.430 \\
196.507 \\
200.603 \\
204.715 \\
208.845 \\
212.991 \\
217.154 \\
221.332 \\
225.526 \\
229.736\end{array}$ & $\begin{array}{l}246.797 \\
251.989 \\
257.202 \\
262.437 \\
267.693 \\
272.969 \\
278.265 \\
283.581 \\
288.916 \\
294.269\end{array}$ & $\begin{array}{l}283.874 \\
289.805 \\
295.760 \\
301.739 \\
307.741 \\
313.765 \\
319.812 \\
325.880 \\
331.968 \\
338.078\end{array}$ & $\begin{array}{l}314.253 \\
320.785 \\
327.344 \\
333.928 \\
340.537 \\
347.170 \\
353.827 \\
360.507 \\
367.209 \\
373.933\end{array}$ & $\begin{array}{l}376.074 \\
383.829 \\
391.614 \\
399.428 \\
407.270 \\
415.140 \\
423.037 \\
430.960 \\
438.909 \\
446.882\end{array}$ \\
\hline $\begin{array}{l}800.0 \\
810.0 \\
820.0 \\
830.0 \\
840.0 \\
850.0 \\
860.0 \\
870.0 \\
880.0 \\
890.0\end{array}$ & $\begin{array}{l}291.337 \\
296.821 \\
302.122 \\
307.440 \\
312.775 \\
318.127 \\
323.494 \\
328.878 \\
334.276 \\
339.690\end{array}$ & $\begin{array}{l}264.733 \\
269.524 \\
274.330 \\
279.152 \\
283.989 \\
288.841 \\
293.708 \\
298.588 \\
303.483 \\
308.391\end{array}$ & $\begin{array}{l}233.960 \\
238.198 \\
242.451 \\
246.717 \\
250.997 \\
255.290 \\
259.596 \\
263.914 \\
268.245 \\
272.588\end{array}$ & $\begin{array}{l}299.640 \\
305.029 \\
310.435 \\
315.858 \\
321.297 \\
326.752 \\
332.223 \\
337.710 \\
343.211 \\
348.727\end{array}$ & $\begin{array}{l}344 \cdot 207 \\
350.355 \\
356.523 \\
362.709 \\
368.913 \\
37.5 \cdot 134 \\
381.373 \\
387.628 \\
393.900 \\
400.188\end{array}$ & $\begin{array}{l}380.679 \\
387.445 \\
394.232 \\
401.039 \\
407.864 \\
414.709 \\
421.572 \\
428.454 \\
435.352 \\
442.268\end{array}$ & $\begin{array}{l}454.880 \\
462.902 \\
470.946 \\
479.013 \\
487.102 \\
495.212 \\
503.343 \\
511.494 \\
519.665 \\
527.855\end{array}$ \\
\hline $\begin{array}{l}900.0 \\
910.0 \\
920.0 \\
930.0 \\
940.0 \\
950.0 \\
960.0 \\
970.0 \\
980.0 \\
990.0 \\
000.0\end{array}$ & $\begin{array}{l}345.119 \\
350.562 \\
356.019 \\
361.489 \\
366.973 \\
372.470 \\
377.981 \\
383.503 \\
389.038 \\
394.585 \\
400.143\end{array}$ & $\begin{array}{l}313.312 \\
318.246 \\
323.193 \\
328.151 \\
333.123 \\
338.105 \\
343.100 \\
348.105 \\
353.122 \\
358.149 \\
363.187\end{array}$ & $\begin{array}{l}276.943 \\
281.309 \\
285.686 \\
290.075 \\
294.474 \\
298.883 \\
303.303 \\
307.733 \\
312.173 \\
316.622 \\
321.081\end{array}$ & $\begin{array}{l}354.257 \\
359.802 \\
365.359 \\
370.930 \\
376.514 \\
382.111 \\
387.720 \\
393.341 \\
398.974 \\
404.619 \\
410.275\end{array}$ & $\begin{array}{l}406.492 \\
412.810 \\
419.144 \\
425.492 \\
431.854 \\
438.230 . \\
444.619 \\
451.022 \\
457.437 \\
463.865 \\
470.305\end{array}$ & $\begin{array}{l}449.200 \\
456.149 \\
463.113 \\
470.093 \\
477.088 \\
484.098 \\
491.122 \\
498.160 \\
505.211 \\
512.276 \\
519.354\end{array}$ & $\begin{array}{l}536.064 \\
544.291 \\
552.536 \\
560.798 \\
569.077 \\
577.373 \\
585.684 \\
594.012 \\
602.354 \\
610.711 \\
619.083\end{array}$ \\
\hline
\end{tabular}


Table V. Properties of charged particles (BB69, TP69,MT65. Flectron masses to be divided by 1000).

\begin{tabular}{|c|c|c|c|c|c|c|c|}
\hline \multirow[t]{2}{*}{ } & \multirow[t]{2}{*}{2} & \multirow{2}{*}{$\begin{array}{l}\text { Lifetime } \\
\text { nano sec }\end{array}$} & \multirow{2}{*}{$\begin{array}{l}\text { Charge } \\
10^{-19} \mathrm{C}\end{array}$} & \multicolumn{3}{|c|}{ Mass } & \multirow[t]{2}{*}{$\mathrm{m}_{\mathrm{n}}$} \\
\hline & & & & $10^{-24} \mathrm{~B}$ & $\mathrm{amu}$ & $\mathrm{MeV}$ & \\
\hline $\begin{array}{l}\text { LECTROA } \\
\text { MUON } \\
\text { PION } \\
\text { KAON } \\
\text { SIGMA+ } \\
\text { SIGMA- }\end{array}$ & $\begin{array}{l}1 \\
1 \\
1 \\
1 \\
1 \\
1\end{array}$ & $\begin{array}{l}\text { STABLE } \\
2198.3 \\
26.04 \\
12.35 \\
0.081 \\
0.164\end{array}$ & $\begin{array}{l} \pm 1.60219 \\
\pm 1.60219 \\
\pm 1.60219 \\
\pm 1.60219 \\
+1.60219 \\
-1.60219\end{array}$ & $\begin{array}{l}0.910956 \\
0.188357 \\
0.248823 \\
0.880322 \\
2.120318 \\
2.134436\end{array}$ & $\begin{array}{l}0.548593 \\
0.113432 \\
0.149846 \\
0.530147 \\
1.276895 \\
1.285398\end{array}$ & $\begin{array}{r}511.004 \\
105.6598 \\
139.578 \\
493.82 \\
1189.40 \\
1197.32\end{array}$ & $\begin{array}{l}0.544630 \\
0.112613 \\
0.148763 \\
0.526317 \\
1.267671 \\
1.276112\end{array}$ \\
\hline & & $\begin{array}{l}\text { Ass exc } \\
\mathrm{MeV}\end{array}$ & & & & & \\
\hline $\begin{array}{l}1 \mathrm{~N} \\
1 \mathrm{H} \\
2 \mathrm{H} \\
3 \mathrm{H} \\
3 \mathrm{HE} \\
4 \mathrm{HE} \\
6 \mathrm{LL} \\
7 \mathrm{~L} 1 \\
7 \mathrm{BE} \\
9 \mathrm{BE} \\
10 \mathrm{~B} \\
11 \mathrm{~B}\end{array}$ & $\begin{array}{l}0 \\
1 \\
1 \\
1 \\
2 \\
2 \\
3 \\
3 \\
4 \\
4 \\
5 \\
5\end{array}$ & $\begin{array}{r}8.0714 \\
7.2890 \\
13.1359 \\
14.9500 \\
14.9313 \\
2.4248 \\
14.0854 \\
14.9073 \\
15.7689 \\
11.3505 \\
12.0522 \\
8.6677\end{array}$ & $\begin{array}{l}0 . \\
1.60219 \\
1.60219 \\
1.60219 \\
3.20438 \\
3.20438 \\
4.80658 \\
4.80658 \\
6.40877 \\
6.40877 \\
8.01096 \\
8.01096\end{array}$ & $\begin{array}{r}1.674920 \\
1.672614 \\
3.343569 \\
5.007334 \\
5.006390 \\
6.644626 \\
9.985570 \\
11.647561 \\
11.648186 \\
14.961372 \\
16.622243 \\
18.276741\end{array}$ & $\begin{array}{l}1.0086652 \\
1.0072766 \\
2.0135536 \\
3.0155011 \\
3.0149325 \\
4.0015059 \\
6.0134789 \\
7.0143591 \\
7.0147245 \\
9.0099911 \\
0.0101958 \\
10006503\end{array}$ & $\begin{array}{r}939.553 \\
938.259 \\
1875.587 \\
2808.883 \\
2808.353 \\
3727.328 \\
5601.443 \\
6533.743 \\
6534.093 \\
8392.637 \\
9324.309 \\
10252.406\end{array}$ & $\begin{array}{l}1.0013786 \\
1.0000000 \\
1.9990076 \\
2.9937170 \\
2.9931526 \\
3.9725990 \\
5.9700375 \\
6.9636862 \\
6.9640599 \\
8.9449027 \\
9.9378820 \\
0.9270507\end{array}$ \\
\hline $\begin{array}{l}12 C \\
13 C \\
14 \mathrm{C} \\
14 \mathrm{~N} \\
15 \mathrm{~N} \\
160 \\
170 \\
180 \\
19 \mathrm{~F} \\
20 \mathrm{NE} \\
21 \mathrm{NE} \\
22 \mathrm{NE}\end{array}$ & $\begin{array}{r}6 \\
6 \\
6 \\
7 \\
7 \\
8 \\
8 \\
8 \\
9 \\
10 \\
10 \\
10\end{array}$ & $\begin{array}{r}0 . \\
3.1246 \\
3.0198 \\
2.8637 \\
.1004 \\
-4.7365 \\
-.8077 \\
-.7824 \\
-1.4860 \\
-7.0415 \\
-5.7299 \\
-8.0249\end{array}$ & $\begin{array}{l}315 \\
315 \\
115 \\
534 \\
534 \\
753 \\
753 \\
753 \\
973 \\
192 \\
192 \\
192\end{array}$ & $\begin{array}{l}0 \\
1 \\
6 \\
6 \\
1 \\
9 \\
4 \\
1 \\
7 \\
3 \\
3 \\
3\end{array}$ & $\begin{array}{l}9 \\
4 \\
2 \\
6 \\
3 \\
1 \\
3 \\
4 \\
6 \\
7 \\
9\end{array}$ & $\begin{array}{l}08 \\
14 \\
91 \\
24 \\
41 \\
75 \\
85 \\
91 \\
58 \\
72 \\
65 \\
51\end{array}$ & $\begin{array}{l}981502 \\
98145 \\
981035 \\
879343 \\
750105 \\
719738 \\
547767 \\
562582 \\
\$ 25685 \\
367424 \\
270724\end{array}$ \\
\hline $\begin{array}{l}23 N A \\
24 M G \\
25 M G \\
26 M G \\
27 A L \\
285 I \\
295 I \\
30 S I \\
31 P\end{array}$ & $\begin{array}{l}11 \\
12 \\
12 \\
12 \\
13 \\
14 \\
14 \\
14 \\
15\end{array}$ & $\begin{array}{l}-9.5283 \\
13.9333 \\
13.1907 \\
16.2142 \\
17.1961 \\
21.4899 \\
21.8936 \\
24.4394 \\
24.4376\end{array}$ & $\begin{array}{l}411 \\
630 \\
630 \\
630 \\
849 \\
068 \\
068 \\
068 \\
288\end{array}$ & $\begin{array}{l}1 \\
6 \\
7 \\
7 \\
3 \\
5 \\
7\end{array}$ & $\begin{array}{l}3 \\
7 \\
9 \\
0 \\
3\end{array}$ & $\begin{array}{l}23 \\
24 \\
25 \\
26 \\
26 \\
27 \\
28\end{array}$ & $\begin{array}{l}8177014 \\
8052379 \\
7988053 \\
7883589 \\
7795437 \\
7671987 \\
7593444 \\
7496071 \\
7418404\end{array}$ \\
\hline $\begin{array}{l}32 S \\
335 \\
34 S \\
36 S \\
35 C L \\
37 C L \\
36 A R \\
38 A R \\
40 A R \\
39 K \\
40 K \\
40 C A\end{array}$ & $\begin{array}{l}16 \\
16 \\
16 \\
16 \\
17 \\
17 \\
18 \\
18 \\
18 \\
19 \\
19 \\
20\end{array}$ & $\begin{array}{l}26.012 \\
26.5826 \\
29.9335 \\
30.6550 \\
29.0145 \\
31.7648 \\
30.2316 \\
34.7182 \\
35.0383 \\
33.8033 \\
33.5333 \\
34.8476\end{array}$ & $\begin{array}{l}25.63507 \\
25.63507 \\
25.63507 \\
27.23726 \\
27.23726 \\
28.83945 \\
28.83945 \\
28.83945 \\
30.44164 \\
30.44164 \\
32.04383\end{array}$ & $\begin{array}{l}735569 \\
390126 \\
709903 \\
051385 \\
367545 \\
708836 \\
021900 \\
342392 \\
683151 \\
344164 \\
340910\end{array}$ & $\begin{array}{l}32.9626845 \\
33.9590871 \\
35.9583126 \\
34.9595251 \\
36.9565725 \\
35.9576699 \\
37.9528533 \\
39.9525096 \\
38.9532869 \\
39.9535768 \\
39.9516172\end{array}$ & $\begin{array}{l}30704.121 \\
31632.251 \\
33494.492 \\
32564.140 \\
34424.353 \\
33493.894 \\
35352.369 \\
37215.012 \\
36284.294 \\
37216.006 \\
37214.180\end{array}$ & $\begin{array}{l}2.7245615 \\
3.7137661 \\
15.6985491 \\
4.7069770 \\
6.6895976 \\
5.6979111 \\
7.6786813 \\
9.6638921 \\
8.6718877 \\
9.6649515 \\
9.6630060\end{array}$ \\
\hline
\end{tabular}


Table VI. B of Moliere's theory for $z=1,2$ and 6 , variable $\beta$ and thickness s. For any value of $z$ at $\beta=0, B$ is the same as for $z=1$. The theory is valid only for $B$ 4.5. Linear interpolation for $Z$ or $\beta^{2}$ will give sufficient accuracy. Logarithmic interpolation is required for $\mathbf{s}$.

\begin{tabular}{|c|c|c|c|c|c|c|c|c|c|c|c|c|c|c|}
\hline \multirow[t]{2}{*}{ Z } & \multicolumn{10}{|c|}{$\mathrm{z}=1$} & \multicolumn{2}{|c|}{$z=2$} & \multicolumn{2}{|c|}{$z=6$} \\
\hline & $\mathrm{g} / \mathrm{cm}^{2}$ & $\beta^{2}=0$ & 0.005 & 0.01 & 0.02 & 0.05 & 0.1 & 0.2 & 0.5 & 1.0 & 0.1 & 1.0 & 0.1 & 1.0 \\
\hline 3 & $\begin{array}{c}10^{-3} \\
10^{-2} \\
10^{-1} \\
1\end{array}$ & $\begin{array}{l}10.5 \\
13.0 \\
15.4 \\
17.9\end{array}$ & $\begin{array}{r}8.8 \\
11.5 \\
14.0 \\
16.4\end{array}$ & $\begin{array}{r}8.3 \\
10.8 \\
13.3 \\
15.8\end{array}$ & $\begin{array}{r}7.6 \\
10.2 \\
12.8 \\
15.2\end{array}$ & $\begin{array}{r}6.6 \\
9.2 \\
11.7 \\
14.2\end{array}$ & $\begin{array}{r}5.7 \\
8.5 \\
11.0 \\
13.5\end{array}$ & $\begin{array}{r}4.9 \\
7.7 \\
10.3 \\
12.8\end{array}$ & $\begin{array}{r}3.8 \\
6.6 \\
9.2 \\
11.8\end{array}$ & $\begin{array}{r}2.8 \\
5.7 \\
8.5 \\
11.0\end{array}$ & $\begin{array}{r}7.4 \\
10.0 \\
12.5 \\
14.9\end{array}$ & $\begin{array}{r}4.6 \\
7.4 \\
10.0 \\
12.6\end{array}$ & $\begin{array}{l}- \\
- \\
-\end{array}$ & $\begin{array}{l}- \\
- \\
-\end{array}$ \\
\hline 10 & $\begin{array}{c}10^{-3} \\
10^{-2} \\
10^{-1} \\
1\end{array}$ & $\begin{array}{r}8.2 \\
10.7 \\
13.3 \\
15.7\end{array}$ & $\begin{array}{r}8.0 \\
10.5 \\
13.0 \\
15.4\end{array}$ & $\begin{array}{r}7.7 \\
10.3 \\
12.8 \\
15.2\end{array}$ & $\begin{array}{r}7.4 \\
9.9 \\
12.4 \\
14.8\end{array}$ & $\begin{array}{c}6.7 \\
9.25 \\
11.8 \\
14.3\end{array}$ & $\begin{array}{r}6.0 \\
8.7 \\
11.2 \\
13.7\end{array}$ & $\begin{array}{r}5.2 \\
8.0 \\
10.5 \\
13.1\end{array}$ & $\begin{array}{r}4.2 \\
7.0 \\
9.6 \\
12.1\end{array}$ & $\begin{array}{r}3.2 \\
6.2 \\
8.8 \\
11.4\end{array}$ & $\begin{array}{r}7.2 \\
9.8 \\
12.3 \\
14.8\end{array}$ & $\begin{array}{r}4.9 \\
7.7 \\
10.3 \\
12.8\end{array}$ & $\begin{array}{r}8.1 \\
10.6 \\
1311 \\
15.5\end{array}$ & $\begin{array}{r}7.2 \\
9.7 \\
12.3 \\
14.7\end{array}$ \\
\hline 20 & $\begin{array}{c}10^{-3} \\
10^{-2} \\
10^{-1} \\
1\end{array}$ & $\begin{array}{r}6.8 \\
9.4 \\
12.0 \\
14.4\end{array}$ & $\begin{array}{r}6.7 \\
9.3 \\
11.9 \\
14.4\end{array}$ & $\begin{array}{r}6.6 \\
9.3 \\
11.8 \\
14.3\end{array}$ & $\begin{array}{r}6.5 \\
9.2 \\
11.7 \\
14.2\end{array}$ & $\begin{array}{r}6.2 \\
8.9 \\
11.4 \\
13.9\end{array}$ & $\begin{array}{r}5.8 \\
8.5 \\
11.0 \\
13.5\end{array}$ & $\begin{array}{r}5.2 \\
7.9 \\
10.5 \\
13.1\end{array}$ & $\begin{array}{r}4.2 \\
7.1 \\
9.7 \\
12.2\end{array}$ & $\begin{array}{r}3.5 \\
6.4 \\
9.0 \\
11.5\end{array}$ & $\begin{array}{r}6.5 \\
9.2 \\
11.7 \\
14.2\end{array}$ & $\begin{array}{r}5.0 \\
7.8 \\
10.3 \\
12.8\end{array}$ & $\begin{array}{r}6.8 \\
9.4 \\
11.9 \\
14.4\end{array}$ & $\begin{array}{r}6.4 \\
9.1 \\
11.6 \\
14.2\end{array}$ \\
\hline 50 & $\begin{array}{l}10^{-3} \\
10^{-2} \\
10^{-3} \\
1\end{array}$ & $\begin{array}{r}4.7 \\
7.5 \\
10.0 \\
12.5\end{array}$ & $\begin{array}{r}4.7 \\
7.5 \\
10.0 \\
12.5\end{array}$ & $\begin{array}{r}4.7 \\
7.5 \\
10.0 \\
12.5\end{array}$ & $\begin{array}{r}4.6 \\
7.4 \\
10.0 \\
12.5\end{array}$ & $\begin{array}{r}4.6 \\
7.4 \\
10.0 \\
12.5\end{array}$ & $\begin{array}{r}4.5 \\
7.3 \\
9.9 \\
12.4\end{array}$ & $\begin{array}{r}4.3 \\
7.2 \\
9.7 \\
12.2\end{array}$ & $\begin{array}{r}3.7 \\
6.6 \\
9.2 \\
11.8\end{array}$ & $\begin{array}{r}3.2 \\
6.0 \\
8.8 \\
11.3\end{array}$ & $\begin{array}{r}4.6 \\
7.5 \\
10.0 \\
12.6\end{array}$ & $\begin{array}{r}4.1 \\
7.0 \\
9.6 \\
12.1\end{array}$ & $\begin{array}{r}4.7 \\
7.5 \\
10.1 \\
12.5\end{array}$ & $\begin{array}{r}4.6 \\
7.4 \\
10.0 \\
12.5\end{array}$ \\
\hline 100 & $\begin{array}{c}10^{-3} \\
10^{-2} \\
10^{-1} \\
1\end{array}$ & $\begin{array}{r}3.1 \\
6.0 \\
8.7 \\
11.2\end{array}$ & $\begin{array}{r}3.1 \\
6.0 \\
8.7 \\
11.2\end{array}$ & $\begin{array}{r}3.1 \\
-6.0 \\
8.7 \\
11.2\end{array}$ & $\begin{array}{r}3.1 \\
6.0 \\
8.7 \\
11.2\end{array}$ & $\begin{array}{r}3.0 \\
6.0 \\
8.7 \\
11.2\end{array}$ & $\begin{array}{r}3.0 \\
5.9 \\
8.6 \\
11.1\end{array}$ & $\begin{array}{r}3.0 \\
5.9 \\
8.6 \\
11.1\end{array}$ & $\begin{array}{r}2.8 \\
5.7 \\
8.4 \\
10.9\end{array}$ & $\begin{array}{r}2.5 \\
5.4 \\
8.2 \\
10.7\end{array}$ & $\begin{array}{r}3.1 \\
6.0 \\
8.7 \\
11.2\end{array}$ & $\begin{array}{r}2.9 \\
5.8 \\
8.5 \\
11.0\end{array}$ & $\begin{array}{r}3.1 \\
6.0 \\
8.7 \\
11.2\end{array}$ & $\begin{array}{r}3.1 \\
6.0 \\
8.7 \\
11.2\end{array}$ \\
\hline
\end{tabular}


TABLE VII. MULTIPLE SCATTERING DIFFERENTIAL DISTRIBUTION FUNCTION F(X) (FROM MZ67).

\begin{tabular}{|c|c|c|c|c|c|c|c|c|}
\hline$B=$ & 4 & 5 & 6 & 7 & 8 & 9 & 10 & 12 \\
\hline $\begin{array}{l}0 \\
.2 \\
.4 \\
.6 \\
.8 \\
1.0 \\
1.2 \\
1.4 \\
1.6 \\
1.8 \\
2.0\end{array}$ & $\begin{array}{r}1.0 \\
.94070 \\
.78389 \\
.58102 \\
.38726 \\
.23800 \\
.14139 \\
.08650 \\
.05666 \\
.03899 \\
.02685\end{array}$ & $\begin{array}{r}1.0 \\
.94546 \\
.79992 \\
.60800 \\
.41889 \\
.26632 \\
.16116 \\
.09681 \\
.05986 \\
.03840 \\
.02506\end{array}$ & $\begin{array}{c}1.0 \\
.94850 \\
.81017 \\
.62535 \\
.43939 \\
.28491 \\
.17437 \\
.10393 \\
.06226 \\
.03816 \\
.02387\end{array}$ & $\begin{array}{c}1.0 \\
.95058 \\
.81721 \\
.63731 \\
.45,363 \\
.29793 \\
.18377 \\
.10911 \\
.06410 \\
.03807 \\
.02303\end{array}$ & $\begin{array}{c}1.0 \\
.95208 \\
.82232 \\
.64601 \\
.46402 \\
.30752 \\
.19077 \\
.11304 \\
.06556 \\
.03805 \\
.02240\end{array}$ & $\begin{array}{c}1.0 \\
.95321 \\
.82616 \\
.65259 \\
.47192 \\
.31486 \\
.19616 \\
.11612 \\
.06673 \\
.03806 \\
.02192\end{array}$ & $\begin{array}{c}1.0 \\
.95409 \\
.82916 \\
.65772 \\
.47811 \\
.32063 \\
.20045 \\
.11859 \\
.06769 \\
.03809 \\
.02154\end{array}$ & $\begin{array}{c}1.0 \\
.95537 \\
.83351 \\
.66520 \\
.48716 \\
.32913 \\
.20681 \\
.12231 \\
.06918 \\
.03817 \\
.02097\end{array}$ \\
\hline $\begin{array}{l}2.2 \\
2.4 \\
2.6 \\
2.8 \\
3.0 \\
3.2 \\
3.4 \\
3.6 \\
3.8 \\
4.0\end{array}$ & $\begin{array}{l}.01793 \\
.01164 \\
.00799 \\
.00549 \\
.00397 \\
.00300 \\
.00232 \\
.00182 \\
.00145 \\
.00115\end{array}$ & $\begin{array}{l}.01628 \\
.01048 \\
.00716 \\
.00489 \\
.00349 \\
.00259 \\
.00198 \\
.00154 \\
.00121 \\
.00096\end{array}$ & $\begin{array}{l}.01507 \\
.00956 \\
.00646 \\
.00438 \\
.00310 \\
.00227 \\
.00171 \\
.00137 \\
.00103 \\
.0008 ?\end{array}$ & $\begin{array}{l}.01416 \\
.00883 \\
.00589 \\
.00396 \\
.00277 \\
.00202 \\
.00151 \\
.00116 \\
.00090 \\
.00071\end{array}$ & $\begin{array}{l}.01345 \\
.00824 \\
.00543 \\
.00361 \\
.00251 \\
.00181 \\
.00135 \\
.00103 \\
.00080 \\
.00063\end{array}$ & $\begin{array}{r}.01288 \\
.00775 \\
.00504 \\
.00332 \\
.00229 \\
.00164 \\
.00122 \\
.00093 \\
.00072 \\
.00056\end{array}$ & $\begin{array}{l}.01241 \\
.00735 \\
.00471 \\
.00308 \\
.00211 \\
.00150 \\
.00111 \\
.00084 \\
.00065 \\
.00051\end{array}$ & $\begin{array}{l}.01170 \\
.00673 \\
.00419 \\
.00269 \\
.00182 \\
.00128 \\
.00094 \\
.00071\end{array}$ \\
\hline $\begin{array}{l}4.2 \\
4.4 \\
4.6 \\
4.8 \\
5.0 \\
5.2 \\
5.4 \\
5.6 \\
5.0 \\
6.0\end{array}$ & $\begin{array}{l}.00093 \\
.00075 \\
.00062 \\
.00051 \\
.00043 \\
.00036 \\
.00030 \\
.00026 \\
.00027 \\
.00019\end{array}$ & $\begin{array}{l}.00077 \\
.00 n 62 \\
.00051 \\
.00042 \\
.00035 \\
.00030 \\
.00 \cap 25 \\
.00 \cap 21 \\
.00019 \\
.00016\end{array}$ & $\begin{array}{l}.00065 \\
.00053 \\
.00043 \\
.00036 \\
.00030 \\
.00025 \\
.00021 \\
.00018 \\
.00016 \\
.00014\end{array}$ & $\begin{array}{l}.00057 \\
.00046 \\
.00038 \\
.00031 \\
.00026 \\
.00022 \\
.00019 \\
.00016 \\
.00014 \\
.00011\end{array}$ & $\begin{array}{r}.00050 \\
.00041 \\
.00033 \\
.00027 \\
.00023 \\
.00019 \\
.00016 \\
.00014 \\
.00012 \\
.00011\end{array}$ & $\begin{array}{l}.00045 \\
.00037 \\
.00030 \\
.00025 \\
.00021 \\
.00018 \\
.00015 \\
.00113 \\
.00011 \\
.00010\end{array}$ & $\begin{array}{r}.00041 \\
.00033 \\
.00027 \\
.00022 \\
.00019 \\
.00016 \\
.00013\end{array}$ & \\
\hline
\end{tabular}


TABLE VIII. MULTIPLE SCATTERING INTEGRAL DISTRIBUTION FUNCTION. GIVEN IS THE FRACTION OF INCIDENT PARTICLES FOUND INSIIDE A CONE OF HALF. ANGLE $X$.

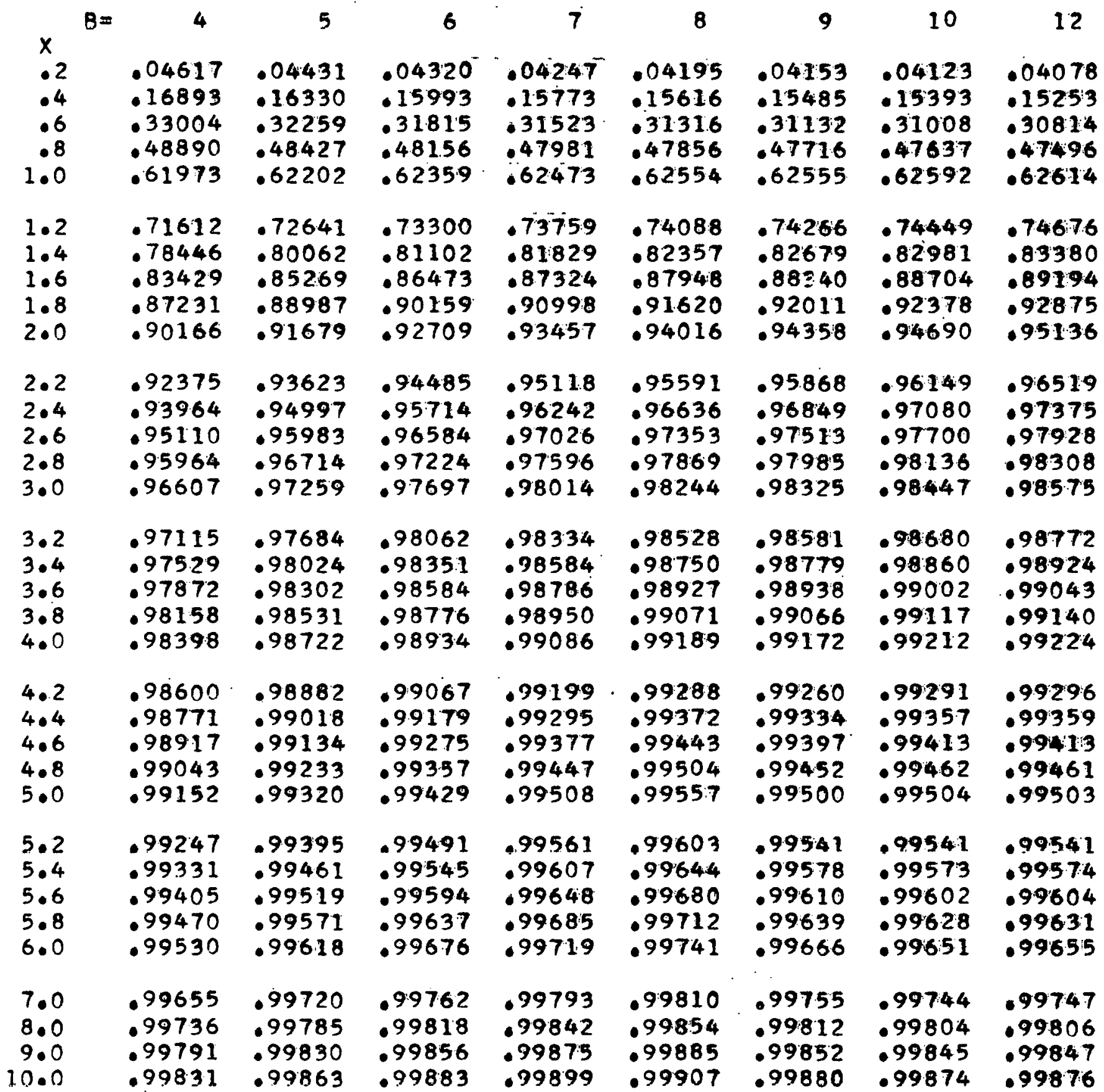




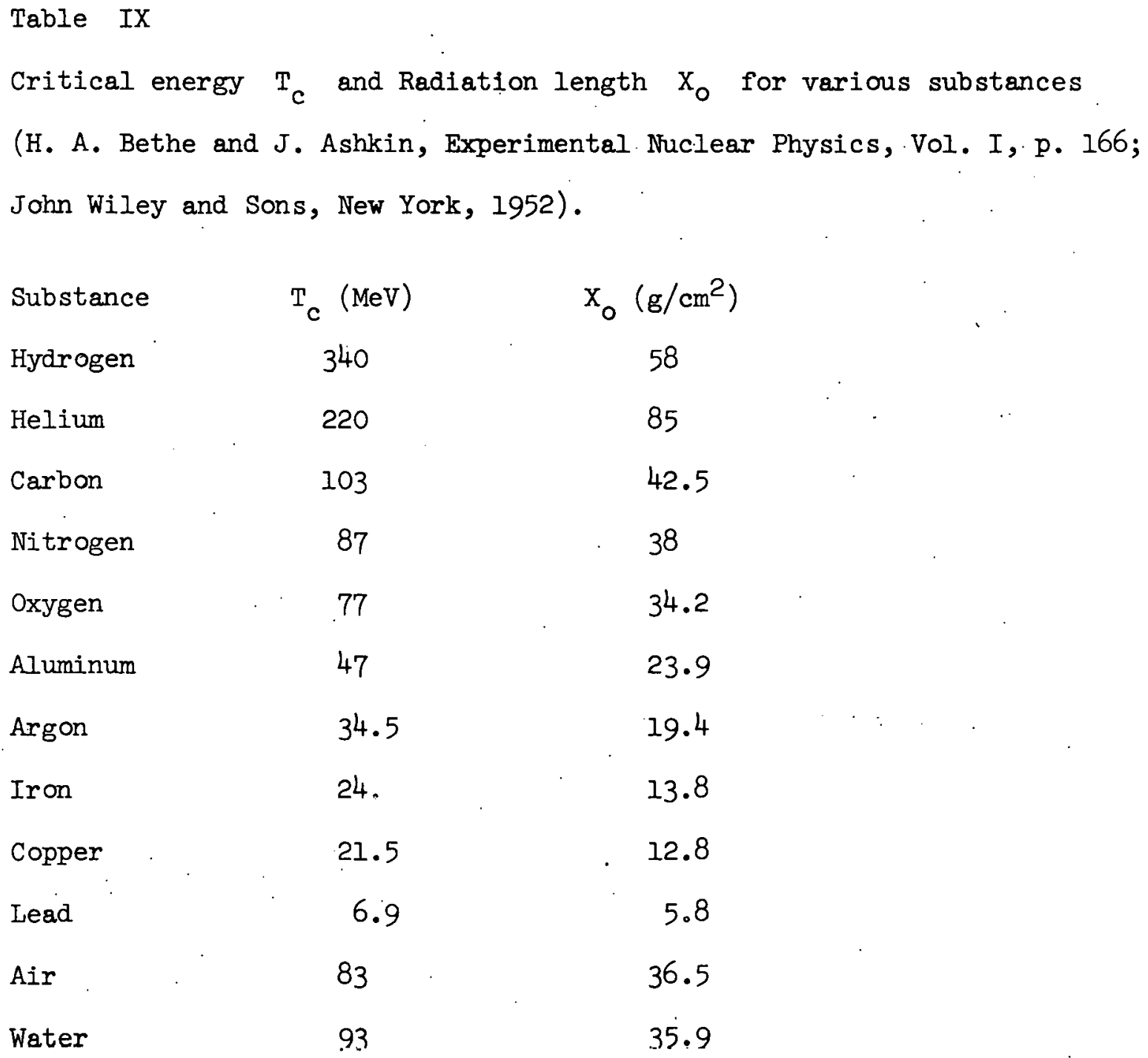


Table X

The comparison of maximum electron ranges $R_{\max }$ with Spencer's $\mathrm{X}_{\max }$. Positrons of 0.1 MeV are indicated by 0.1. . Experimental ranges from GF59; csda ranges from BS67; $X_{\text {max }}$ is the value at which $J(x)$ reaches a value of 0.001 (SP59).

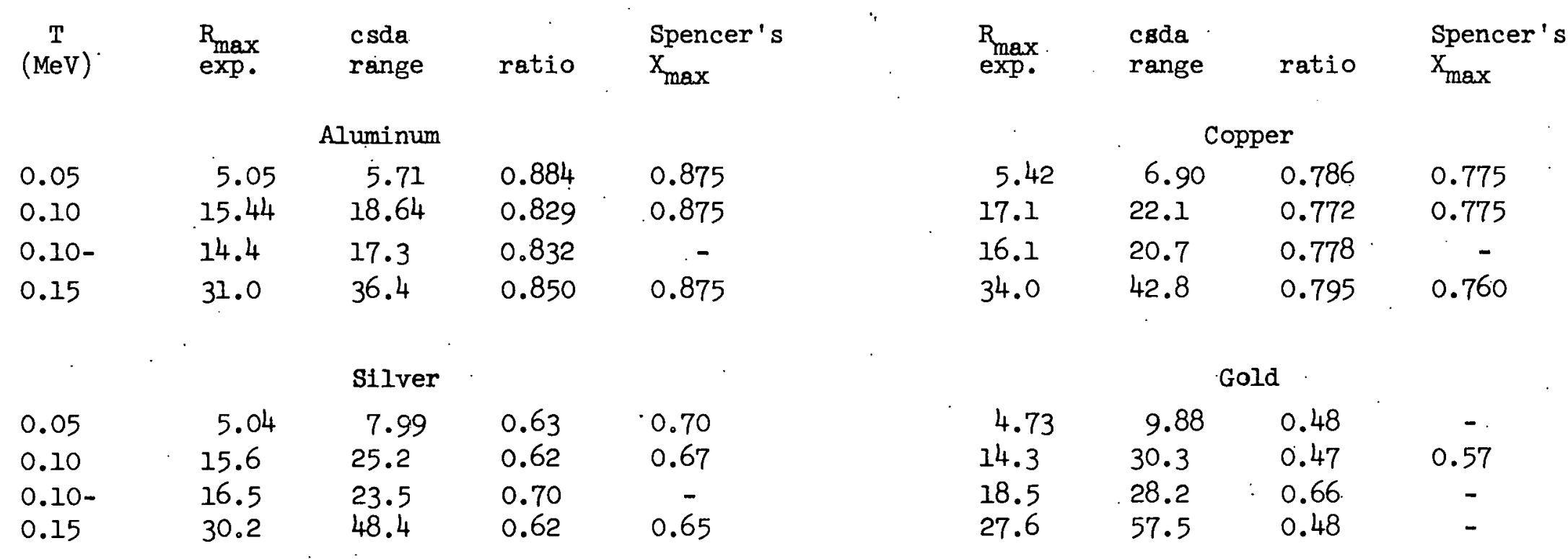


Table XI

Average energy $w$ for the formation of an ion pair for various particles.

\begin{tabular}{|c|c|c|c|c|c|c|c|}
\hline & $\begin{array}{l}\text { Particle } \\
\text { T. }(\mathrm{MeV})\end{array}$ & \multicolumn{2}{|c|}{$\begin{array}{r}\beta \\
\cong \quad 0.3 \\
\end{array}$} & $\begin{array}{l}\mathrm{p} \\
\mathrm{l}\end{array}$ & $\begin{array}{l}a \\
5 \\
\end{array}$ & \multicolumn{2}{|c|}{$\begin{array}{l}\text { Fission fragments } \\
\text { light | heavy }\end{array}$} \\
\hline Gas & & & & & & & \\
\hline $\mathrm{H}_{2}$ & & & 36.6 & & 36.2. & & \\
\hline $\mathrm{He}$ & & & 41.5 & & 46.0 & & . \\
\hline $\mathbb{N}_{2}$ & & & 34.6 & 36.6 & 36.39 & & \\
\hline $\mathrm{O}_{2}$ & & & 31.8 & 31.5 & 32.3 & & \\
\hline $\mathrm{Ne}$ & & & 36.2 & 28.6 & 35.7 & & \\
\hline A & & & 26.2 & 26.4 & 26.3 & 28.0 & 29.5 \\
\hline $\mathrm{Kr}$ & & & 24.3 & & 24.0 & & \\
\hline $\mathrm{Xe}$ & & & 21.9 & & 22.8 & & \\
\hline air & & & 33.7 & 36.0 & 34.98 & & \\
\hline $\mathrm{CO}_{2}$ & & & 32.9 & 34.9 & 34.1 & & \\
\hline $\mathrm{CH}_{4}$ & & & 27.3 & & 29.1 & & \\
\hline $\mathrm{C}_{2} \mathrm{H}_{2}$ & & & 25.7 & & 27.3 & & \\
\hline $\mathrm{C}_{2} \mathrm{H}_{4}$ & & & 26.3 & & 28.03 & & \\
\hline $\mathrm{C}_{2} \mathrm{H}_{6}$ & & & 24.6 & & 26.6 & & \\
\hline $\mathrm{C}_{3} \mathrm{H}_{8}$ & & & 27.8 & & & & \\
\hline $\mathrm{C}_{4} \mathrm{H}_{10}$ & & & 23.0 & & 24.8 & & \\
\hline $\mathrm{C}_{6} \mathrm{H}_{14}$ & & & 22.4 & & & & \\
\hline $\mathrm{BF}_{3}$ & & & & & 35.6 & & \\
\hline $\mathrm{NH}_{3}$ & & & 34.8 & & 30.5 & & \\
\hline $\mathrm{C}_{2} \mathrm{H}_{5} \mathrm{OH}$ & & & & & 32.6 & & \\
\hline $\mathrm{C} \mathrm{Cl}_{2} \mathrm{~F}_{2}$ & & & & & 29.5 & & \\
\hline $\mathrm{SO}_{2}$ & & & & & 32.5 & & \\
\hline $\mathrm{H}_{2} \mathrm{O}$ & & & 30.1 & & 37.6 & & \\
\hline
\end{tabular}




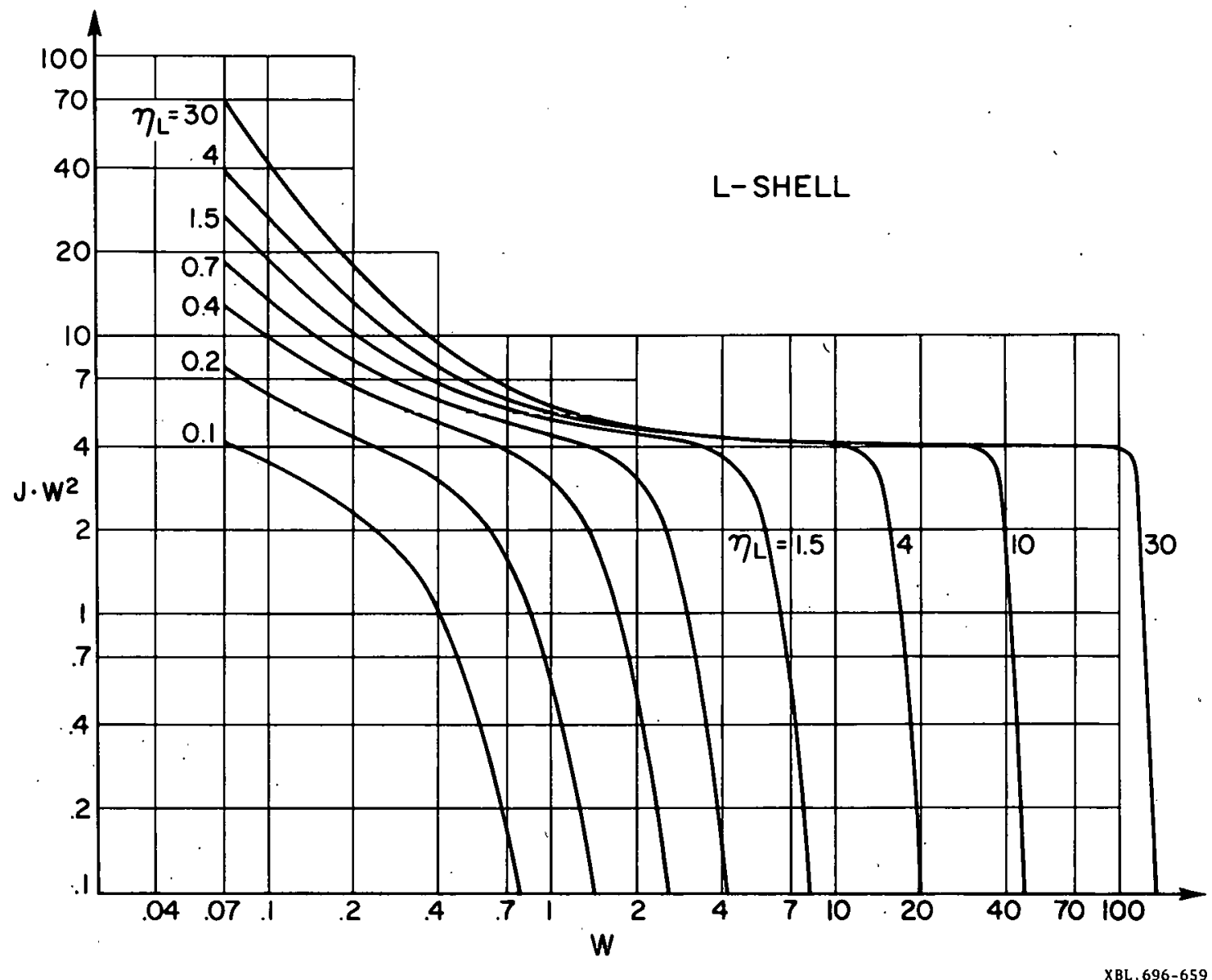

Fig. 1. First Born approximation of the excitation function $\mathrm{J}$ for L-shell electrons relative to free electron excitation function $J^{\prime}=1 / w^{2}$. Plotted is $J / J^{\prime}=J W^{2}$ as a function of $\delta$-ray energy $W=E /$ $\left[13.6 \mathrm{eV}(\mathrm{z}-4.15)^{2}\right]$. The "ionization" energy $\mathrm{W}_{\min } \cong I_{L}$ is approximately 0.09 for $\mathrm{Al}, 0.17$ for $\mathrm{Pb}$. The matrix elements are calculated with hydrogenic wave functions. In Bohr's papers, the rise at small $\mathrm{W}$ is described as a resonance effect. 


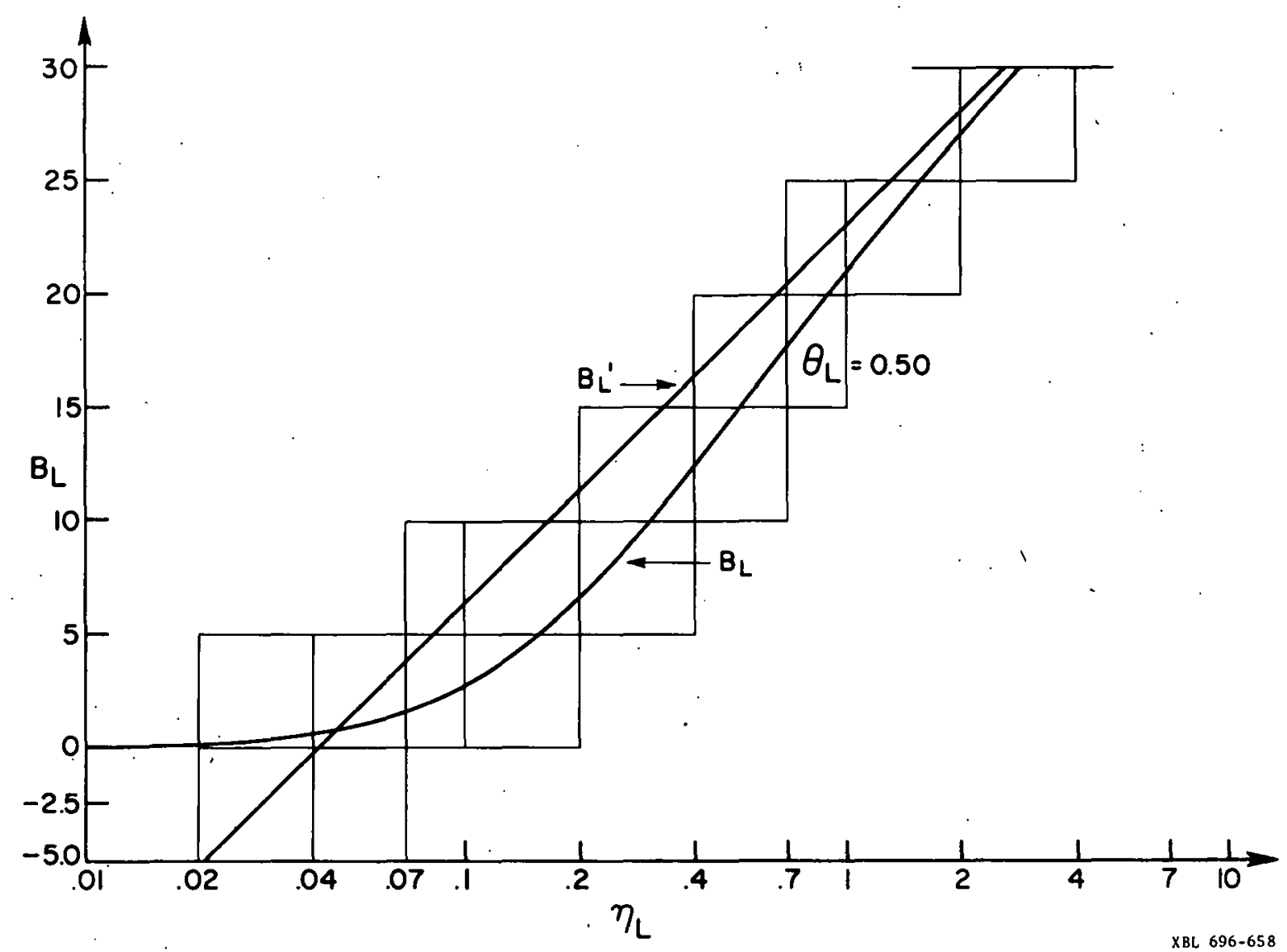

Fig. 2. The stopping number $B=\int W J$ dW for $I$-shell electrons in copper. Also given is the asymptotic expression $B^{\prime}=S_{L}^{\prime} \ln \left(2 \mathrm{mv}^{2} / I_{L}\right)$. The difference between the two functions is the shell correction C, Eq. (3-3); it is a basic part of the quantum mechanical theory. 


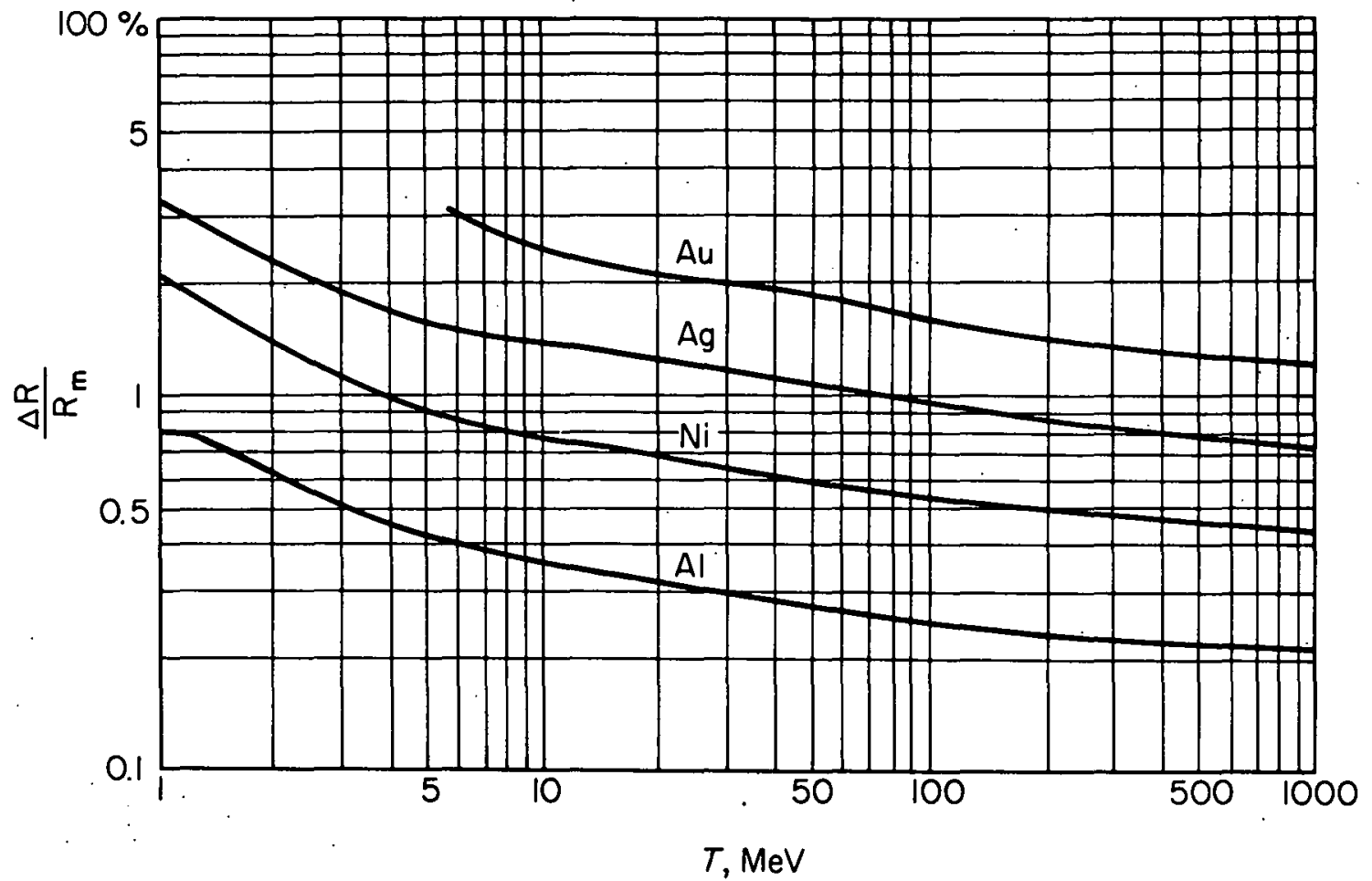

Fig. 3. The fractional multiple-scattering correction for different elements as a function of proton energy $T$. The experimental median projected range $R_{m}$ is related to the csda range $R_{0}$ through $R_{0}=R_{m}+\Delta R$. Corrections due to nuclear diffraction scattering are neglected. Accuracy 10 to $20 \%$. 


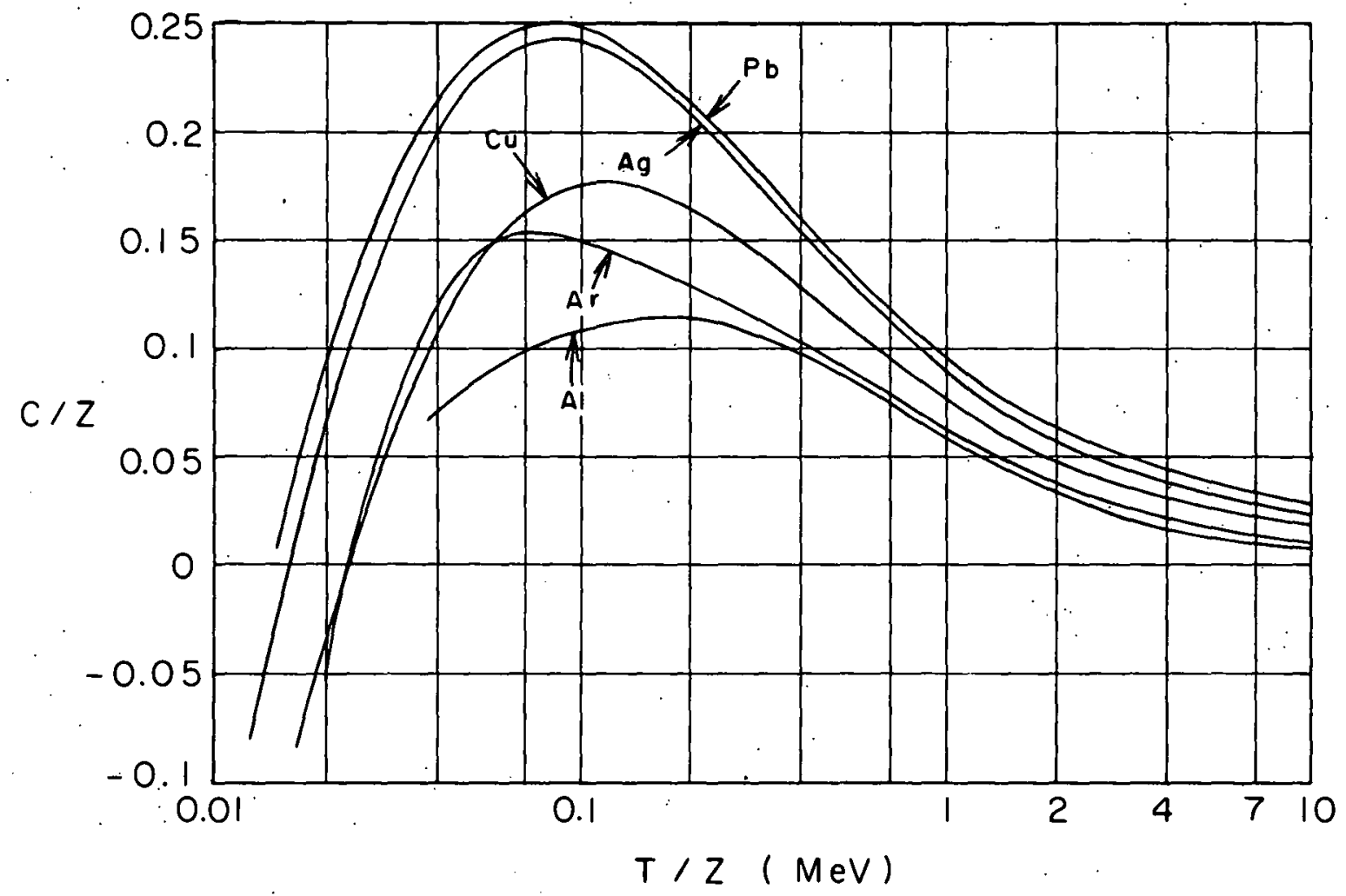

XBL696-2957

Fig. 4. Practical shell corrections $c / z$ for particles of charge +1 . The abscissa is $T / Z=T_{1} /\left(m_{r} Z\right)$, see Eq. $(3-8)$. For $Z \leqq 25$, Walske's, and for $Z>25$, Bonderup's shell corrections are modified to fit experimental data for protons and deuterons. In this procedure, deviations from the first Born approximation are included in $\mathrm{C} / \mathrm{Z}$, and the shell corrections depend on the Incldent particle charge iz. f'or $\mathrm{c} / \mathrm{L}<-0.1$, the Bonderup corrections do not fit the data well. 


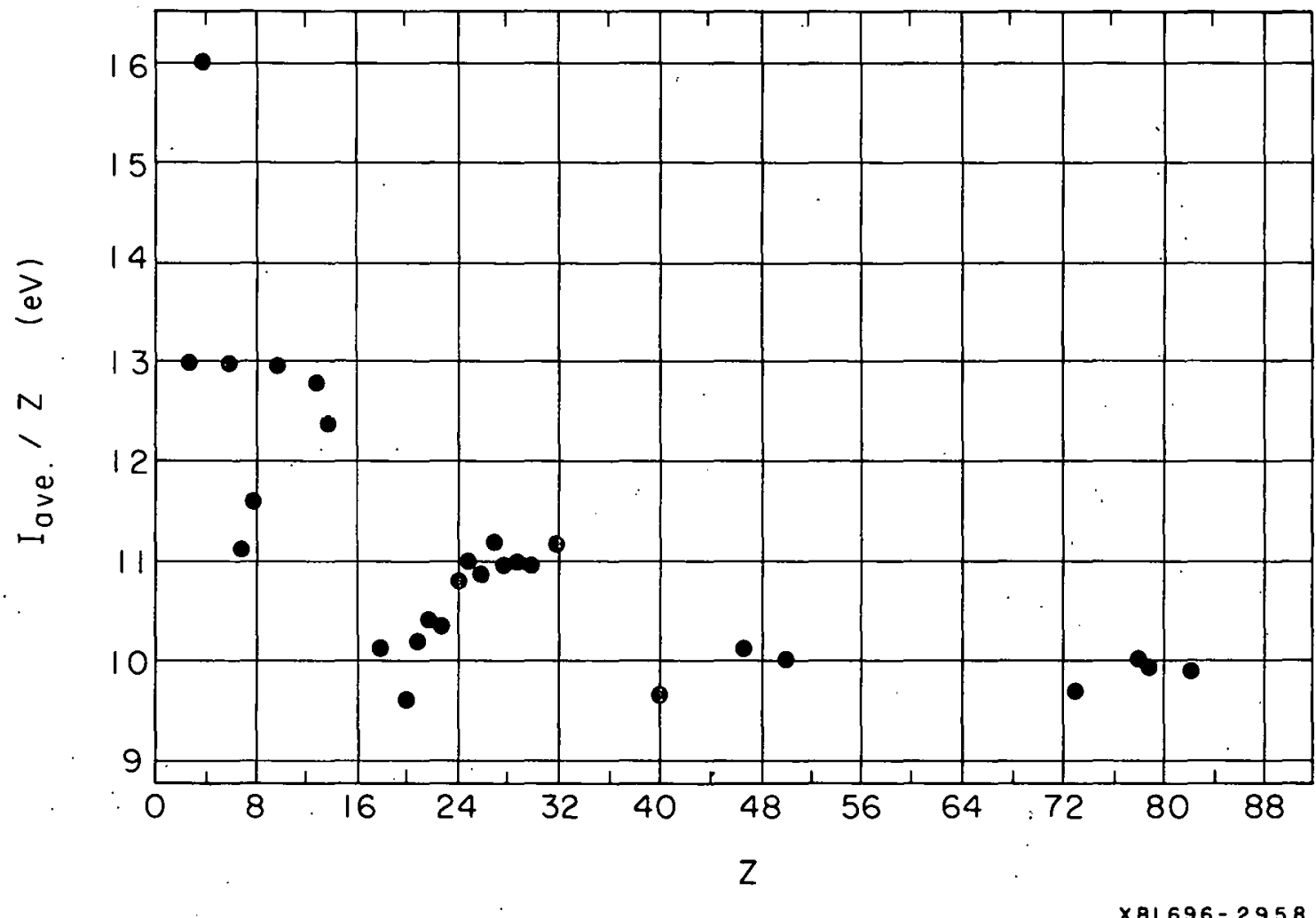

Fig. 5. The mean excitation energy $I_{\text {ave }}$ for different elements. Given is $I_{\text {ave }} / \mathrm{Z}$ versus $\mathrm{Z}$. For $\mathrm{H}_{2}, \mathrm{I}_{\text {ave }}=19.2 \mathrm{eV}$, for He, $I_{\text {ave }}=41.3 \mathrm{eV}$, from $\propto$-particle measurements. The values represent the authors present opinion, and may change by several percent. The strong fluctuations found for neighboring elements are significant though. 


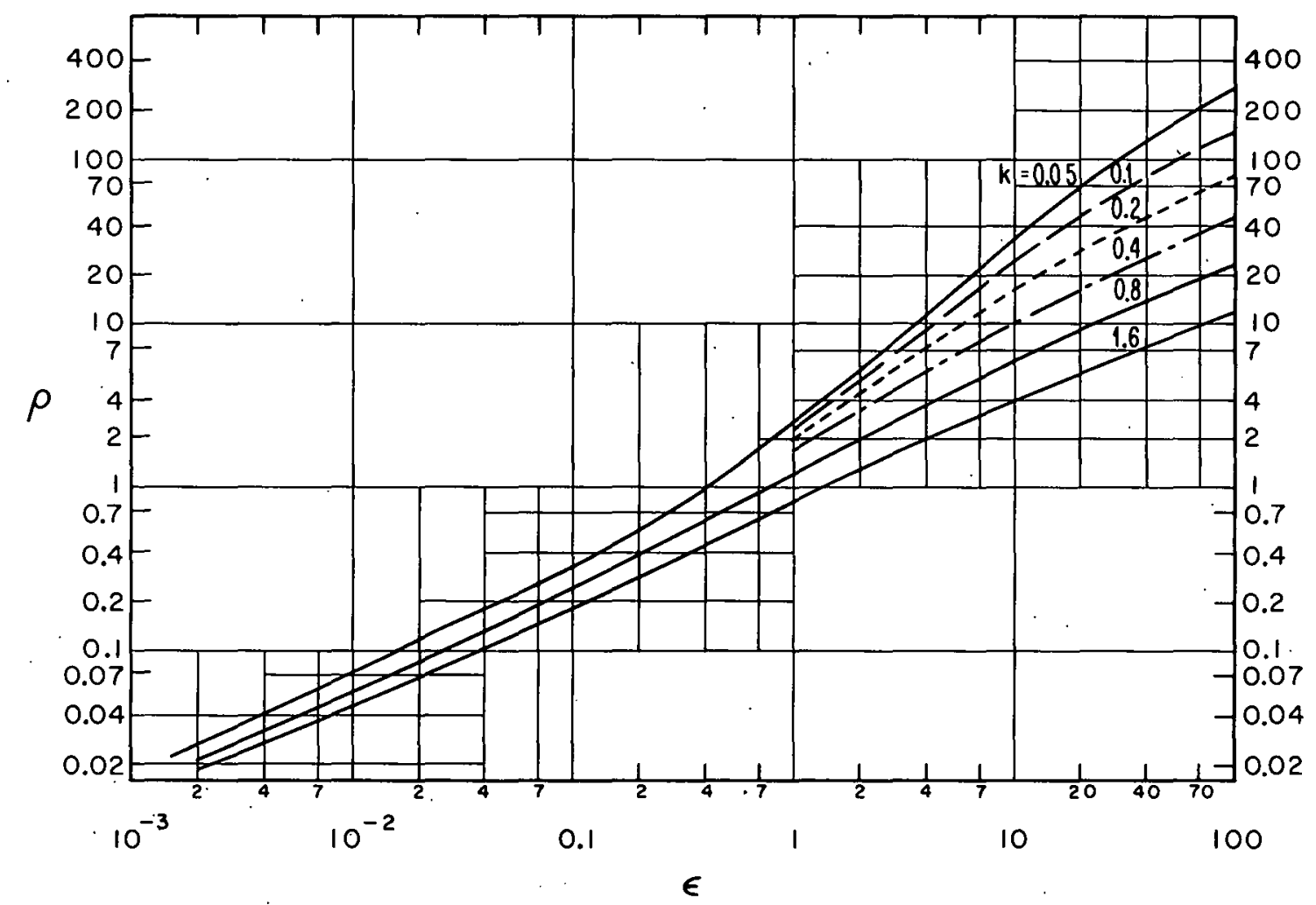

XBL695-2763

Fig. 6. Range-energy relation for low energy ions. The dimension less parameters $\epsilon$ (for the kinetic energy) and $p$ (for the range) are defined in Eqs. $(6-4)$ and $(6-5)$. The parameter $k$, Eq. $(6-8)$, is related to the low energy electronic stopping power. 
Fig. 7. Contour lines for the straggling distribution function $\Phi\left[\Phi\left(\Delta_{u}\right)=\int_{0}^{u_{f}} f(\Delta)\right.$ ds where $f(\Delta)$ is the vavilov function $]$ in silicon for particles of velocity $\beta^{2}=0.04(T \sim 20 \mathrm{MeV}$ for protons). The curves are similar for other velocities. The Vavilov theory has been modified for the quantum mechanical corrections. The Vavilov parameter is

$$
x_{V}=7.49 \cdot 10^{-2} \mathrm{sz}^{2}\left(1-\beta^{2}\right) / \beta^{4}
$$

(for silicon; $s$ in $\mathrm{g} / \mathrm{cm}^{2}$ ). Plotted is the energy loss $p$ (dimension less) which exceeds the energy loss of $\Phi \%$ of the incident particles. The actual energy loss is $\Delta=\bar{\Delta}+p \sigma$ where $\bar{\Delta}$ is the mean energy loss $(\bar{\Delta}=s S)$, and $\sigma$ is the standard deviation

$$
\sigma^{2}=78,250 \text { s } z^{2}\left(1-\beta^{2} / 2\right) /\left(1-\beta^{2}\right) \cdot \mathrm{keV}^{2}
$$

Example: $40 \mathrm{MeV}$ protons, $\mathrm{s}=0.02 \mathrm{~g} / \mathrm{cm}^{2}, \beta^{2}=0.08$, $x_{V}=0.22, \bar{\Delta}=0.02 \cdot 11.72=0.234 \mathrm{MeV}, \sigma=40 \mathrm{KeV}$. For $\Delta=\bar{\Delta}, p=0$, and about $58 \%$ of all the protons lose less than $234 \mathrm{keV}$. The exact answer is $61.6 \%$. On the other hand, for $\Phi=96 \%, p \sim 2.0$ and $\Delta=234+80 \mathrm{keV}=314 \mathrm{keV}$. Thus, $4 \%$ of the protons Iose more than $314 \mathrm{keV}$ (the exact answer is $315 \mathrm{keV}$ ). 


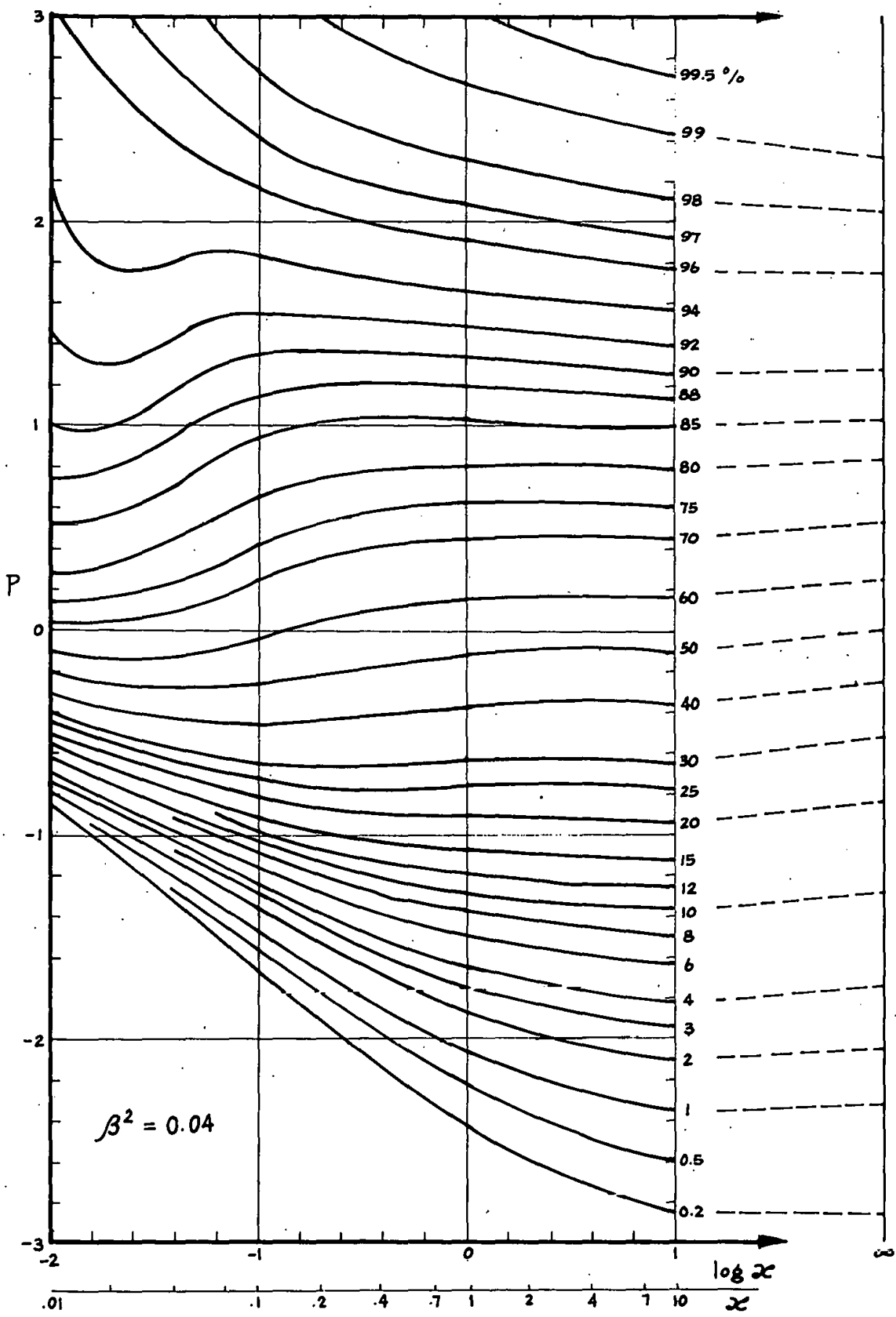

XBL $696-755$ 


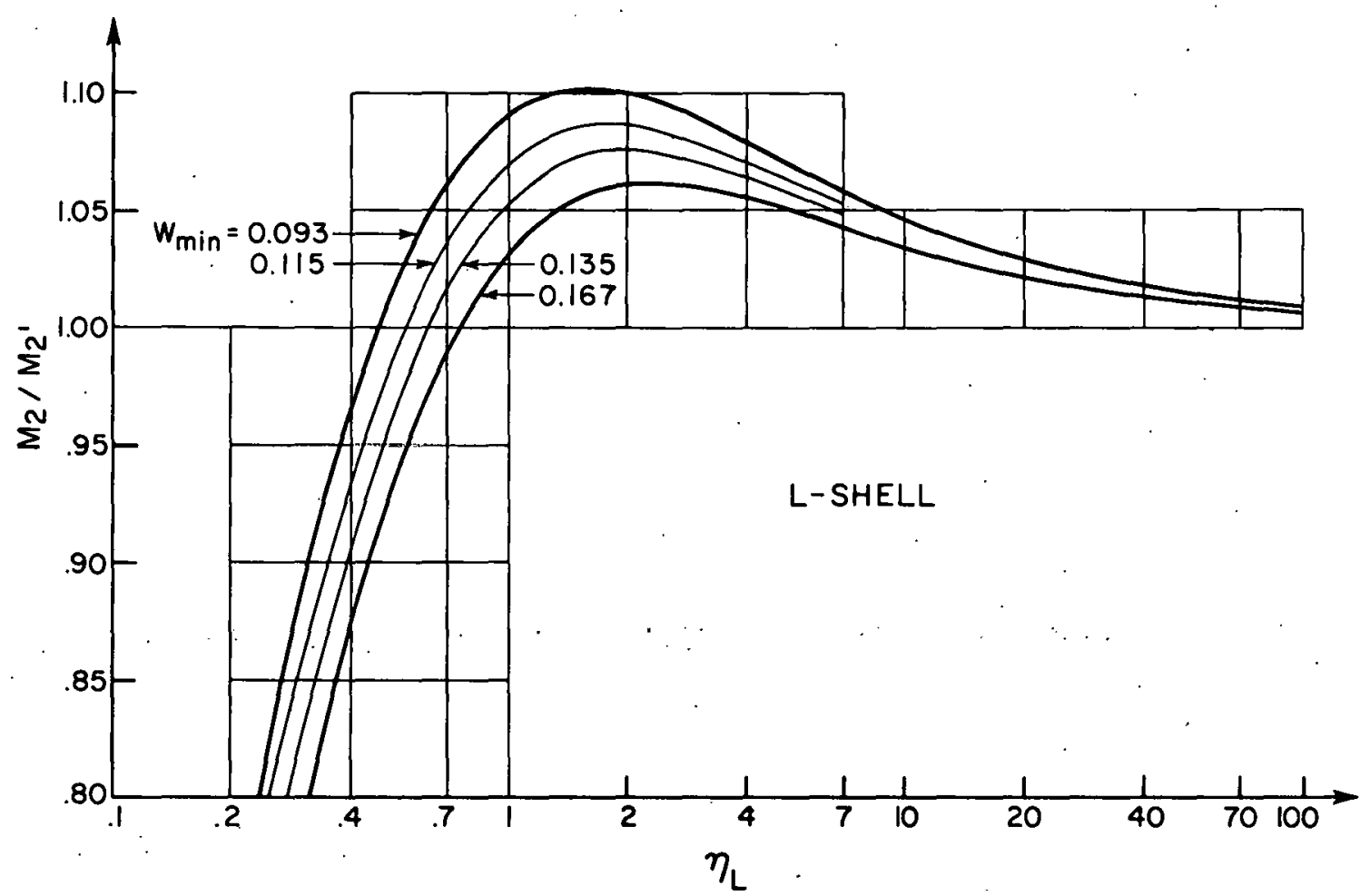

$X B L$ 696-656

Fig. 8. The ratio $M_{2} / M_{2}^{\prime}$ of the second moments of the quantum mechanical, Eq. (2-2), and the free electron cross sections, Eq. (2-1), for the I-shell. The curves apply for silicon $\left(W_{\min }=0.093\right)$, copper $(0.115)$ Silver (0.135) and lead (0.167). 


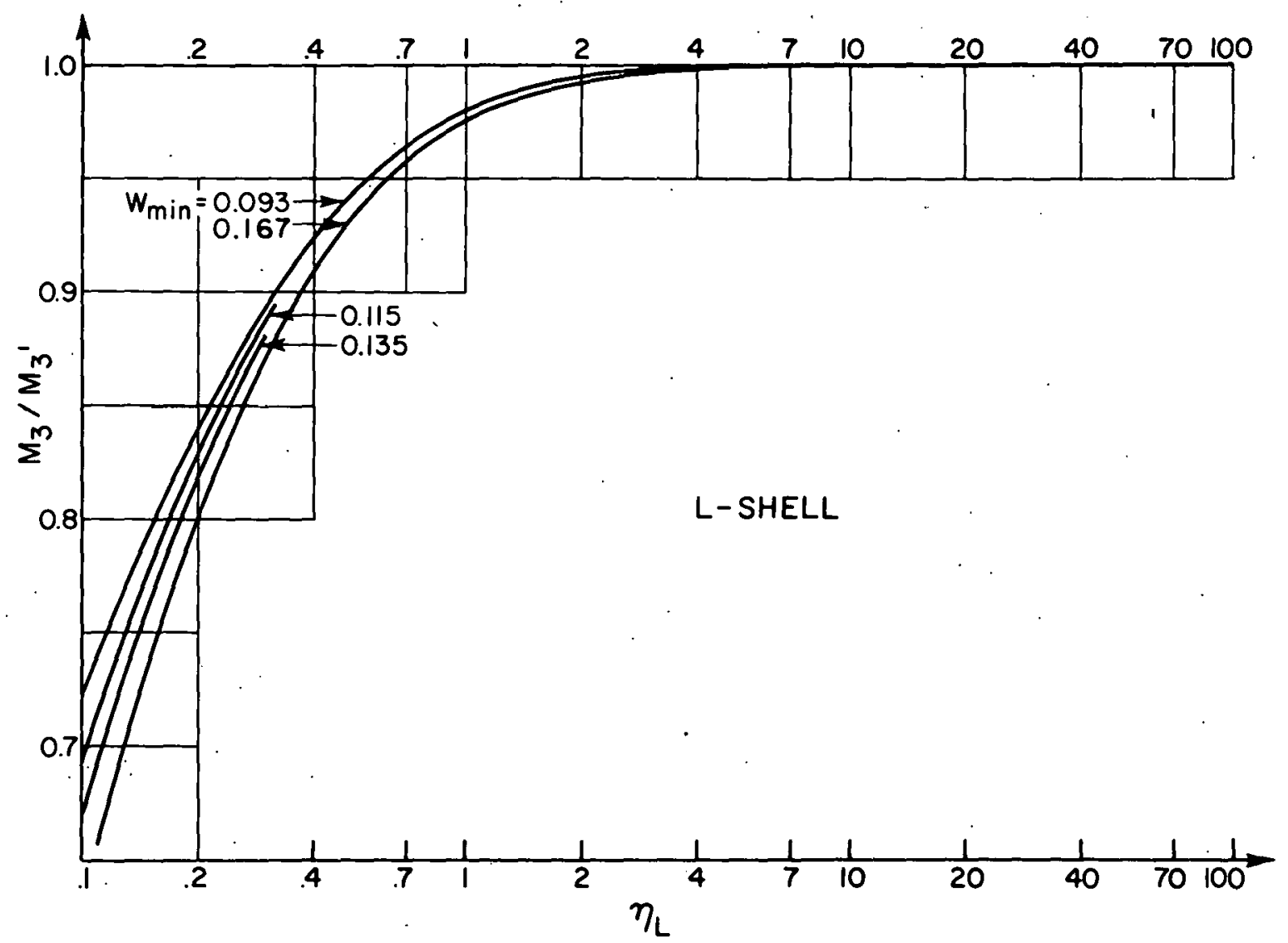

XBL $696-655$

Fig. 9. The ratio $\mathrm{M}_{3} / \mathrm{M}_{3}$ of the third monents for the L-shell (see Fig. 8 for the elements). Notice that the asymetry (skewess) is reduced at lower energies. 


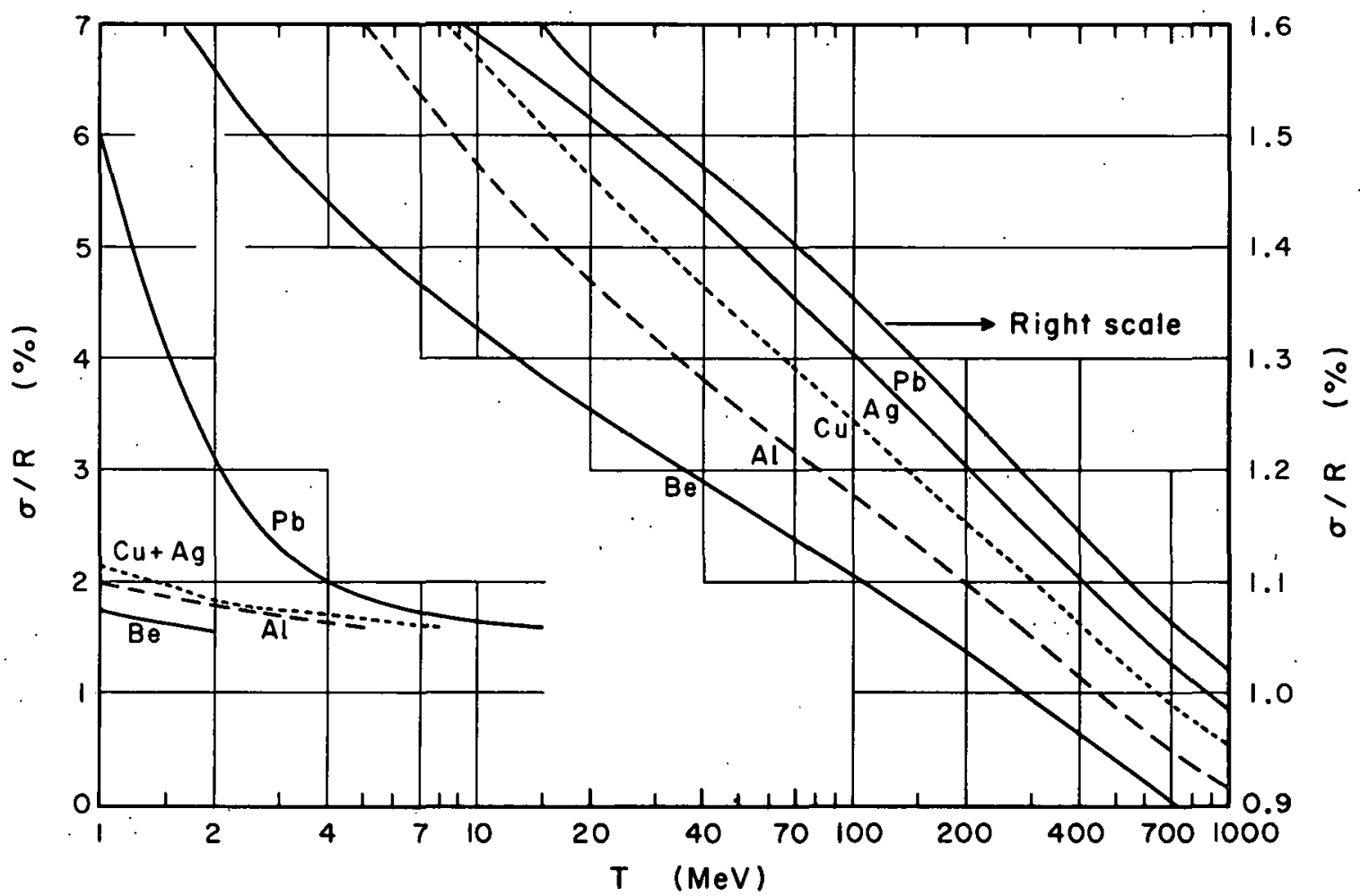

X8L695-2762

Fig: 10. The range straggling parameter $\sigma / R(\%)$ for protons of kinetic energy $T$ in different elements. $\sigma / R$ is corrected for the quantum mechanical effects (estimated from Fig. 8). 
1

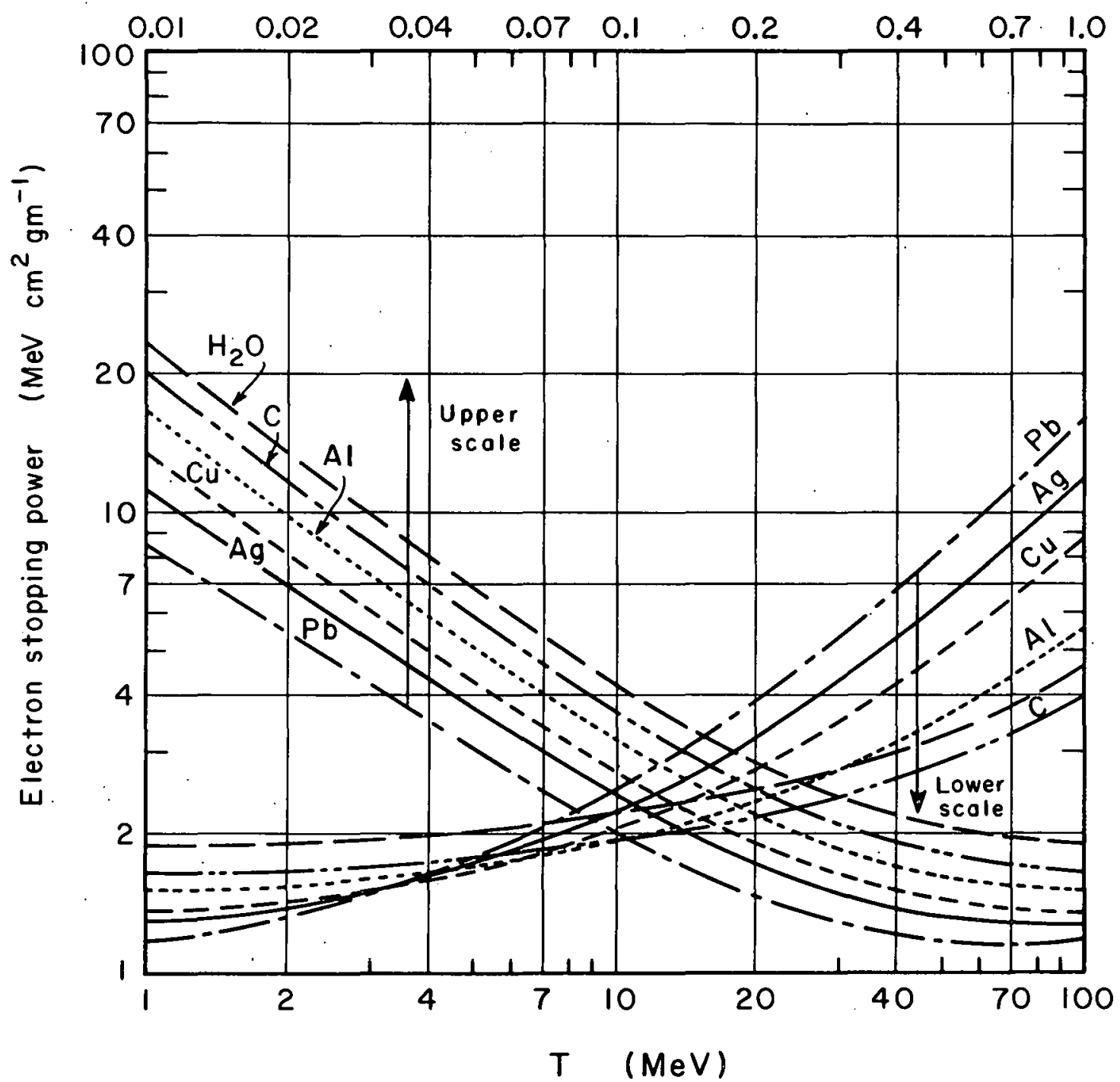

XBL695-2764

Fig. 11. Calculated electron mass stoping power $S$, including collision and radiation loss for different materials (BS67). The stopping power for $\mathrm{Na} \mathrm{I}$ is within $1 \%$ of $\mathrm{S}$ for $\mathrm{Ag}$. 
86.

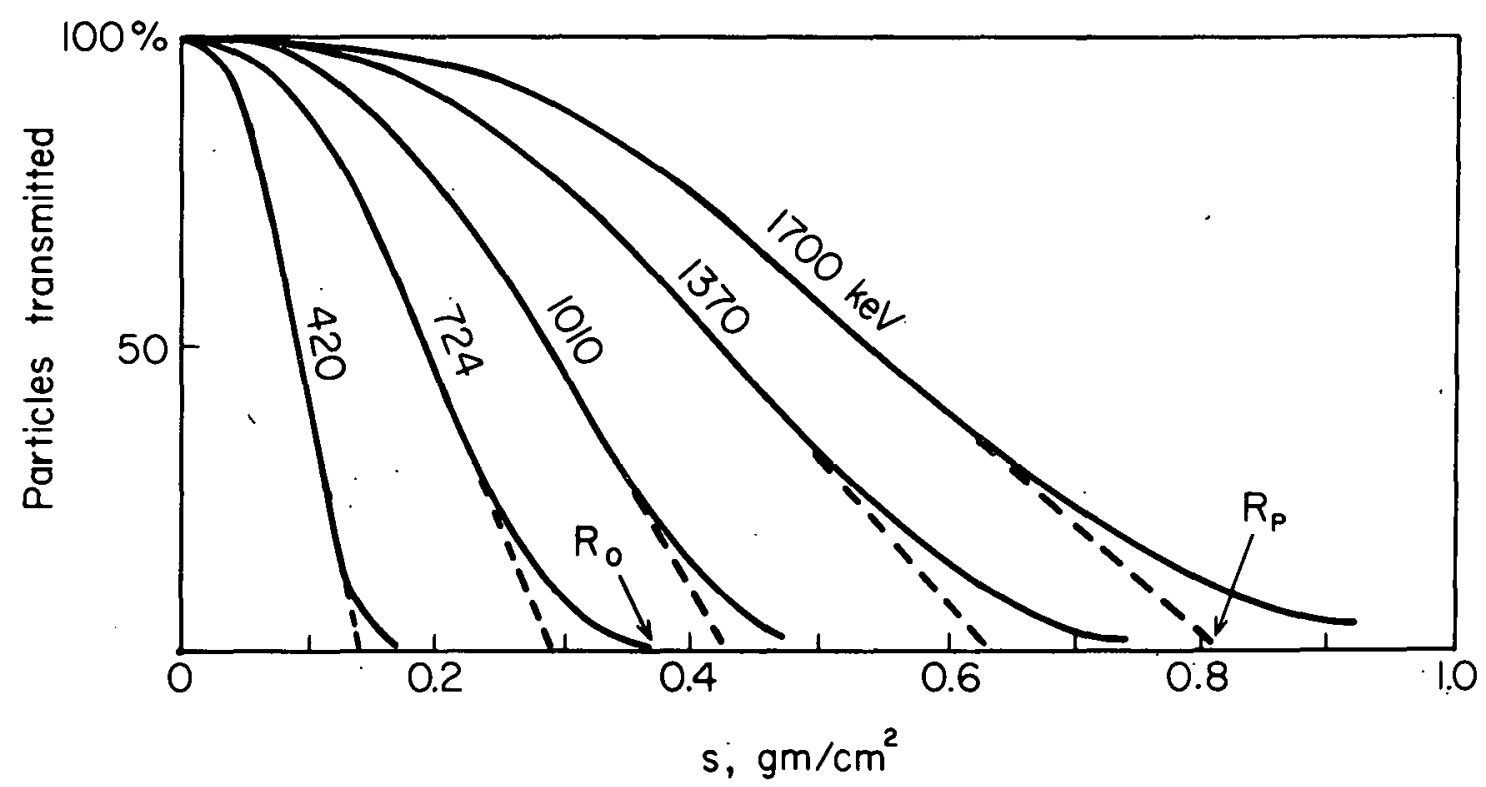

Fig. 12. Absorption curve of mono-energetic electrons. $R_{p}$ is defined as the extrapolated range, $\mathrm{R}_{\mathrm{o}}$ as the maximum range (BK58). 


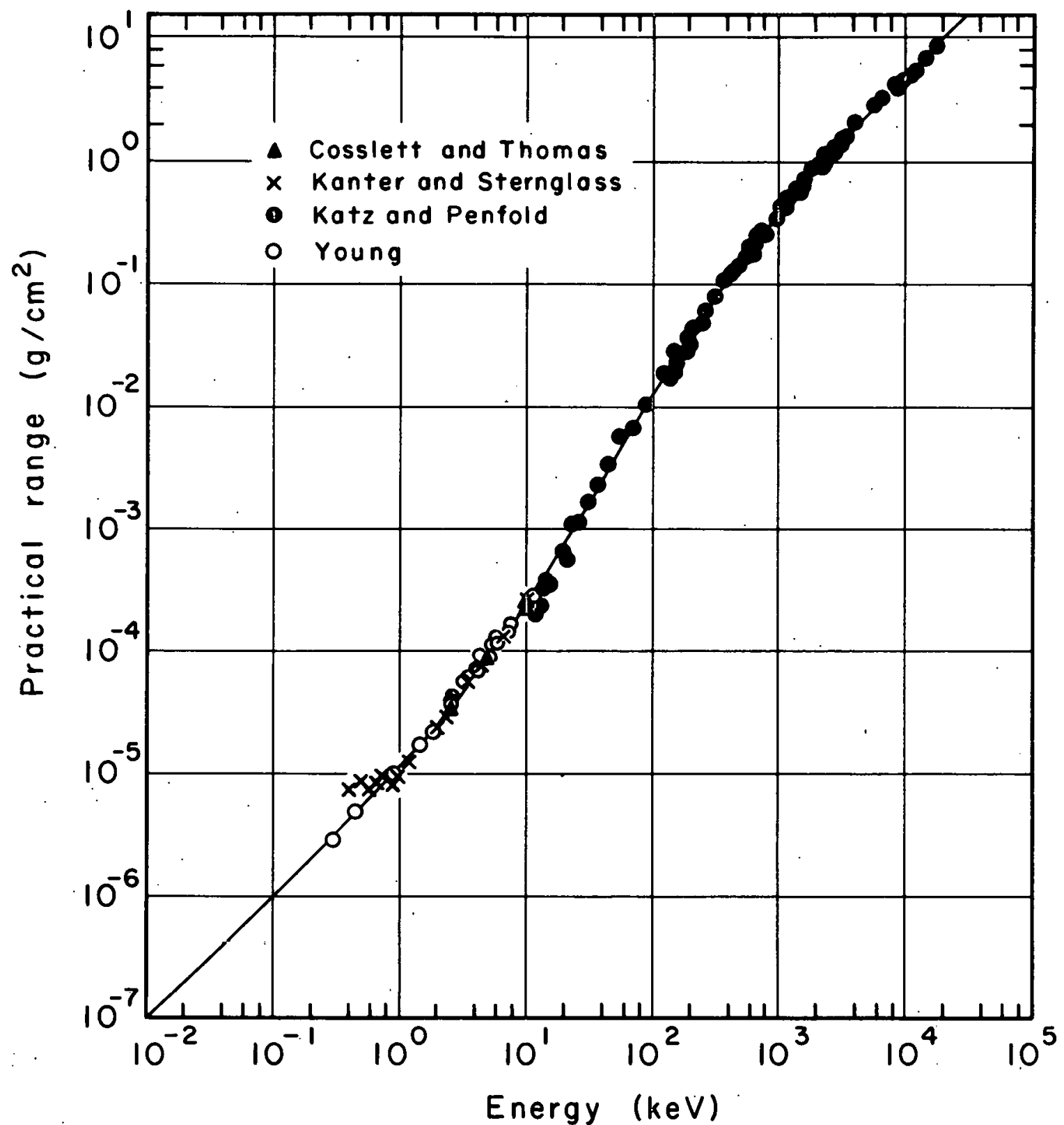

XBL695-2765

Fig. 13. Practical range in aluminum versus electron energy (KK68). Coslett and Thomas (CT65); Kanter and Sternglass, Phys. Rev. 126, 620 (1962); Katz and Penfold (KP52); Young, Phys. Rev. 103, 292 (1956). 